University of Tennessee Health Science Center

UTHSC Digital Commons

\title{
Analysis of Community-Based Accumulation of Home Medications (CACHES) Found at Death Scenes in Davidson County, Tennessee
}

Carrie E. Plummer

University of Tennessee Health Science Center

Follow this and additional works at: https://dc.uthsc.edu/dissertations

Part of the Other Public Health Commons, and the Public Health and Community Nursing Commons

\section{Recommended Citation}

Plummer, Carrie E. , "Analysis of Community-Based Accumulation of Home Medications (CACHES) Found at Death Scenes in Davidson County, Tennessee" (2013). Theses and Dissertations (ETD). Paper 216. http://dx.doi.org/10.21007/etd.cghs.2013.0248. 


\title{
Analysis of Community-Based Accumulation of Home Medications (CACHES) Found at Death Scenes in Davidson County, Tennessee
}

\begin{abstract}
Introduction: Stockpiling of unused medications by community-dwelling individuals results in Communitybased ACcumulation of Home mEdicationS (CACHES). CACHES place the individual, health care and justice system, and ecosystem at risk for adverse outcomes including: a) diversion of prescription medications by friends and family, b) pediatric poisonings, c) adverse drug events, d) increased criminal justice system costs related to prescription drug abuse, e) increased health care costs, and f) pollution of local water supplies via improper medication disposal. This study explores the relationship among individual risk factors (gender, race, age, comorbid conditions), geographical location, health care risk factors (number of prescribers and dispensaries), and CACHES.

Methods: This study involved an analysis of existing data extracted from death scene charts created by the Medical Examiners and Medicolegal Death Scene Investigators of Forensic Medical, PLC in Nashville, Tennessee from January 1 through December 31, 2011. The study examined the prevalence, size, and composition of CACHES found in decedents' homes. In addition, this study included a descriptive analysis of demographic data (gender, race, age, and comorbid conditions) and presence of CACHES. Additionally, the geographic locations of CACHES were mapped. Finally, the relationship between health care risk factors (number of prescribers and dispensaries) and CACHES was explored.
\end{abstract}

Results: The analyses showed no statistical differences in gender, race, or age between decedents with medications (used and unused) in the home and decedents without medications. The study sample was predominantly male, Caucasian/Non-Hispanic, and older than the Davidson County population. Fifty-six percent of decedents had CACHES. More than half had $\geq 4$ bottles of unused medications with a mean of $38.9 \pm 43.7$ pills. Sixty percent of the unused medications came from two major classes - those affecting the central nervous system and the cardiovascular system. The CACHES group was significantly older, had a higher likelihood of having a psychiatric diagnosis, and used more prescribers and dispensaries. The analyses did not support a statistical difference between the two groups with regards to gender, race, or total number of comorbid conditions. There was insufficient data to perform an analyses on the relationship between geographical location (Zip code) and CACHES.

Discussion/Conclusions: Limitations in the original data as well as differences in study design complicated a direct comparison of the prevalence, size, and composition of the CACHES to other studies. However, this exploratory study corroborates the CACHES model's assertion that the stockpiling of unused medications is a pervasive problem. Furthermore, the analyses support advanced age, having a psychiatric comorbid condition, and the use of multiple prescribers and dispensaries increases the individual's risk for the accumulation of unused medications in the home. Additional research is needed to further illuminate the relationship between gender, race, and the number of comorbid conditions and CACHES.

\section{Document Type}

Dissertation

Degree Name

Doctor of Philosophy (PhD)

Program

Nursing 
Research Advisor

Michael A. Carter, D.N.Sc., D.N.P.

\section{Keywords}

Disposal, Diversion, Environment, Health Care System, Medications, Regulations

\section{Subject Categories}

Medicine and Health Sciences | Nursing | Other Public Health | Public Health | Public Health and Community Nursing 


\title{
Analysis of Community-Based Accumulation of Home Medications (CACHES) Found at Death Scenes in Davidson County, Tennessee
}

\author{
A Dissertation \\ Presented for \\ The Graduate Studies Council \\ The University of Tennessee \\ Health Science Center
}

\author{
In Partial Fulfillment \\ Of the Requirements for the Degree \\ Doctor of Philosophy \\ From The University of Tennessee
}

By

Carrie E. Plummer

August 2013 
Copyright (C 2013 by Carrie E. Plummer. All rights reserved. 


\section{DEDICATION}

This dissertation is dedicated to:

My family for their encouragement and belief in me, My friends for their endless willingness to listen to me vent and reassure me I would finish,

Jared, Courtney, and the rest of the Ugly Mugs crew for their support and countless raspberry lattes, and

Bonnie McCrickard - a friend, colleague, and fount of knowledge. 


\section{ACKNOWLEDGEMENTS}

I would like to thank my committee members Dr. Patricia Cowen, Dr. Simonne Nouer, and Dr. Patricia Speck for their time and guidance.

I would like to thank the John A. Hartford Foundation's National Hartford Centers of Gerontological Nursing Excellence Award Program for providing me with financial and educational support through the last two years of my doctoral education. Through their generosity I was given the opportunity to develop my research, education, policy and leadership skills.

I would also like to thank my Hartford consultants: Dr. Kam Nola, Dr. Linda Norman, and Bonnie McCrickard, LCSW. Your willingness to provide me with both your time and expertise was invaluable in the development of my skills as a researcher.

Additional thanks and gratitude to the staff at Forensic Medical Management Services, PLC for graciously granting me access to the death scene investigations data. In particular, I would like to thank Fran Wheatley, Kathy VanBuren, Lisa Robison, and Dr. Amy McMaster Hawes for their generosity.

Finally, I would like to thank Dr. Michael Carter, Dr. Veronica Engle, and Dr. Lorraine Mion for their mentorship during my doctoral program. Their dedication to providing me with constructive feedback and encouragement was essential to my success as a doctoral student. 


\begin{abstract}
Introduction: Stockpiling of unused medications by community-dwelling

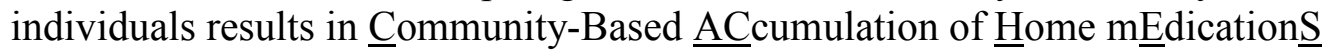
(CACHES). CACHES place the individual, health care and justice system, and ecosystem at risk for adverse outcomes including: a) diversion of prescription medications by friends and family, b) pediatric poisonings, c) adverse drug events, d) increased criminal justice system costs related to prescription drug abuse, e) increased health care costs, and f) pollution of local water supplies via improper medication disposal. This study explores the relationship among individual risk factors (gender, race, age, comorbid conditions), geographical location, health care risk factors (number of prescribers and dispensaries), and CACHES.

Methods: This study involved an analysis of existing data extracted from death scene charts created by the Medical Examiners and Medicolegal Death Scene Investigators of Forensic Medical, PLC in Nashville, Tennessee from January 1 through December 31, 2011. The study examined the prevalence, size, and composition of CACHES found in decedents' homes. In addition, this study included a descriptive analysis of demographic data (gender, race, age, and comorbid conditions) and presence of CACHES. Additionally, the geographic locations of CACHES were identified. Finally, the relationship between health care risk factors (number of prescribers and dispensaries) and CACHES was explored.
\end{abstract}

Results: The analyses showed no statistical differences in gender, race, or age between decedents with medications (used and unused) in the home and decedents without medications. The study sample was predominantly male, Caucasian/NonHispanic, and older than the Davidson County population. Fifty-six percent of decedents had CACHES. More than half had $\geq 4$ bottles of unused medications with a mean of 38.9 \pm 43.7 pills. Sixty percent of the unused medications came from two major classes those affecting the central nervous system and the cardiovascular system. The CACHES group was significantly older, had a higher likelihood of having a psychiatric diagnosis, and used more prescribers and dispensaries. The analyses did not support a statistical difference between the two groups with regards to gender, race, or total number of comorbid conditions. There was insufficient data to perform an analyses on the relationship between geographical location (Zip code) and CACHES.

Discussion/Conclusions: Limitations in the original data as well as differences in study design complicated a direct comparison of the prevalence, size, and composition of the CACHES to other studies. However, this exploratory study corroborates the CACHES model's assertion that the stockpiling of unused medications is a pervasive problem. Furthermore, the analyses support advanced age, having a psychiatric comorbid condition, and the use of multiple prescribers and dispensaries increases the individual's risk for the accumulation of unused medications in the home. Additional research is needed to further illuminate the relationship between gender, race, and the number of comorbid conditions and CACHES. 


\section{TABLE OF CONTENTS}

CHAPTER 1. INTRODUCTION .................................................................................

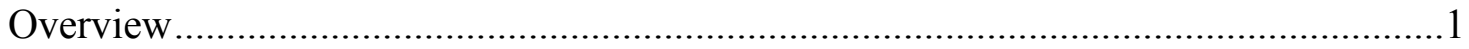

Purpose of the Study ..........................................................................................

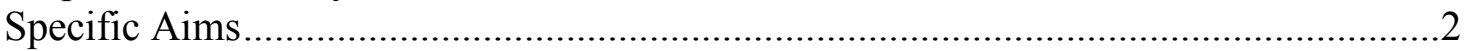

Specific Aim One

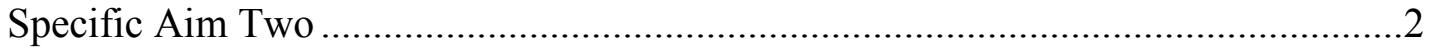

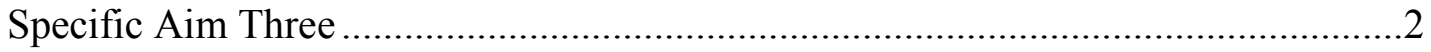

Specific Aim Four .......................................................................................

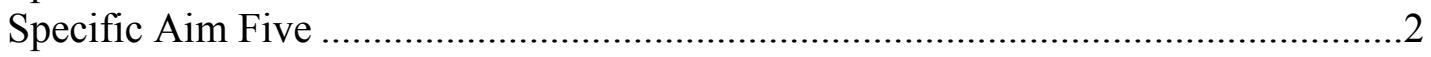

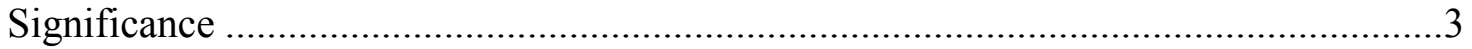

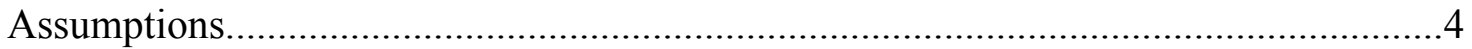

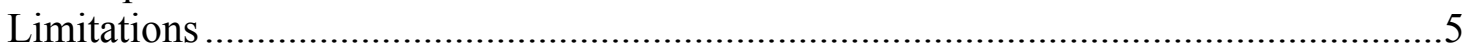

CHAPTER 2. LITERATURE REVIEW AND CONCEPTUAL FRAMEWORK .....6

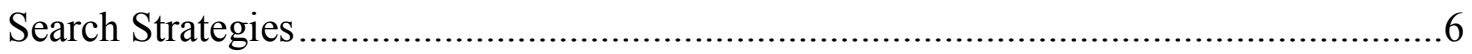

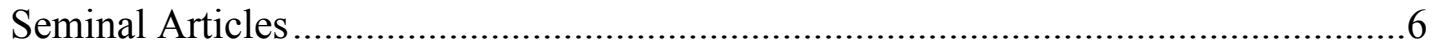

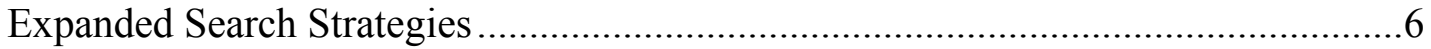

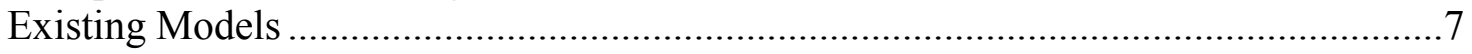

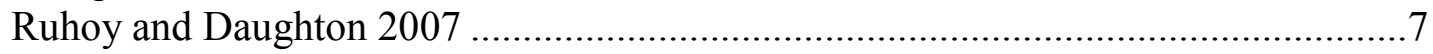

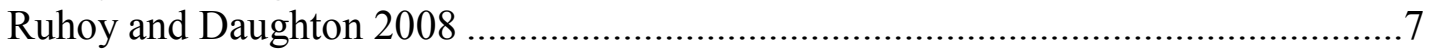

Daughton and Ruhoy 2008 ............................................................................. 9

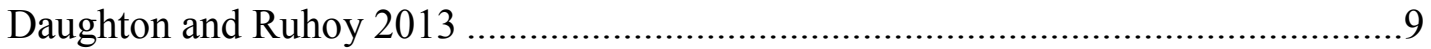

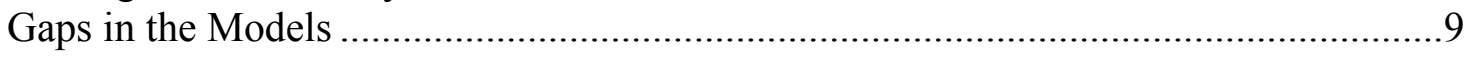

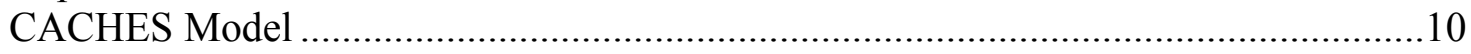

CACHES Model: Risk Factors ............................................................................ 10

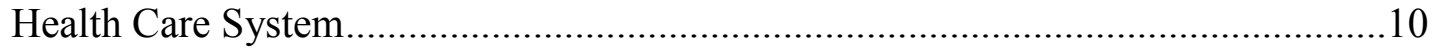

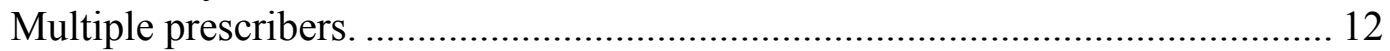

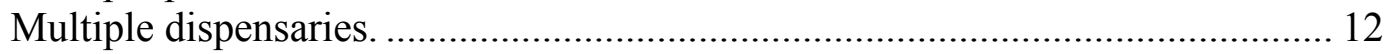

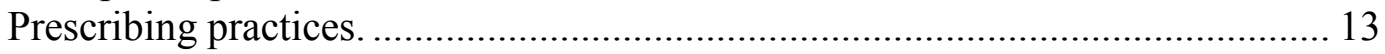

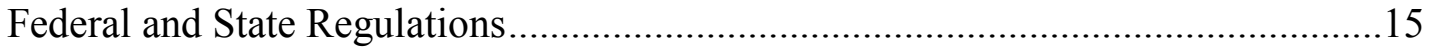

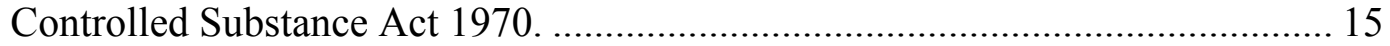

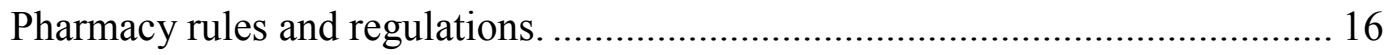

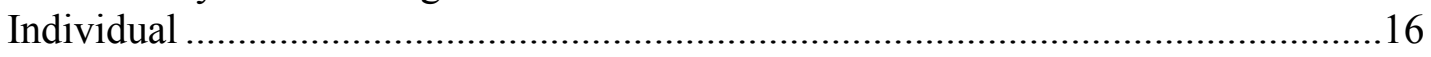

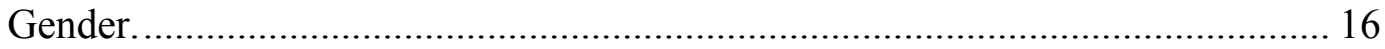

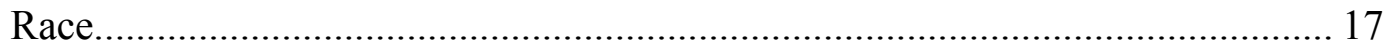

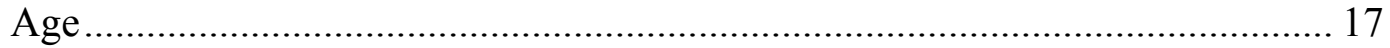

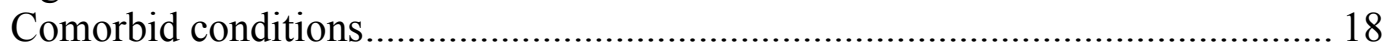

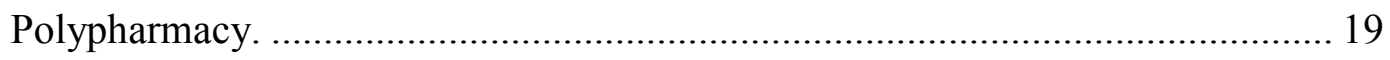

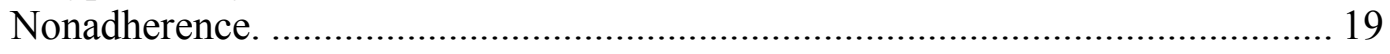

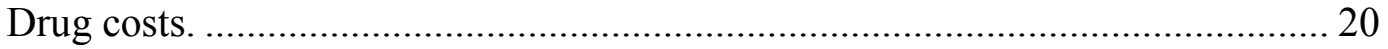

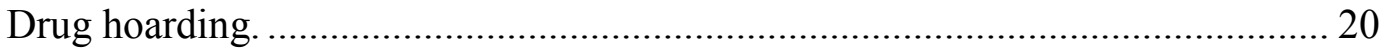

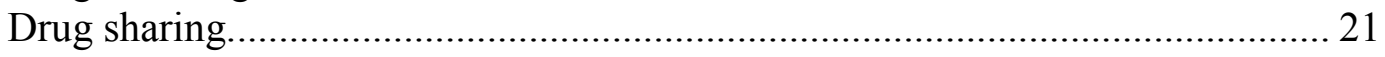




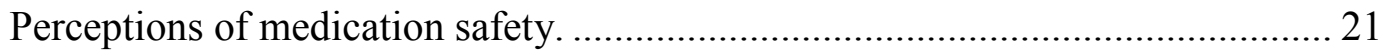

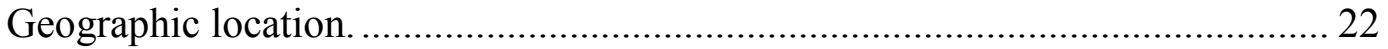

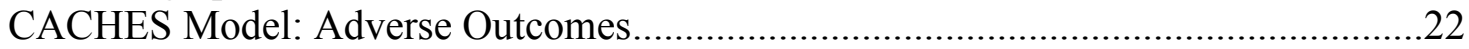

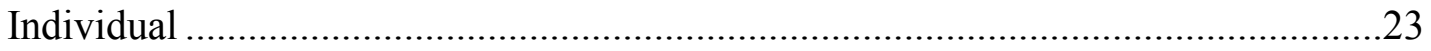

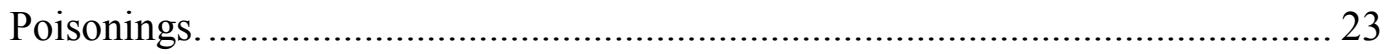

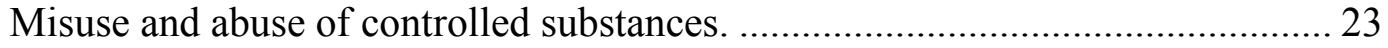

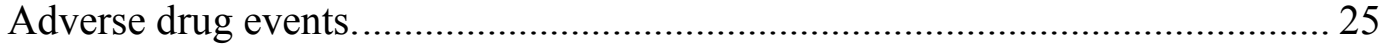

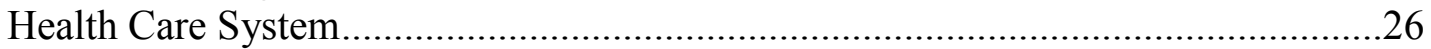

Increased utilization of health care resources. ................................................ 26

Unused medications as wasted health care dollars. ........................................ 27

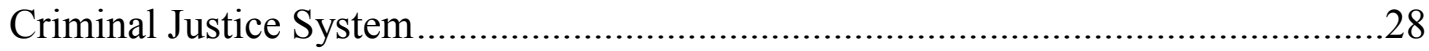

Victimization costs (drug theft, property damage/loss, loss in productivity)...... 29

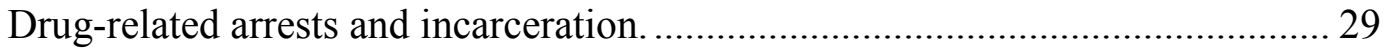

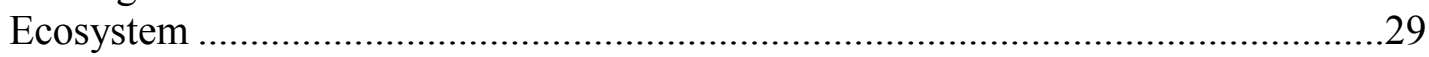

CHAPTER 3. METHODOLOGY ....................................................................................31

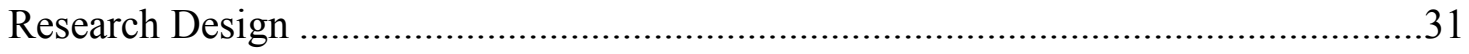

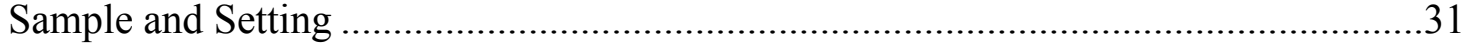

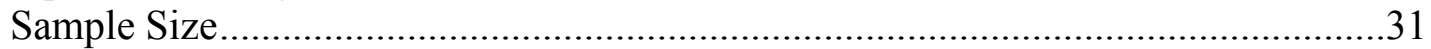

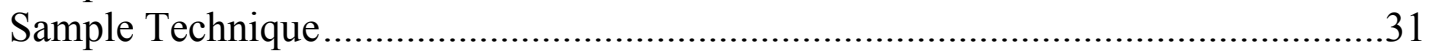

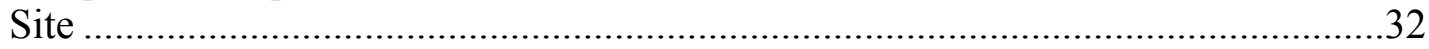

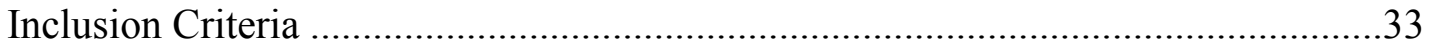

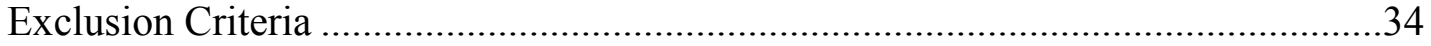

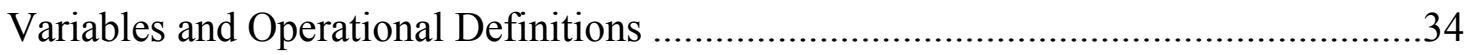

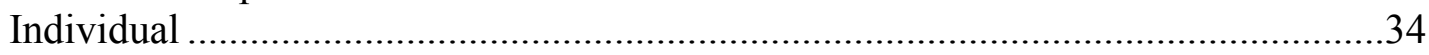

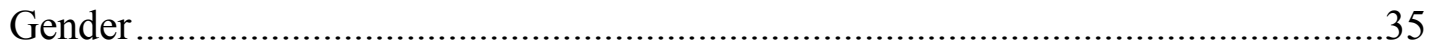

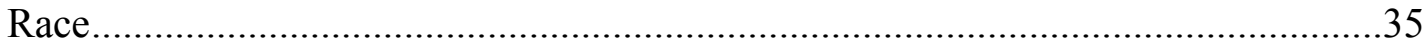

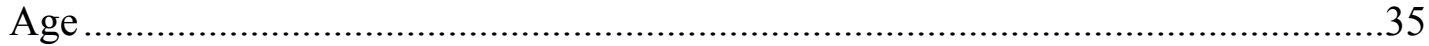

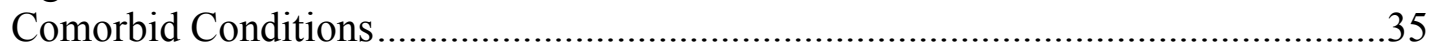

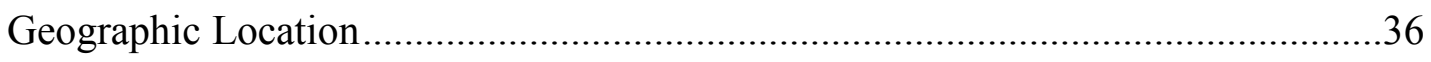

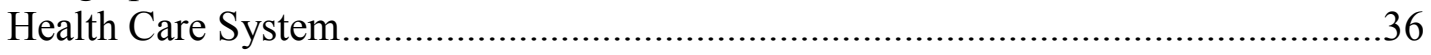

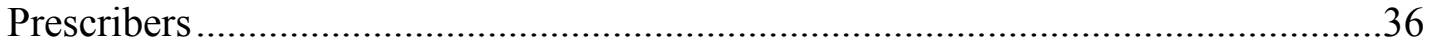

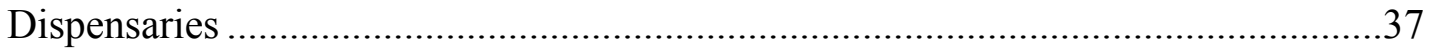

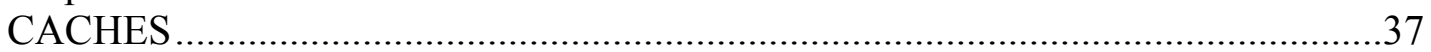

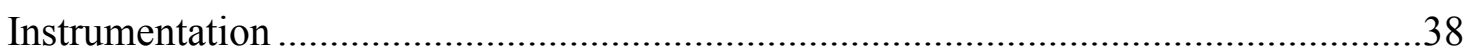

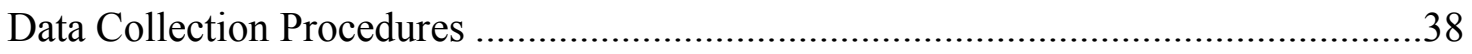

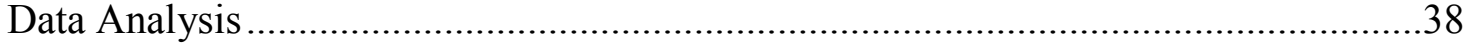

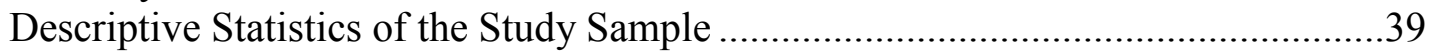

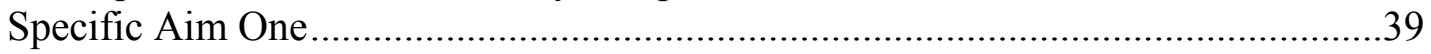

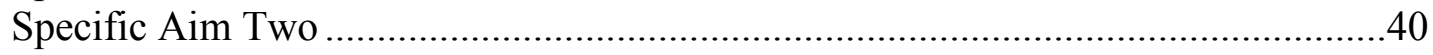

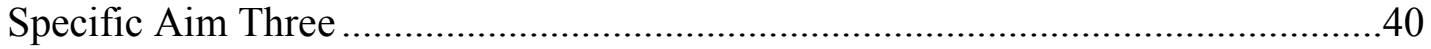

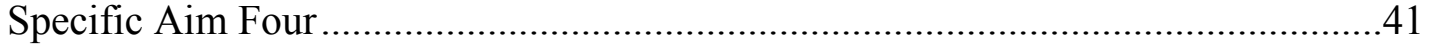

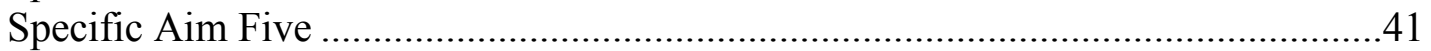

Protection of Human Subjects ............................................................................... 41 


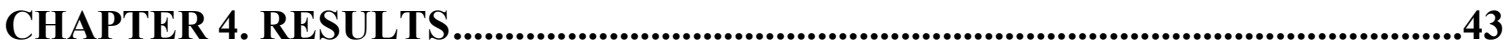

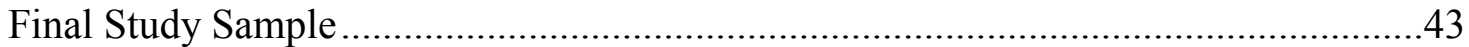

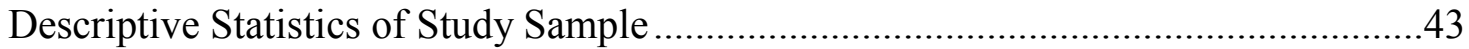

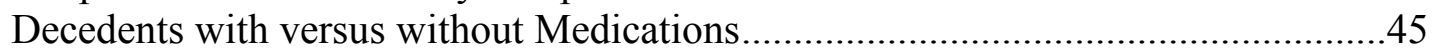

Sample Demographics versus Davidson County Demographics.................................45

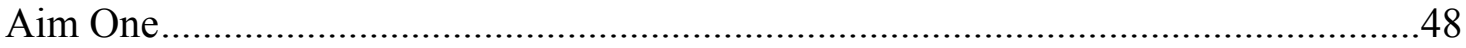

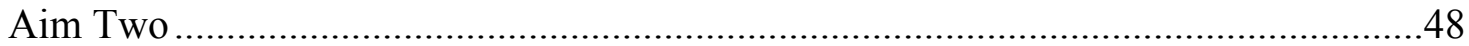

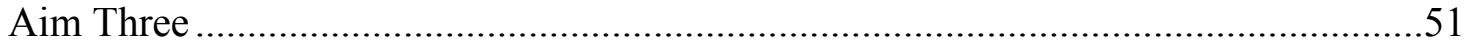

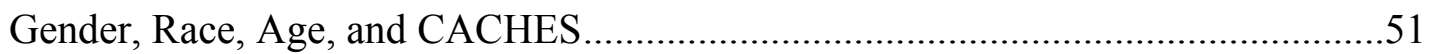

Comorbid Conditions and CACHES …………………....................................51

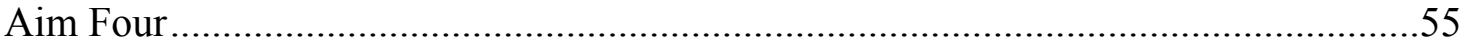

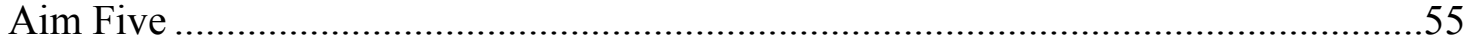

CHAPTER 5. DISCUSSION ............................................................................................60

CACHES Sample versus Davidson County Population ..............................................60

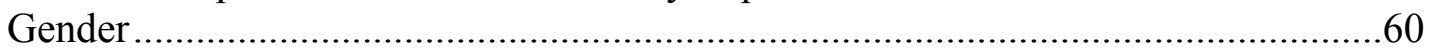

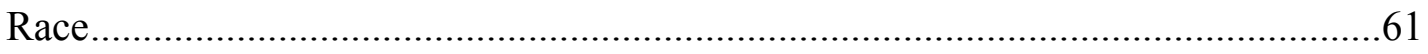

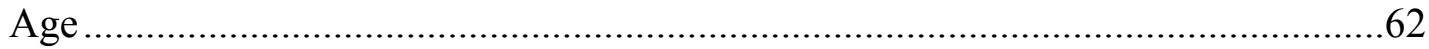

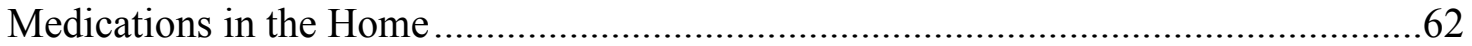

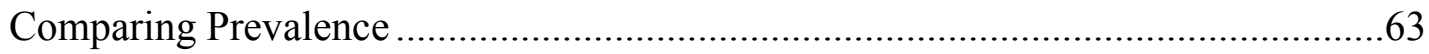

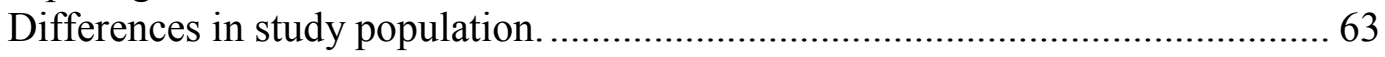

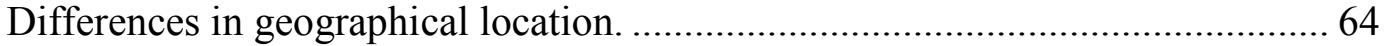

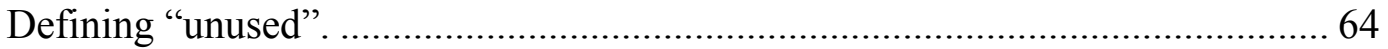

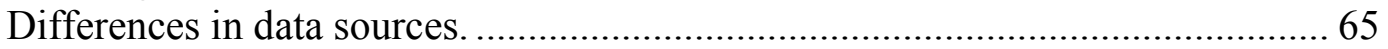

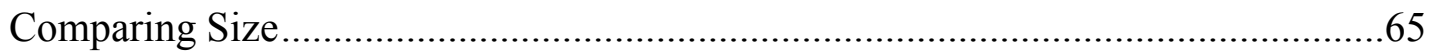

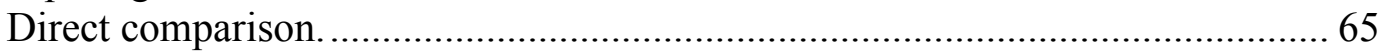

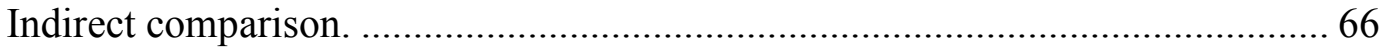

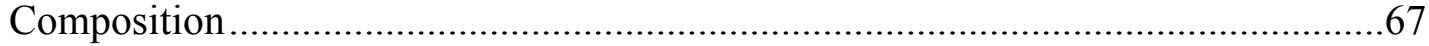

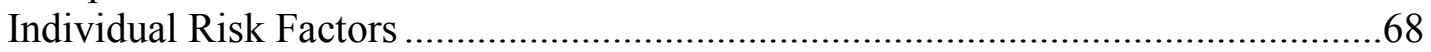

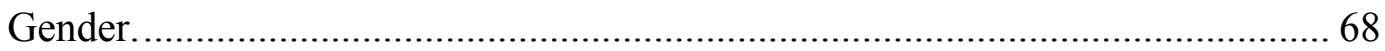

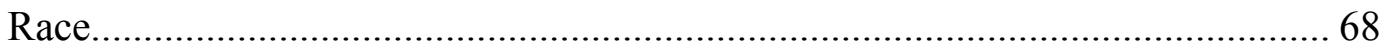

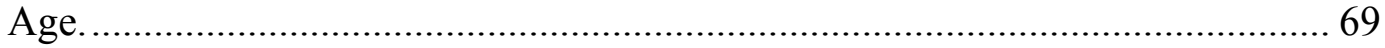

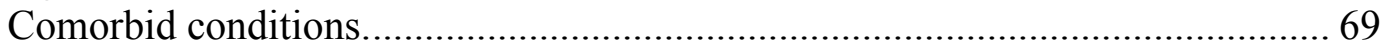

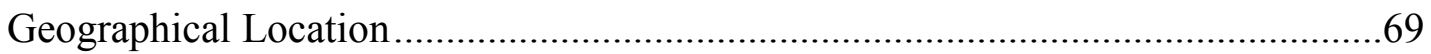

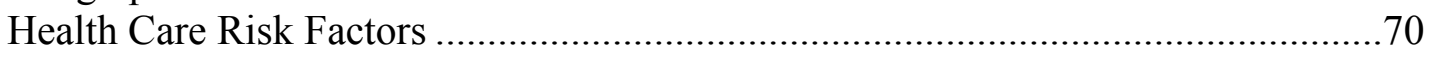

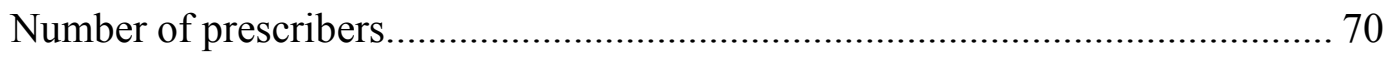

Number of dispensaries........................................................................... 71

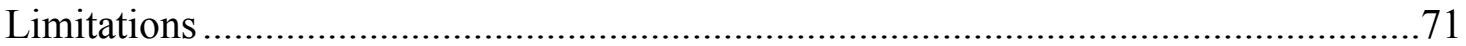

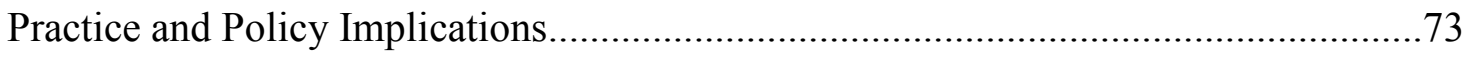

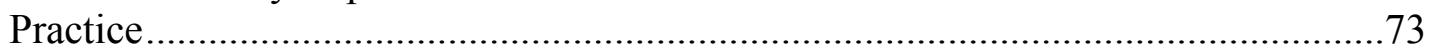

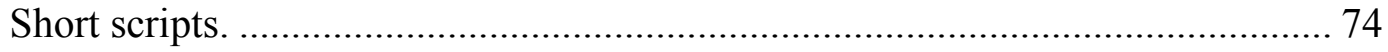

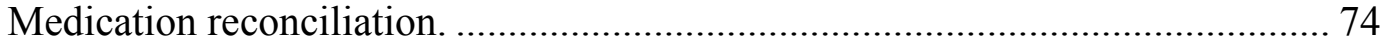

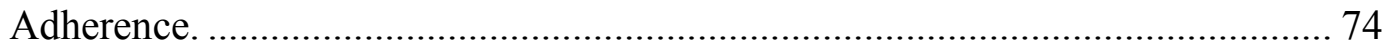

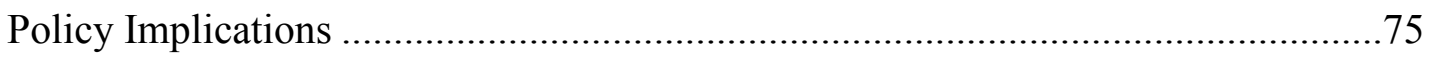

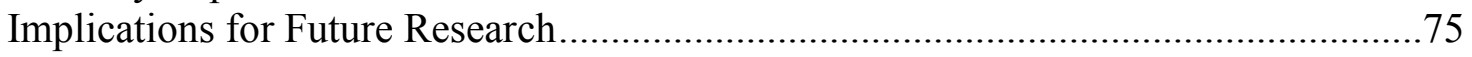

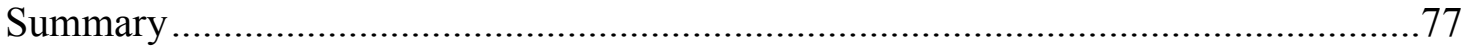




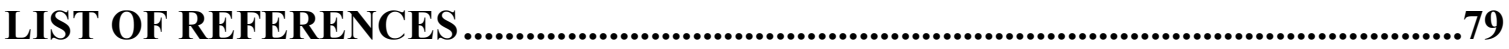

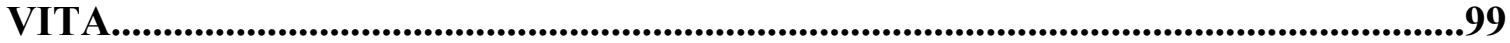




\section{LIST OF TABLES}

Table 2-1. Expanded Sources Searched for the Review of Literature …………….........8

Table 4-1. Demographic Data for Subjects Who Died at Home with Medications in the Home versus Those without Medications in the Home $(N=290) \ldots \ldots . . .46$

Table 4-2. Demographic Data of Subjects versus Demographic Data for the Population of Davidson County

Table 4-3. Number of Bottles of Medications Found among Decedents with CACHES $(N=812)$

Table 4-4. Frequency of Classes of Unused Medications among Decedents with CACHES ( $N=812$ Medication Bottles)

Table 4-5. Demographic Data of Decedents Who Died at Home with CACHES $(N=163)$ versus Those without CACHES $(N=16)$.

Table 4-6. Total Comorbid Conditions and Presence or Absence of Psychiatric, Substance Abuse, and Cognitive Disorder Diagnoses for Decedents with Medications (Currently in Use and Unused) in the Home $(N=210)$

Table 4-7. Total Comorbid Conditions and Presence or Absence of Psychiatric, Substance Abuse, and Cognitive Disorder Diagnoses for Decedents with CACHES $(N=163)$ versus Those without CACHES $(N=16)$ in the Home

Table 4-8. Frequency Table of Number of CACHES per Zip Code $(N=163) \ldots$ 56

Table 4-9. Frequency Distribution of the Number of Prescribers Used by Decedents with CACHES in the Home $(N=161)$

Table 4-10. Frequency Distribution of the Number of Prescribers Used by Decedents without CACHES in the Home $(N=15)$

Table 4-11. Descriptive Statistics of the Number of Prescribers Used by Decedents with CACHES and without CACHES $(N=176)$

Table 4-12. Frequency Distribution of the Number of Dispensaries Used by

Decedents with CACHES in the Home $(N=162)$

Table 4-13. Frequency Distribution of the Number of Dispensaries Used by

Decedents without CACHES in the Home $(N=15)$.

Table 4-14. Descriptive Statistics of the Number of Dispensaries Used by Decedents with CACHES and without CACHES $(N=177)$ 


\section{LIST OF FIGURES}

Figure 2-1. Conceptual Framework for Community-Based ACcumulation of Home MEdicationS (CACHES) ........................................................................11

Figure 4-1. Process of Excluding Subjects for Dissertation Study...............................44 


\section{LIST OF ABBREVIATIONS}

$\begin{array}{ll}\text { AMA } & \text { American Medical Association } \\ \text { APIs } & \text { Active Pharmaceutical Ingredients } \\ \text { CACHES } & \text { Community-Based Accumulation of Home Medications } \\ \text { CJS } & \text { Criminal Justice System } \\ \text { DAWN } & \text { Drug Abuse Warning Network } \\ \text { DEA } & \text { Drug Enforcement Administration } \\ \text { DOJ } & \text { Department of Justice } \\ \text { ED } & \text { Emergency Department } \\ \text { FDA } & \text { Food and Drug Administration } \\ \text { FM } & \text { Forensic Medical, PLC } \\ \text { HCP } & \text { Health Care Provider } \\ \text { HCS } & \text { Health Care System } \\ \text { MEBCFPs } & \text { Medical Examiners Board Certified Forensic Pathologists } \\ \text { MLDIs } & \text { Medicolegal Death Investigators } \\ \text { MNPD } & \text { Metro Nashville Police Department } \\ \text { NAME } & \text { National Association of Medical Examiners } \\ \text { NDIC } & \text { National Drug Intelligence Center } \\ \text { NSDUH } & \text { National Survey on Drug Use and Health } \\ \text { ONDCP } & \text { Office of National Drug Control Policy } \\ \text { OTC } & \text { Over the Counter } \\ \text { SAMHSA } & \text { Substance Abuse and Mental Health Services Administration } \\ \text { SBIRT } & \text { Screening, Brief Intervention, and Referral for Treatment } \\ \text { SILJ } & \text { Survey of Inmates in Local Jails } \\ & \end{array}$




\section{CHAPTER 1. INTRODUCTION}

\section{Overview}

Stockpiling of unused prescription and over-the-counter medications by health care consumers results in $\underline{\text { Community-Based }}$ ACcumulation of Home mEdication $\underline{S}$ (CACHES). CACHES endanger public health placing the individual, health care and justice systems, and the ecosystem at risk for adverse outcomes. Adverse outcomes include: a) youth and adults diverting prescription medications from the family medicine cabinet for the purpose of getting high; b) pediatric poisonings secondary to accidental ingestion of prescription or over-the-counter medications; c) increased emergency department visits and hospitalizations related to adverse drug events (ADEs); d) increased criminal justice system costs related to prescription drug abuse (e.g. theft, victimization costs, incarceration); e) increased health care costs associated with the treatment of prescription drug overdose, misuse, and abuse; and f) pollution of local water supplies because of improper disposal of unused medications via sewering defined as flushing medications down the sink or toilet.

Researchers Christian Daughton and Ilene Ruhoy developed several theoretical models addressing the issue of accumulated medications, improper disposal, and the entry points of Active Pharmaceutical Ingredients (APIs) into the environment. Each of these models have a different focus including: a) the mechanisms by which the individual consumer stockpiles medication and introduces APIs into the environment (Ruhoy \& Daughton, 2007); b) the accumulation of unused medications in places such as hospitals, long term care facilities, veterinary offices, livestock farms, and pharmaceutical factories and their preferred disposal routes (Ruhoy \& Daughton, 2008); c) factors affecting health care providers prescribing habits their contribution to medication wastage (Ruhoy \& Daughton, 2008); d) the pathways of biologic exposure to APIs for both humans and the environment (Daughton \& Ruhoy, 2008); and e) how “one-size-fits-all” prescribing behaviors and nonadherence contribute to medication stockpiling and subsequent adverse outcomes including increased healthcare costs, poisonings, and diversion (Daughton \& Ruhoy, 2013).

The CACHES model builds upon these existing models while incorporating additional supporting literature. In addition, the CACHES model offers perspective on external (federal and state regulations, health care system) and individual factors leading to the development of CACHES and the adverse outcomes associated with stockpiled medications in the home.

\section{Purpose of the Study}

The purpose of this pilot study was to examine the prevalence, size, and composition of CACHES found in decedents' homes in Davidson County, Tennessee from January 1, 2011 through December 31, 2011. In addition, this study sought to 
investigate the individual, geographic, and health care risk factors associated with the formation of CACHES. Individual risk factors included gender, race, age, and comorbid conditions. Geographic risk was examined through capturing the location of CACHES data by Zip code. Finally, health care risk factors included the number of prescribers and number of dispensers associated with CACHES.

\section{Specific Aims}

The CACHES pilot study had five specific aims including:

\section{Specific Aim One}

To describe the prevalence of CACHES found in decedents' homes in Davidson County, Tennessee from January 1, 2011 through December 31, 2011.

\section{Specific Aim Two}

To examine the size and composition of CACHES found in decedents' homes in Davidson County, Tennessee from January 1, 2011 - December 31, 2011.

\section{Specific Aim Three}

Among decedents with medications in the home, to compare individual risk factors (gender, race, age, comorbid conditions) between those with CACHES and those without CACHES.

\section{Specific Aim Four}

To describe the relationship between geographic location (Zip code) and the presence of CACHES in decedents' homes.

\section{Specific Aim Five}

Among decedents with medications in the home, to compare health care systems risk factors (number of prescribers, number of dispensaries) between those with CACHES to those without CACHES. 


\section{Significance}

Over the last two decades, there has been an increase in prescription and over the counter (OTC) drug use across all age groups in the United States (Gu, Dillon, \& Burt, 2010; Kaiser Family Foundation, 2010a; Raofi \& Schappert, 2006; Thomas, Conrad, Casler, \& Goodman, 2006). In 2011, Tennessee had the third highest rate of prescriptions per capita at 17.6 with the national average being 12.1 (Kaiser Family Foundation, 2011b). There has been a corresponding increase in the misuse and/or abuse of certain prescription drug classes especially opioids, benzodiazepines, and stimulants (U.S. Drug Enforcement Administration, 2012). The 2010 National Survey on Drug Use and Health (NSDUH) results show 7.0 million persons $\geq 12$ years of age reporting the nonmedical use of prescription drugs in the past month including using these drugs to get high (Substance Abuse and Mental Health Services Administration, 2011c). The majority $(70 \%)$ of first-time misusers accessed these prescription drugs from the family medicine cabinet, a family member, or friend (Office of National Drug Control Policy, 2011; Substance Abuse and Mental Health Services Administration, 2011c).

Unused medications also pose a household hazard to young children (Bronstein et al., 2011; Bronstein et al., 2010; Meyer et al., 2007; Schillie, Shehab, Thomas, \& Budnitz, 2009; Substance Abuse and Mental Health Services Administration, 2010a). An analysis of data from the National Electronic Injury Surveillance System collected during 2004 through 2005 identified approximately 58,000 Emergency Department (ED) visits made by children for treatment of accidental poisonings secondary to the consumption of over-the-counter (OTC) or prescription medications (Schillie et al., 2009). Reflecting the upward trend of prescription drug use, a follow up study in 2008 identified 69,121 ED visits related to accidental ingestion of pharmaceuticals by children $\leq 5$ years of age (Substance Abuse and Mental Health Services Administration, 2010a).

Stockpiles of unused and expired medications can lead to the individual being confused as to which medications are current versus those that have been discontinued. This situation contributes to accidental ingestion of duplicate classes of medications, overdosing, increased likelihood of drug-drug interactions, and/or the use of contraindicated medications. These medication errors contribute to adverse drug events (ADEs). Older adults are the most frequent consumers of prescription medications. As such they are at particular risk for these types of medication errors and subsequent adverse drug events, which often require a trip to the ED or hospitalization (Green, Hawley, \& Rask, 2007; Prybys, Melville, Hanna, Gee, \& Chyka, 2002; Wasserfallen, Bourgeois, Bula, Yersin, \& Buclin, 2003; Werder \& Preskorn, 2003).

Federal and state regulatory barriers limit consumer access to safe and efficient disposal choices for unused and/or expired medications. As a result, in addition to stockpiling unused medications, individuals frequently improperly dispose of medications in the trash or via flushing down the sink or toilet (Abrons, Vadala, Miller, \& Cerulli, 2010; Glassmeyer et al., 2009; Kotchen, Kallaos, Wheeler, Wong, \& Zahller, 2009; Kuspis \& Krenzelok, 1996; Ruhoy \& Daughton, 2008; Seehusen \& Edwards, 2006; Wennmalm, Gunnarsson, \& Eckermann, 2010). Components of these medications, 
termed Active Pharmaceutical Ingredients (APIs), eventually end up in local streams and rivers, as well as drinking-water supplies (Barnes et al., 2008; Daughton \& Ruhoy, 2009a; Daughton, 2010b; Glassmeyer et al., 2009; Stackelberg et al., 2004; Wennmalm et al., 2010; Westerhoff, Yoon, Snyder, \& Wert, 2005). APIs have a negative impact on the health of aquatic (Bound \& Voulvoulis, 2005; Gross-Sorokin, Roast, \& Brighty, 2006; Jobling, Nolan, Tyler, Brighty, \& Sumpter, 1998; Kidd et al., 2007; Orlando et al., 2004), microbe (Furtula et al., 2010; Schwartz, Kohnen, Jansen, \& Obst, 2006; Wennmalm et al., 2010; Zhang, Zhang, \& Fang, 2009), and higher level life forms (Oaks et al., 2006; Roig, Greenwood, \& Barcelo, 2009).

A two-month doctoral internship with the Office of National Drug Control Policy (ONDCP) afforded insight into the Obama Administration's current policies regarding public health risks associated with medications in the home, the potential for misuse, abuse, and diversion, and the Administrations' public policy recommendations to effect change. This internship provided networking opportunities with federal and state-level professionals involved in addressing prescription drug misuse and abuse. In addition, meetings including the ONDCP, Food and Drug Administration (FDA), Department of Justice (DOJ), Drug Enforcement Administration (DEA), the Substance Abuse and Mental Health Services Administration (SAMHSA), the American Medical Association (AMA), and state leaders in health care focused on the contributory role of federal and state regulations in the development of CACHES and the associated adverse outcomes for the individual, health care, and criminal justice system (Office of National Drug Control Policy, 2008, 2011). These observations and insights are incorporated into the CACHES conceptual framework.

\section{Assumptions}

The assumptions made during the development of the conceptual framework, methods, and analyses include:

1. Medicolegal Death Investigators (MLDIs) and Medical Examiners Board Certified Forensic Pathologists (MEBCFPs) follow the National Association of Medical Examiners (NAME) guidelines and Tennessee legal code regarding the collection and reporting of death scene data including: medications, on-scene investigation notes and photography, autopsy and toxicology reports, and the recording of Death Certificate data including the cause, nature, and contributing factors of death.

2. Prescription and OTC medications in the home serve as a public health threat to the individuals living or visiting in the home. 


\section{Limitations}

This study included the following limitations:

1. The data were obtained via a convenience sampling of decedents examined by Forensic Medical, PLC. Forensic Medical is called onto a death scene of a violent (homicide), traumatic (suicide, accidental), or unexpected death. These data may not be representative of the larger population.

2. The data were restricted to in-home deaths in Davidson County, Tennessee. These data may not be representative of populations in other geographical regions.

3. According to Tennessee law, MLDIs may only search for and collect medications that are: a) stored in "typical" locations such as the family medicine cabinet, bathroom and kitchen counters, refrigerator, and/or bedside table; or, b) in "plain sight"; and, c) are prescribed and dispensed to the decedent. As a result of these medicolegal processes, it is likely the study data are an underrepresentation of the number of medications stockpiled in the decedents' homes.

4. The pilot study sample size does not provide sufficient power for correlational statistics. As a result, the findings are limited to a descriptive analysis of the data. 


\section{CHAPTER 2. LITERATURE REVIEW AND CONCEPTUAL FRAMEWORK}

The purpose of this chapter is to: a) document search strategies in the review of the CACHES literature, b) describe expanded search strategies, c) examine and critique existing models, d) identify the gaps in the CACHES literature, e) explicate the CACHES model's concepts and propositions, and f) describe how the CACHES model provides a foundation for future research and practice.

\section{Search Strategies}

The first step in the development of the CACHES conceptual model was to evaluate the current literature. A search of the literature, using PubMed, OVID, and Google Scholar, highlighted an interdisciplinary interest in CACHES with germane articles found in nursing, medical, pharmacy, environmental chemistry, microbiology, and environmental health journals. Search limits consisted of English language articles published from 1980 to present. Key search terms included: adverse drug events, poisonings, drug disposal, hoarding and sharing medications, age, race, gender and health care utilization, pharmaceutical waste, prescription drug abuse and misuse, and diversion.

\section{Seminal Articles}

The initial review of the literature identified a handful of seminal articles coauthored by Drs. Christian Daughton and Ilene Ruhoy. These two researchers developed several conceptual models including: a) Disposal as a Contributor to Drugs in the Environment (Ruhoy \& Daughton, 2007), b) Accumulation and Disposal of Pharmaceuticals (Ruhoy \& Daughton, 2008), c) Unanticipated Exposure to Active Pharmaceutical Ingredient (APIs) Residue from the Environment (Daughton \& Ruhoy, 2008), d) Factors Influencing Drug Consumption (Ruhoy \& Daughton, 2008), and e) One-Size-Fits-All Drug Dosing: Risks to Health and the Environment, and Increased Health Care Costs (Daughton \& Ruhoy, 2013). These conceptual frameworks are discussed in more detail under the existing models section. Written communication with Dr. Daughton resulted in access to a 10,000-citation database of primarily environmental references housed on the United States Environmental Protection Agency's (EPA) website. In addition, a phone conference with a regional EPA representative, Virginia Thompson (Philadelphia Office), provided additional feedback on the development of the CACHES conceptual framework.

\section{Expanded Search Strategies}

The standard search engines (PubMed, Google Scholar, and OVID) provided access to relevant peer-reviewed literature. However, these peer-reviewed articles provided minimal national, regional, and state statistics on prescription drug misuse, 
abuse, and diversion, poisonings, overdoses, and prescription drug-related crime data. In addition, the scientific literature did not offer sufficient commentary on the role of federal and state regulations on medication disposal laws. These gaps in the scientific literature required the use of expanded search strategies as indicated in Table 2-1.

\section{Existing Models}

Ruhoy and Daughton developed five major conceptual models addressing the issue of medication accumulation, disposal practices, and the introduction of APIs into the ecosystem. What follows is an examination of these models, identification of existing gaps, and an introduction to the CACHES model.

\section{Ruhoy and Daughton 2007}

In their 2007 article, Ruhoy and Daughton presented their conceptual framework, "Disposal as a Contributor to Drugs in the Environment". In this model, they identify the mechanisms by which the individual consumer introduces APIs into the environment. These mechanisms include: a) excretion of APIs by humans into sewer systems, b) sewering of topical APIs secondary to bathing, c) introduction of "leftover" medications into landfills via household trash, and d) purposeful sewering of unused medications via flushing down the sink or toilet (Ruhoy \& Daughton, 2007). Ruhoy and Daughton (2007) identify one outlier disposal method, "Take-Backs", which result in the incineration of unused consumer medications. In their model, this particular disposal method does not contribute to the introduction of APIs into the environment. Ruhoy and Daughton (2007) also highlight how leftover medications can accumulate in the consumer's home through behaviors such as inadvertent and/or purposeful stockpiling. They propose a portion of these stockpiled medications are diverted from the consumer's household for purposeful abuse or can contribute to pediatric accidental poisonings (Ruhoy \& Daughton, 2007).

\section{Ruhoy and Daughton 2008}

In their second conceptual model, "Accumulation and Disposal of Pharmaceuticals", Ruhoy and Daughton (2008) enlarge the scope of their previous model from the individual as the primary medication accumulation point to also include: physician outpatient clinics, pharmacies at long term care facilities and hospitals, outpatient pharmacies, hospices, veterinary offices, agriculture centers, and reverse distributors. In addition, this model identifies the mechanisms of disposal used at each of these accumulation points as either sewering, landfills, or incineration (Ruhoy \& Daughton, 2008).

"Factors Influencing Drug Consumption" identifies the factors influencing health care providers' prescribing habits and the dispensing of medications. In addition, the 


\section{Table 2-1. Expanded Sources Searched for the Review of Literature}

\begin{tabular}{ll}
\hline Topics & \multicolumn{1}{c}{ Sources } \\
\hline $\begin{array}{l}\text { National, regional, and state statistics } \\
\text { on prescription drug misuse, abuse, } \\
\text { and diversion }\end{array}$ & $\begin{array}{l}\text { National Drug Intelligence Center } \\
\text { Office of National Drug Control Policy } \\
\text { Substance Abuse and Mental Health } \\
\text { Services Administration }\end{array}$ \\
$\begin{array}{l}\text { National trends in accidental pediatric } \\
\text { prescription drug poisonings }\end{array}$ & $\begin{array}{c}\text { Substance Abuse and Mental Health } \\
\text { Administration }\end{array}$ \\
$\begin{array}{l}\text { Morbidity and mortality data related } \\
\text { to adverse drug events, misuse, abuse, } \\
\text { and overdoses on prescription drugs }\end{array}$ & $\begin{array}{l}\text { Center for Disease Control and Prevention } \\
\text { Substance Abuse and Mental Health } \\
\text { Services Administration }\end{array}$ \\
$\begin{array}{l}\text { Department of Transportation } \\
\text { Crime rates related to prescription }\end{array}$ & National Drug Intelligence Center \\
Current federal policy statements & \\
regarding prescription drug epidemic & Orug Enforcement Administration \\
& Substance Abuse and Mental Health \\
& Services Administration \\
\hline
\end{tabular}


researchers list specific patient behaviors (increased consumer acquisition, nonadherence) leading to increased accumulation of consumer medication wastage (Ruhoy \& Daughton, 2008). This model also suggests potential changes by both providers (small quantity trials, installment dispensing, abuse and addiction prevention, medication reuse) and patients (concordance) to reduce this wastage (Ruhoy \& Daughton, 2008).

\section{Daughton and Ruhoy 2008}

The conceptual model, "Unanticipated Exposure to Active Pharmaceutical Ingredient (APIs) Residue from the Environment" highlights the pathways of biologic exposure for both humans and the environment to APIs (Daughton \& Ruhoy, 2008). The authors emphasize this exposure is done without consent and the source of these exposures stems from the introduction of APIs to sewage via excretion and disposal of medications (Daughton \& Ruhoy, 2008).

\section{Daughton and Ruhoy 2013}

"One-Size-Fits-All Drug Dosing: Risks to Health and the Environment, and Increased Health Care Costs" identifies prescribing behaviors (dose larger than needed to achieve therapeutic outcome, polypharmacy) and patient factors (adverse drug reactions, self-medicating, noncompliance) responsible for the accumulation of excess medications. In addition, this model focuses on the downstream impact of these excesses, including: introduction of APIs into the environment, increased health care costs, poisonings, diversion, and abuse (Daughton \& Ruhoy, 2013).

\section{Gaps in the Models}

While there is growing evidence of concern about CACHES, there are limitations in the existing conceptual models as well as gaps in the literature as to the contributing factors and adverse outcomes associated with CACHES. Ruhoy's and Daughton's models provide an in depth analysis of where unused medications accumulate at the micro (consumer) and macrosystem (health care, agricultural, and pharmaceutical industry) level and how these systems dispose of these unwanted medications.

In addition to Ruhoy and Daughton's work, there are a handful of other studies examining the stockpiling of unused and expired medications in the home setting. However, the majority of these studies were done in Europe, the Middle East, New Zealand, and Australia. There has not been extensive research on this topic in the United States (U. S.). It is difficult to generalize the findings of these studies to the U.S. when taking into consideration the differences in the health care systems (e.g. fewer prescriptions per capita, centralized health care system, pharmacy-as-disposal site) and possible demographic variations. 


\section{CACHES Model}

The CACHES model (Figure 2-1) includes six major concepts: health care system (HCS), federal and state regulations, individual, CACHES, criminal justice system (CJS), and ecosystem. In addition, the model identifies characteristics for each of the major concepts. On the left-hand side, three major concepts (health care system, federal and state regulations, individual) and their characteristics are classified as risk factors leading to the stockpiling of medications in the home. Multiple prescribers, multiple providers, and prescribing practices are health care system characteristics directly contributing to the individual's risk for CACHES. The Controlled Substance Act (1970) and pharmacy rules and regulations, characteristics of state and federal regulations, also increase the individual's risk for accumulating unused medications in the home. Finally, characteristics of the individual (gender, race, age, comorbid conditions, polypharmacy, nonadherence, drug costs, drug hoarding, drug sharing, perceptions of medication safety, and geographic location) affect the individual's risk for having CACHES in the home setting.

Adverse outcomes associated with CACHES are indicated on the right-hand side of Figure 2-1. For the individual, adverse outcomes include: poisonings, misuse or abuse of prescription medications, and adverse drug events. Increased utilization of health care resources and unused medications representing wasted health care dollars are health care system associated adverse outcomes. Adverse outcomes in the criminal justice system include victimization costs and increased drug-related arrests and incarcerations. Inappropriate disposal of CACHES of prescription drugs introduce active pharmaceutical ingredients (APIs) into sewers and landfills, ultimately adversely affecting the ecosystem. Finally, these APIs eventually contaminate local water supplies thereby placing the individual at risk for exposure.

The concepts and their characteristics examined in this pilot study are highlighted in gray in Figure 2-1. The individual characteristics include: gender, race, age, comorbid conditions, and geographic location. Health care system characteristics are the number of prescribers and number of dispensaries. Finally, data on the identified CACHES will be analyzed. What follows is a definition for each major concept and their associated characteristics. In addition, this section discusses the relationships between the major concepts, as well as the relationships between the associated characteristics and major concepts.

\section{CACHES Model: Risk Factors}

\section{Health Care System}

The health care system (HCS) is defined as the setting(s) in which the individual receives health care. Examples of health care settings include: primary care office, specialty clinic, Emergency Department, hospital, substance abuse treatment center, and 


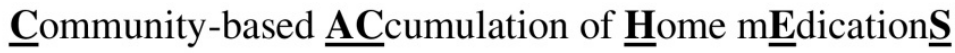

(CACHES)

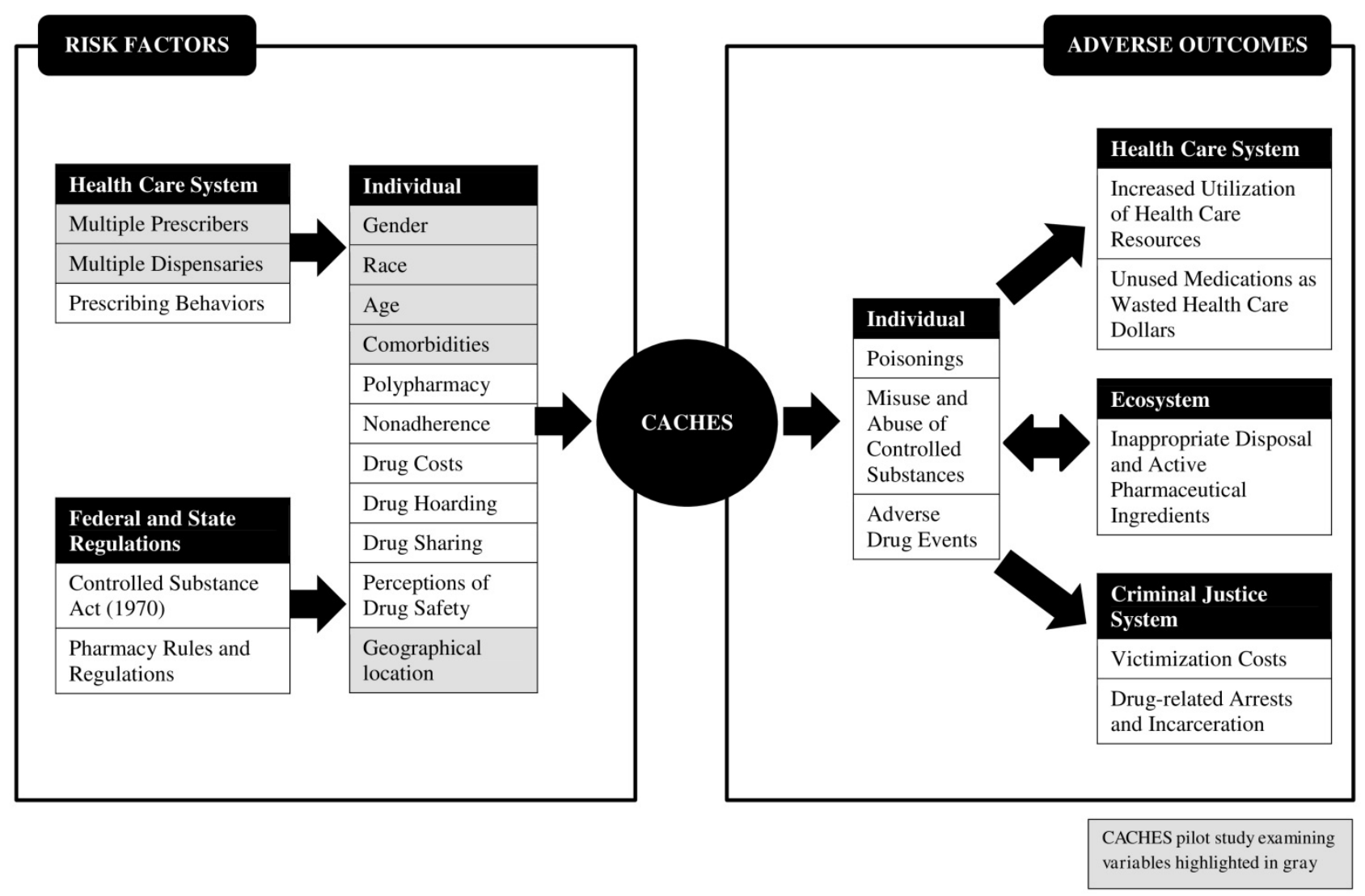

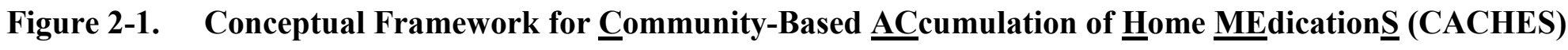


long term care facility. As noted previously, the HCS plays a dual role in the CACHES model. On the risk factors (left-hand) side of the model, the HCS has a positive contributory influence on the individual's risk for CACHES. In the United States (U.S.), health care delivery frequently is decentralized. Health care consumers often are seen by multiple prescribers (primary care providers, specialists, dentists) and use multiple dispensaries (pharmacies). Furthermore, provider prescribing practices contribute to the overprescribing of medications - in particular controlled substances. In the CACHES model, both communication breakdowns among providers and provider prescribing practices place the individual at increased risk for CACHES.

Multiple prescribers. In today's health care system, patients often receive care in a variety of settings and from a variety of health care providers (Barat, Andreasen, \& Damsgaard, 2000; Green et al., 2007; Prybys et al., 2002; Sorensen, Stokes, Purdie, Woodward, \& Roberts, 2005, 2006). The CACHES model defines these providers (physicians, nurse practitioners, physician assistants, and dentists) as prescribers - as each has the potential to write prescriptions for the individual seeking health care. This decentralized health care delivery system is often complicated by a lack of communication among prescribers, which contributes to confusion as to what medications the patient is currently taking (Baena et al., 2006; Barat et al., 2000; Green et al., 2007; Junius-Walker, Theile, \& Hummers-Pradier, 2006; Sorensen et al., 2005; Torrible \& Hogan, 1997; Wasserfallen et al., 2003). This confusion places the individual at risk for duplicate prescriptions (Sorensen et al., 2005, 2006; Torrible \& Hogan, 1997), polypharmacy (Barat et al., 2000; Hajjar, Cafiero, \& Hanlon, 2007; Junius-Walker et al., 2006), and nonadherence (Baena et al., 2006; Barat et al., 2000; Sorensen et al., 2005). These issues not only place the individual at risk for adverse outcomes (Baena et al., 2006; Barat et al., 2000; Gray-Winnett, Davis, Yokley, \& Franks, 2010; Green et al., 2007; Hajjar et al., 2007; Junius-Walker et al., 2006; Sorensen et al., 2005, 2006; Torrible \& Hogan, 1997; Wasserfallen et al., 2003), but also contribute to the accumulation of unused and expired medications in the home (Barat et al., 2000; Daughton \& Ruhoy, 2008; Junius-Walker et al., 2006; Ruhoy \& Daughton, 2008; Sorensen et al., 2005, 2006; Torrible \& Hogan, 1997). In the CACHES model, the use of multiple prescribers increases the individual's risk for CACHES.

Multiple dispensaries. The CACHES model defines dispensaries as any commercial pharmacy (national chain pharmacies, independent pharmacies, physician clinics) where prescription and OTC medications are dispensed to the individual. Individuals obtaining prescriptions from multiple dispensaries are at higher risk for both duplicate prescriptions and contraindicated medication regimens (Boparai \& KorcGrodzicki, 2011; Torrible \& Hogan, 1997). Duplicate prescriptions are defined as having two prescriptions for the same medication or within the same class of medications. Contraindicated medication regimens are defined as medications that, when taken concurrently, have a high risk for drug-drug interactions (Boparai \& Korc-Grodzicki, 2011; Torrible \& Hogan, 1997). Duplicative errors and the prescription of contraindicated medication regimens increased a patient's risk for adverse drug events 
(Boparai \& Korc-Grodzicki, 2011; Torrible \& Hogan, 1997). The individual will often self-discontinue or is instructed by his/her provider to discontinue the medication(s) believed responsible for the adverse drug event (ADE). In the setting of a 30- or 90-day supply of medications, this can result in a significant number of doses remaining unused. In disposal studies, patients report adverse drug events as a common reason for unused medications (Coma, Modamio, Lastra, Bouvy, \& Marino, 2008; Langley, Marriott, Mackridge, \& Daniszewski, 2005; Mackridge \& Marriott, 2007; Shin, Kim, \& Lee, 2009). Analysis of administrative drug claims data also identify the use of multiple dispensaries as a significant risk factor for the overprescribing, misuse and/or abuse of prescription opioids (Parente et al., 2004; Sullivan et al., 2010). In the CACHES model, the use of multiple dispensaries places the individual at risk for the accumulation of unused medications in the home and adverse outcomes associated with these CACHES.

Prescribing practices. Health care provider prescribing practices play a contributing role in the formation of CACHES. Overprescribing of antibiotics, pain medications, and other classes of medications results in the accumulation of unused and expired medications in the home. Of note, overprescribing is a term describing several different prescribing practices. Overprescribing can be defined as writing a prescription when a pharmacological intervention is not required. One common illustration of this practice is the prescribing of an antibiotic for a viral upper respiratory infection.

Overprescribing also includes prolonged treatment duration for an acute health care issue. Multiple studies found this to be a common prescribing practice in the treatment of acute low back pain (Cantrill et al., 2012; Tacci, Webster, Hashemi, \& Christiani, 1999). In addition, prescribers often write "large prescriptions", defined as a one to three month supply, (Steiner, Robbins, Roth, \& Hammond, 1993) with the intent of increasing adherence via improved access to the medication (Steiner et al., 1993). However, this practice can contribute to the accumulation of unused medications in the home when the medication is discontinued due to a lack of effectiveness, the patient has issues with side effects, and/or has a more serious adverse drug event (Steiner et al., 1993; Wennmalm et al., 2010). The literature reflects a relationship between the above listed prescribing practices and unused medications. Common reasons reported for the return of unused medications include a) physician discontinued medication (Langley et al., 2005; Mackridge \& Marriott, 2007), b) adverse event (Langley et al., 2005; Mackridge \& Marriott, 2007), and c) patient discontinued due to side effects (Langley et al., 2005; Mackridge \& Marriott, 2007).

At worst, the easy availability of certain classes of medications, specifically opioids, is identified as contributing to the increase of prescription drug misuse and abuse. The majority of youth and adults reporting recent opioid misuse obtained these medications through a friend or family member (Substance Abuse and Mental Health Services Administration, 2011c). Following the supply chain backwards, greater than $70 \%$ of these friends and family members obtained their opioid prescription from one medical provider (Manchikanti \& Singh, 2008; Substance Abuse and Mental Health Services Administration, 2011c). 
Over the last two decades, opioids have become the most commonly prescribed class of medications in the U.S. (Grady, Berkowitz, \& Katz, 2011; Manchikanti \& Singh, 2008; Paulozzi \& Xi, 2008; Volkow, McLellan, \& Cotto, 2011). A 2011 report analyzing pharmacy dispensing trends of generic and brand drugs showed hydrocodone ranked as the first and second most common prescription dispensed in the United States (Bartholow, 2012). Nationwide, pharmacies dispensed 104,457,000 prescriptions for hydrocodone with the third most common prescription, Levothyroxine sodium, trailing far behind at 43,958,000 (Bartholow, 2012). Wisniewski, Purdy and Blondell's (2008) epidemiological study showed a statistically significant relationship between increased prescribing of opioids and the subsequent nonmedical use of opioid medicines. This trend is associated with increased ED visits secondary to the sequelae related to prescription opioid misuse (Manchikanti et al., 2012; Wisniewski et al., 2008), as well as an increase in the number of deaths due to accidental overdoses of opioid medications (Manchikanti et al., 2012; Warner, Chen, \& Makuc, 2009).

Health care providers report discomfort with prescribing opioids for the treatment of non-cancer pain (Bhamb et al., 2006; Breuer, Cruciani, \& Portenoy, 2010; Paulozzi et al., 2012; Salinas et al., 2012; Wolfert, Gilson, Dahl, \& Cleary, 2010). Providers also report a gap in graduate education on best practices for prescribing prescription opioids (Breuer et al., 2010; Paulozzi et al., 2012; Wolfert et al., 2010). As a result, many providers do not incorporate appropriate opioid abuse risk-reduction strategies including pain contracts, urine drug screens, short-scripts, or prescription drug monitoring programs (Bhamb et al., 2006; Paulozzi et al., 2012; Salinas et al., 2012; Wolfert et al., 2010). These prescriber behaviors contribute to increased access to and, subsequently, the misuse and/or abuse of prescription opioids in the United States (Paulozzi et al., 2012).

In response to these issues the Office of National Drug Control Policy, the Substance Abuse and Mental Health Administration, and the Food and Drug Administration, as well as several Congressional leaders, have proposed mandatory continuing education for health care providers who prescribe opioids (Food and Drug Administration, 2011a, 2011b; Paulozzi et al., 2012). In November 2011, the FDA released for public comments a draft Risk Evaluation and Mitigation Strategy (REMS) for Schedule II, long-acting and extended-release opioids (Food and Drug Administration, 2011a). Topics covered by the REMS include correct prescribing practices for Schedule II opioids; using the screening, brief intervention and referral to treatment (SBIRT) to identify patients with potential misuse/abuse issues; and incorporating prescription drug monitoring programs and pain contracts into the management of chronic pain patients (Food and Drug Administration, 2011a).

In the CACHES model, provider prescribing behaviors have a direct effect on the individual - placing him/her at risk for CACHES of unused medications. These behaviors include prescribing medications that are not warranted, prescribing long-scripts for an acute issue, and prescribing large prescriptions for a new medication without first establishing effectiveness or tolerance. Furthermore, the overprescribing of prescription 
opioids results in excess supplies in the home, which in turn is linked to the rising incidence of nonmedical use of prescription opioids.

\section{Federal and State Regulations}

Current federal and state regulations serve as barriers to the individual seeking safe and environmentally-friendly disposal of expired and unused medications. In the CACHES model, federal and state regulations are defined as those laws and regulatory guidelines directly related to the disposal of unused prescription medications by the individual. The Controlled Substance Act 1970 and Pharmacy rules and regulations are each discussed in turn.

Controlled Substance Act 1970. The Comprehensive Drug Abuse Prevention and Control Act of 1970, also known as the Controlled Substance Act (CSA) dictates the manufacturing, distribution, prescribing, and dispensing of controlled substances ("Comprehensive Drug Abuse Prevention and Control Act of 1970," 1970). Controlled substances are pharmaceuticals identified as having a high potential risk for abuse. Under the CSA, an end user is identified as the individual prescribed a controlled substance. By law, the end user must dispose of unused controlled substances via sewering or throwing it in the trash. In addition, he/she may return unused controlled substances to law enforcement officials such as local police departments, sheriff's departments, drug enforcement administration officials, or specially designated "antidrug" National Guardsmen ("Comprehensive Drug Abuse Prevention and Control Act of 1970," 1970; Glassmeyer et al., 2009; Herring, Shah, Shah, \& Gupta, 2008).

The CSA law was designed specifically to reduce the diversion of legally prescribed controlled substances towards channels of illegal use/abuse. Unfortunately, this law also serves as a barrier for easily accessible and environmentally-friendly disposal options for the individual with unused and unwanted controlled medications ("Comprehensive Drug Abuse Prevention and Control Act of 1970,," 1970; Daughton, 2003; Glassmeyer et al., 2009; Herring et al., 2008). When surveyed, the majority of end users report flushing unused medications down the toilet or sink or throwing them out in the trash (Bound \& Voulvoulis, 2005; Glassmeyer et al., 2009; Kallaos, Wheeler, Wong, \& Zahller, 2007; Kuspis \& Krenzelok, 1996; Seehusen \& Edwards, 2006). Many report lack of access to and/or discomfort with dropping off unused medications with law enforcement officials (Glassmeyer et al., 2009; Kallaos et al., 2007; Kotchen et al., 2009; Ortner \& McCullagh, 2010).

The CSA not only affects individual end users but also has a direct impact on hospices (McCullagh, Schim, \& Ortner, 2012; Ortner \& McCullagh, 2010), and in some instances, hospitals (Senft, 2010) and nursing homes (Senft, 2010). Standard operating procedures for the disposal of controlled substances include sewering unused medications at the time of the patient's death or discharge (Ortner \& McCullagh, 2010). This practice 
was established with the goal of preventing staff or family members diverting the patient's medications for nonmedical use (Ortner \& McCullagh, 2010).

In October 2010, the U.S. Congress passed an amendment S. 3397 titled the "Safe and Secure Drug Disposal Act" significantly revising the Controlled Substance Act (CSA) of 1970. Currently the DEA is holding public forums discussing how this amendment will affect regulatory standards (Jones, 2011). The intent of this amendment is to open the door for pharmacies and community-based drug disposal efforts to receive unused controlled substances and other non-controlled prescription and over-the-counter medications for destruction without the need for direct law enforcement involvement (Glassmeyer et al., 2009; Jones, 2011; Office of National Drug Control Policy, 2011).

Pharmacy rules and regulations. Variations in state pharmacy laws present a barrier to the enactment of Amendment S. 3397 (Center for Substance Abuse Research, 2012; Daughton, 2003; Glassmeyer et al., 2009; Jones, 2011; Seehusen \& Edwards, 2006). Local and state pharmacy boards and larger pharmacy groups, such as the National Association of Chain Drug Stores (NACDS), are opposed to becoming designated disposal sites (Seehusen \& Edwards, 2006; Statement of the National Association of Chain Drug Stores on Drug Waste and Disposal, 2010). They argue that the assumption of this role would result in increased risk for pharmacy theft, increased costs and the need for additional staff (Nola, 2011). As currently written, there is no designated federal funding for pharmacy-based take back programs (Jones, 2011; Nola, 2011). The CACHES conceptual model identifies federal and state regulatory issues as logistical barriers for the individual interested in access to safe and environmentallyfriendly disposal options. These barriers increase the risk of the accumulation of medications in the home.

\section{Individual}

In the CACHES model, the individual is defined as a community-dwelling person. Of note, the individual plays a dual role in the CACHES model. On the lefthand side of the model (Figure 2-1), the individual has certain characteristics placing $\mathrm{him} / \mathrm{her}$ at risk for stockpiling medications in the home. These characteristics include a) gender, b) race, c) age, d) comorbid conditions, e) polypharmacy, f) nonadherence, g) drug coverage, h) drug hoarding, i) drug sharing, $\mathrm{j}$ ) perceptions of medication safety, and k) geographic location. Each characteristic is defined along with a discussion as to its effect on the individual's risk for CACHES.

Gender. In the CACHES model, gender is defined as male or female. According to the literature, females are more likely than males to seek medical care; have higher health care expenditures, including prescription drug purchases; and use prescription drugs (Barat et al., 2000; Carrie, Grynmonpre, \& Blandford, 2006; Fulton \& Allen, 2005; Hofer-Ducklemann, 2012; Kaiser Family Foundation, 2010d; Linjakumpu et al., 2002; 
Owens, 2008; Qato et al., 2008; Shin et al., 2009; Sorensen et al., 2005). In the United States, the Kaiser Family Foundation National Survey (2010d) supports this difference with females filling 14.4 prescriptions/capita versus males who fill 9.5

prescriptions/capita. This gender gap is more pronounced when looking at the state-level data. In Tennessee, females on average filled 21.0 prescriptions per year versus 14.1 for males in 2011 (Kaiser Family Foundation, 2011a). Increased access and usage of prescription and OTC medications increases the likelihood of unused medications (Sorensen et al., 2005). In the CACHES model, female gender increases the risk for the accumulation of unused and expired medications in the home (Sorensen et al., 2005).

Race. The CACHES model defines race according to the categories used by the state Medical Examiners in the completion of state-issued death certificates. These categories include Caucasian/Non-Hispanic, African American, Hispanic, Asian, and Other. Caucasian/Non-Hispanic patients are more likely to have access to and utilize health care resources when compared to Hispanic and African American patients (Adams et al., 2013; Gellad, Haas, \& Safran, 2007; McClelland, Jorgensen, Post, Szklo, \& Kronmal, 2013). This trend can also be seen when looking at racial differences in prescription drug access (Adams et al., 2013; Gellad et al., 2007). These findings are not surprising when comparing the rates of uninsured African Americans (21\%) and Hispanics (32\%) versus 13\% of Caucasians (Kaiser Family Foundation, 2011c).

Multiple studies have examined the relationship between race and medication nonadherence. Findings indicate minority patients (African American and Hispanic) being less adherent than their Caucasian counterparts (Benner et al., 2002; Bosworth et al., 2008; Siegel, Lopez, \& Meier, 2007). Of note, this disparity appears to be related to the costs of the prescription medications (Adams et al., 2013; Gellad et al., 2007; Goldman, Joyce, \& Zheng, 2007; McClelland et al., 2013; Turner, Hollenbeak, Weiner, Have, \& Roberts, 2009) rather than just race alone.

These three issues (access, use, and adherence) complicate the picture of race and CACHES. Due to socioeconomic reasons, minorities are less likely to have access to and be able to purchase prescription medications. A lack of access to medications would reduce the risk of having excess medications stockpiled in the home. However, when able to access prescribed medications, minority patients potentially are less adherent to prescribed regimens, which could contribute to an increased risk of the accumulation of unused medications. The CACHES model identifies race as a risk for CACHES, but recognizes it is just one characteristic of many that may place the individual at risk for stockpiling unused medications in the home.

Age. The CACHES model identifies advanced age ( $\geq 65$ years of age) as placing the individual at higher risk for the accumulation of unused and expired medications in his/her home. The U.S. population will see an estimated $147 \%$ increase in the older adult population, from $12 \%$ in 2000 to a projected $21 \%$ in 2050 (Fulton \& Allen, 2005). Older adults are significant consumers of health care in comparison to any other age group 
(Bartholow, 2012; Carrie et al., 2006; Junius-Walker et al., 2006). Older adults are more likely to have multiple comorbid conditions, seek care from multiple providers, and use multiple pharmacies (Boparai \& Korc-Grodzicki, 2011; Shin et al., 2009; Wasserfallen et al., 2003). A third of the total prescription medications dispensed in the United States are dispensed to older adults (Mansur, Weiss, \& Beloosesky, 2008; Werder \& Preskorn, 2003). In addition, on average, older adults are responsible for $40 \%$ of the total over-thecounter medications purchases (Fulton \& Allen, 2005). More than half of older adults surveyed take 5 or more medications, when combining prescription, over-the-counter, and supplements (Bolle et al., 2008; Boparai \& Korc-Grodzicki, 2011; Fulton \& Allen, 2005; Qato et al., 2008; Torrible \& Hogan, 1997). In the state of Tennessee, older adults filled 42.7 prescriptions per year compared to 15.3 for people ages 19-64 and 3.1 for people ages 0-18 (Kaiser Family Foundation, 2010b). Based on these data, the CACHES model proposes older age ( $\geq 65$ years old) increases the individual's risk for the accumulation of unused and expired medications in the home (Morgan, 2001).

Comorbid conditions. Comorbid conditions is defined as having multiple, concurrent, chronic diagnoses and diseases. Patients with comorbid conditions use more prescription medications (Anderson \& Horvath, 2004; Carrie et al., 2006; Lehnert et al., 2011; Sorensen et al., 2005) and often receive care from multiple providers across various settings (Anderson \& Horvath, 2004; Boparai \& Korc-Grodzicki, 2011; Himmel, Tabache, \& Kochen, 1996; Lehnert et al., 2011; Mansur, Weiss, \& Beloosesky, 2008; Prybys et al., 2002; Starfield, Lemke, Herbert, Pavlovich, \& Anderson, 2005). These medically complex patients often experience acute exacerbations of their underlying diseases, which translates into additional visits (Anderson \& Horvath, 2004; Lehnert et al., 2011) and repeat hospitalizations (Anderson \& Horvath, 2004; Landi et al., 2004; Lehnert et al., 2011).

This pattern of recurrent outpatient visits and hospitalizations can obscure the patient's already complicated medication regimen (Anderson \& Horvath, 2004; Himmel et al., 1996; Mansur, Weiss, \& Beloosesky, 2008). It is not unusual for up to $50 \%$ (Himmel et al., 1996; Mansur, Weiss, \& Beloosesky, 2008) of a patient's "at home" medications to be changed during a hospitalization. In addition, upon discharge, up to $25 \%$ (Himmel et al., 1996) to 37.5\% (Mansur, Weiss, \& Beloosesky, 2008) of the preadmission medications are not restarted. This can contribute to a patient's confusion as to which medications he/she should be taking post hospitalization.

Drug return studies in the United Kingdom (Edwards, 1982; Langley et al., 2005), Canada (Cameron, 1996; Torrible \& Hogan, 1997), Europe (Almarsdottir \& Asgeirsson, 2009; Coma et al., 2008; Ekedahl, 2006; Wasserfallen et al., 2003), the Middle East (Abahussain, Ball, \& Matowe, 2006), New Zealand (Braund, Gn, \& Matthews, 2009; Braund, Peake, \& Shieffelbein, 2009; James, Helms, \& Braund, 2009), and the United States (Garey, Johle, Behrman, \& Meuhauser, 2004; Morgan, 2001; Ruhoy \& Daughton, 2008) found participants cited provider-initiated changes to medication regimens as one of the most common reasons for returning unused medication to be disposed. Extrapolating from these data, a patient with multiple comorbid conditions is likely being 
treated by multiple providers across multiple settings and has a higher frequency of health care visits. This, in turn, increases the chances of multiple changes to the patient's medication regime. For these reasons, the CACHES model identifies comorbid conditions as a factor placing the individual at higher risk for stockpiles of unused medications in the home setting.

Polypharmacy. Adults with multiple comorbidities are at increased risk for polypharmacy (Green et al., 2007; Linjakumpu et al., 2002; Mansur, Weiss, \& Beloosesky, 2008; New England Healthcare Institute, 2009; Prybys et al., 2002; Werder $\&$ Preskorn, 2003). Polypharmacy has been defined in a variety of ways in the scientific literature (Fulton \& Allen, 2005; Hajjar et al., 2007; Hofer-Ducklemann, 2012; Linjakumpu et al., 2002; Veehof, Stewart, Haaijer-Ruskamp, \& Jong, 2000). One common definition for polypharmacy is taking medications that are not clinically indicated (Fulton \& Allen, 2005; Hajjar et al., 2007; Prybys et al., 2002; Sorensen et al., 2004; Veehof et al., 2000). Another common definition is taking five or more concurrent medications whether clinically indicated or not (Fulton \& Allen, 2005; Haider, Johnell, Weitoft, Thorslund, \& Fastbom, 2008; Junius-Walker et al., 2006; Linjakumpu et al., 2002; Werder \& Preskorn, 2003). In the context of the CACHES model, the latter definition of polypharmacy will be used.

Polypharmacy contributes to poor adherence to prescribed medication regimens (Dunbar-Jacob \& Mortimer-Stephens, 2001; Mansur, Weiss, \& Beloosesky, 2008; New England Healthcare Institute, 2009; Prybys et al., 2002; Sorensen et al., 2005; Witticke, Seidling, Lohmann, Send, \& Haefeli, 2013). As the number of concurrently prescribed medications increases, the likelihood of the patient taking all medications as prescribed decreases (Hajjar et al., 2007; New England Healthcare Institute, 2009; Sorensen et al., 2005; Witticke et al., 2013). This incomplete consumption of all prescribed medications leads to the accumulation of unused and expired medications (Barat et al., 2000; Sorensen et al., 2005). The CACHES model proposes a direct relationship between the individual experiencing polypharmacy and the development of CACHES in the home (Barat et al., 2000).

Nonadherence. In the scientific literature, nonadherence is another term with several different definitions and methods of measurement (Fine et al., 2009). The term nonadherence has been defined as one or all of the following patient behaviors: a) not filling a prescription, b) taking less than the prescribed dosage, c) taking more than the prescribed dosage, and d) filling the prescription but failing to take any of the prescribed dosage (Fine et al., 2009; Mansur, Weiss, Hoffman, Gruenewald, \& Beloosesky, 2008). Estimates of nonadherence to medication regimens in patients with chronic diseases ranges from 50 to as high as 60\% (Choudhry et al., 2009; Dunbar-Jacob \& MortimerStephens, 2001; Wasserfallen et al., 2003; Wilke et al., 2012). Measurements of nonadherence include a) patient self-report of taking medications as prescribed and/or number of missed doses (Fine et al., 2009; Grynmonpre, Didur, Montgomery, \& Sitar, 1998), b) provider pill-counts (Fine et al., 2009; Grynmonpre et al., 1998), and c) using 
pharmacy claims to determine if the patient has filled his/her prescription per the prescribed schedule (Choudhry et al., 2009; Fine et al., 2009; Grynmonpre et al., 1998; Martin et al., 2009; Wilke et al., 2012). Each of these methods of measurement has strengths and weakness. Patient self-report of adherence can be biased due to patients desiring to be perceived as adherent. Pill counts are an indirect measure of adherence and presume the absence of a pill/capsule equates to that dose being both ingested by the patient, as well as being ingested at the correct prescribed dosage/frequency. Finally, while pharmacy claims serve as direct evidence the patient is purchasing the prescribed medication, they do not attest to whether the medications are, in fact, being taken by the patient once he/she is at home.

Regardless of these issues of definition and measurement, nonadherence is cited as a common reason for unused medications in the home (Bound \& Voulvoulis, 2005; Coma et al., 2008; Mackridge \& Marriott, 2007; Sorensen et al., 2004; Sorensen et al., 2005). In the CACHES model, nonadherence increases the risk of the accumulation of unused and expired medications in the home (Barat et al., 2000; Langley et al., 2005; Sorensen et al., 2004).

Drug costs. Increases in the percentage of total health care dollars spent on prescription medications versus other health care services has led insurance companies to shift costs to the health care consumer (Kaiser Family Foundation, 2010a). This increased financial burden affects prescription drug use with an inverse relationship between out-of-pocket expenses and a patient's prescription drug use (Kaiser Family Foundation, 2010a; Thomas, Wallack, Lee, \& Ritter, 2002). In response to decreased revenues, insurance plans incentivize the use of 90-day supplies (Ruhoy \& Daughton, 2008) or mail order (Ruhoy \& Daughton, 2008; Thomas et al., 2002) prescription plans by offering the consumer lower copayments. Interim changes to the patient's medication regimen, by a health care provider due to inadequate response or by the patient selfterminating the medication due to adverse effects, make the previous prescription obsolete (Daughton \& Ruhoy, 2008; Langley et al., 2005; Ruhoy \& Daughton, 2008). As a result, the patient is left with multiple doses of unused medication, which contributes to an accumulation in the home (Daughton \& Ruhoy, 2008; Langley et al., 2005; Ruhoy \& Daughton, 2008; Steiner et al., 1993). The CACHES model reflects this relationship with drug costs increasing risk of unused medications in the home.

Drug hoarding. Stockpiling, also known as drug hoarding, behaviors have a direct contributory affect to the development of CACHES. Hoarding behavior is defined as holding onto unused medications past their expiration date and/or prescribed time of use (Bolle et al., 2008; Ellis \& Mullan, 2009; Ruhoy \& Daughton, 2008; Sorensen et al., 2004; Wazaify, Shields, Hughes, \& McElnay, 2005). The motivation for hoarding is multifaceted including desire for cost savings, saving in anticipation of a future need for the medication, and wanting to limit pollution via improper medication disposal (Bolle et al., 2008; Kotchen et al., 2009). 
With increasing cultural awareness of the environmental impact of improper disposal of medications (Abrons et al., 2010; Kotchen et al., 2009), some patients are hoarding medications due to a lack of access to environmentally friendly disposal options in their community. Concerned about the potential consequences of sewering unused medications (Abrons et al., 2010; Kotchen et al., 2009; Seehusen \& Edwards, 2006), patients are left with no other option than to stockpile these medications in their closets, medicine and kitchen cabinets (Seehusen \& Edwards, 2006; Sorensen et al., 2005). Hoarding of unused medications contributes to the formation of CACHES, which place the individual at risk for adverse outcomes including adverse drug events, accidental poisonings, and poor health outcomes related to non-adherence (Goldsworthy, Schwartz, \& Mayhorn, 2008; Sorensen et al., 2005, 2006).

Drug sharing. Studies in the U.S. (Daniel, Honein, \& Moore, 2003; Garnier et al., 2010; Goldsworthy et al., 2008; McCabe, Boyd, \& Teter, 2006; Petersen, Rasmussen, Daniel, Yazdy, \& Honein, 2008; Seehusen \& Edwards, 2006) and internationally (Abahussain et al., 2006; Ellis \& Mullan, 2009) reveal a common theme of individuals, across the lifespan (Daniel et al., 2003; Ellis \& Mullan, 2009; Goldsworthy et al., 2008; Petersen et al., 2008), holding onto unused medications with the intent to share prescription medications with family members or friends (Bolle et al., 2008; Daniel et al., 2003; Ellis \& Mullan, 2009; Garnier et al., 2010; Goldsworthy et al., 2008; McCabe et al., 2006; McCabe, Cranford, Boyd, \& Teter, 2007; Seehusen \& Edwards, 2006; B. White, Blease, \& Bishop, 2006). Common classes of "shared" medications include allergy medications, antibiotics, stimulants, opioids, and benzodiazepines (Bolle et al., 2008; Garnier et al., 2010; Goldsworthy et al., 2008; McCabe et al., 2006; McCabe et al., 2007; Petersen et al., 2008). The CACHES model identifies drug sharing as a risk factor for the stockpiling of medications in the home setting.

Perceptions of medication safety. As mentioned above, individuals across the lifespan hoard medications with the intent to self-medicate (Bolle et al., 2008; Goldsworthy et al., 2008) and/or share their medications with friends and family members for reasons that are both therapeutic (Daniel et al., 2003; Goldsworthy et al., 2008; Petersen et al., 2008) and non-therapeutic (Daniel et al., 2003; Garnier et al., 2010; Goldsworthy et al., 2008; McCabe et al., 2007; Petersen et al., 2008; B. White et al., 2006). These practices carry an implicit perception, by both the individual sharing and the individual borrowing the medication, of the general "safety" of these prescription and OTC medications. The National Institute on Drug Abuse (NIDA) "Monitoring the Future" survey shows a growing trend in youths' perceptions of prescription and overthe-counter medications not being risky due to their legitimate therapeutic uses (Johnston, O'Malley, Bachman, \& Schulenberg, 2011; Office of National Drug Control Policy, 2011). This perception is also common in the adult population (Bolle et al., 2008; Daniel et al., 2003; Goldsworthy et al., 2008). Youth and adults are self-medicating and/or abusing their own or other people's supply of unused medications with little comprehension for the potential adverse side effects (Bolle et al., 2008; Daniel et al., 2003; Langley et al., 2005; Wazaify et al., 2005). The CACHES model identifies this 
misperception of the safety of prescription medications and OTCs as contributing to the retention of used medications in the home with the intent to share and/or use for nonprescribed purposes.

Geographic location. To date there are a handful of studies examining the connection between geographic location (rural versus urban) and prescription medication use (Carrie et al., 2006; Grymonpre \& Hawranik, 2008). However, there is a dearth of studies examining the relationship between an individual's geographic location as a risk for stockpiling medications in the home. In contrast, geographical patterns of prescription drug abuse and misuse have received substantial attention (Brownstein, Green, Cassidy, \& Butler, 2010; Cicero, Dart, et al., 2007; Cicero, Surratt, Inciardi, \& Munoz, 2007; McCabe, 2005; McCabe, Boyd, \& Teter, 2005; Substance Abuse and Mental Health Services Administration, 2005, 2010d, 2011b, 2012). Many prescription drug abusers gain access to their drugs of choice via their own, their family member's, or a friend's home supply. The CACHES model proposes geographic location (classified as Zip code) has a direct relationship with the individual's risk for CACHES - a problem found in multiple regions across the United States (Cicero, Dart, et al., 2007; McCabe, 2005; McCabe et al., 2005; Substance Abuse and Mental Health Services Administration, 2010b, 2011c, 2012).

Researchers have sought to identify geographical patterns associated with specific types of prescription drug misuse/abuse through mapping population level data (Brownstein et al., 2010; Cicero, Dart, et al., 2007; Cicero, Surratt, et al., 2007; Young, Havens, \& Leukefeld, 2012). Multiple studies identify rural populations as having greater risk of prescription drug abuse/misuse than larger urban populations (McCabe et al., 2005; Substance Abuse and Mental Health Services Administration, 2012). However, there are important regional and local variations depending on availability of prescription drugs through both licit (prescribed by health care provider) and illicit (illegal drug trade) channels (Cicero, Surratt, et al., 2007). The CACHES model builds on these previous studies identifying geographic location as a risk factor for the formation of CACHES.

\section{CACHES Model: Adverse Outcomes}

The right-hand side of the CACHES conceptual framework addresses adverse outcomes related to CACHES as experienced by the individual, the health care and criminal justice systems, and the ecosystem. Adverse outcomes affecting the individual include accidental poisonings, misuse or abuse of medications, and adverse drug events. Costly emergency room visits and hospitalizations related to treatment of accidental poisonings, adverse drug events, overdoses, and medication misuse are a fiscal burden and adverse outcome for the health care system. In addition, an increasing number of admissions to substance abuse treatment facilities for prescription drug abuse place financial strain on the health care system. Theft of controlled substances from individuals' homes contributes to increased costs to the criminal justice system. Local, state, and federal criminal justice systems struggle to manage the costs associated with 
the prescription drug-related arrests and incarcerations. Finally, limited disposal options lead to improper disposal practices such as flushing or placing medications in the trash. This introduces APIs into the water supply, ultimately contributing to pollution of the larger ecosystem.

\section{Individual}

On the right-hand side of the CACHES model (Figure 2-1), the individual is identified as at risk for adverse outcomes secondary to his/her exposure to CACHES. Trends in national and state data sets, as provided by the SAMHSA, ONDCP, and DEA websites, offer evidence of the connection between adverse individual health outcomes, including poisonings, deliberate misuse or abuse of prescription medications, and adverse drug events.

Poisonings. In the home environment, unsafe storage and easy access to medications pose a risk to both humans and pets (Bolle et al., 2008; Daughton, 2010a; Dymowski \& Uehara, 1987; Gray-Winnett et al., 2010; Langley et al., 2005; McFee \& Caraccio, 2006; Meyer et al., 2007; Substance Abuse and Mental Health Services Administration, 2010a). Accidental or unintentional poisonings are defined as the unintentional ingestion of or exposure to a substance, which ultimately results in harm (American Association of Poison Control Centers, n.d.; Dymowski \& Uehara, 1987; Meyer et al., 2007; Substance Abuse and Mental Health Services Administration, 2010a). Bronstein et al. (2010) reported a retrospective review of accidental poisonings in households called into poison control centers. Forty-six percent of these calls were related to unintentional exposure to prescription and OTC medications (Bronstein et al., 2010). In young children, unintentional medication poisonings resulting in Emergency Department (ED) visits occurred twice as often as ED visits related to exposure from other household products (Schillie et al., 2009; Substance Abuse and Mental Health Services Administration, 2010a). Over $80 \%$ of ED admissions are because an unsupervised child found and consumed medicines (Schillie et al., 2009). For adolescents (ages 13-19), 88\% of fatalities reported in 2009 to the Poison Control Centers were related to pharmaceuticals (Bronstein et al., 2010). The increasing trend of accidental poisonings from prescription drug exposure and the increasing number of prescriptions per person hints at a potential relationship between these two variables. The CACHES model draws a direct relationship between the number of unused medications found in home and the risk for accidental poisonings (Langley et al., 2005).

Misuse and abuse of controlled substances. In the CACHES model, diversion of medications, in particular controlled substances, for misuse and/or abuse by an individual (i.e. family member or friend) is an associated adverse outcome of CACHES (Daughton \& Ruhoy, 2013; Gray-Winnett et al., 2010; Langley et al., 2005; McCabe et al., 2007; Ruhoy \& Daughton, 2008; B. White et al., 2006). Multiple studies note easy access to controlled substances in the home, where family members frequently do not 
lock up or store controlled substances in a safe location (Bolle et al., 2008; McFee \& Caraccio, 2006). Diversion of these prescription drugs for misuse and abuse is a significant issue in the U.S. affecting individuals across the lifespan and all socioeconomic groups (Garnier et al., 2010; Hall et al., 2008; McCabe et al., 2006; McCabe et al., 2007; Office of National Drug Control Policy, 2008, 2011; Substance Abuse and Mental Health Services Administration, 2011c; B. White et al., 2006; Wisniewski et al., 2008). The Substance Abuse and Mental Health Services Administration (SAMHSA), define nonmedical use as the diversion and misuse/abuse of controlled substances for the purpose of getting high (Substance Abuse and Mental Health Services Administration, 2011c).

Youth and young adult nonmedical use of prescription drugs increased by $20.2 \%$ from 2002 to 2009 (Johnston et al., 2011). SAMHSA's 2009 National Survey on Drug Use and Health (NSDUH) reports recent initiates, or first-time nonmedical users of pain relievers, to be second only to marijuana in persons 12 years and older (Substance Abuse and Mental Health Services Administration, 2010c). Breaking down the NSDUH data by state, Tennessee is one of five states showing a significant increase in the non-medical use of opioid pain relievers in persons 12 and older (Substance Abuse and Mental Health Services Administration, 2010c). Over 46,000 adolescents reported nonmedical use of pain relievers in the past 12 months (Substance Abuse and Mental Health Services Administration, 2010c).

Misuse and abuse of prescription medications also are becoming more prevalent in older adults (Blazer \& Wu, 2009; Han, Gfroerer, \& Colliver, 2009; L. Wu \& Blazer, 2011). In particular, the generation of adults born between 1946 to 1964, also known as the Baby Boomer cohort, is considered to be at increased risk for nonmedical use of prescription medications and illicit substances (Colliver, Compton, Gfroerer, \& Condon, 2006). This generational effect is believed to be secondary to diminishing negative attitudes toward drug use (Blazer \& Wu, 2009; Colliver et al., 2006; Han et al., 2009; Substance Abuse and Mental Health Services Administration, 2010c; L. Wu \& Blazer, 2011). A national survey of individuals entering into substance abuse treatment facilities identified alcohol as the most common reason for admission to treatment facilities in persons 50 years or older; however, opiates were a close second (Substance Abuse and Mental Health Services Administration, 2007). Opiates were listed by those 65 years and older as the primary abused substance in $10.5 \%$ of admissions for treatment in 2005 , which is up from 6.6\% in 1995 (Substance Abuse and Mental Health Services Administration, 2007, 2010d).

An additional concerning trend is the number of individuals fatally overdosing on prescription medications in the setting of nonmedical use (Paulozzi \& Xi, 2008; Wisniewski et al., 2008; Wysowski, 2007). In 2008, for the first time ever, fatal poisonings (all ages) surpassed motor vehicle accidents as the number one cause of accidental death in the United States (Warner, Chen, Makuc, Anderson, \& Minino, 2011). According to the Centers for Disease Control (CDC) National Center for Health Statistics (NCHS), 9 out of 10 poisoning deaths were caused by drugs (Warner et al., 2011), with more than $40 \%$ involving opioid medications (Warner et al., 2011). In the CACHES 
model, exposure to easily accessible controlled substances in the home places the individual at risk for misusing and/or abusing controlled substances and, in some cases, fatal drug overdoses.

Adverse drug events. In the CACHES model, excess unused medications in the home place the individual at risk for ADEs. An ADE is defined as a negative health outcome secondary to medication consumption (Boparai \& Korc-Grodzicki, 2011; Sorensen et al., 2004). ADEs can vary in severity. On the milder end of the ADE spectrum, a patient can experience a drug rash secondary to antibiotic allergy. Typically, this requires discontinuation of the medication, but no further medical intervention. In contrast, a more severe example of an ADE would be a patient experiencing significant bradycardia (heart rate $<40$ beats per minute) secondary to taking two different betablocker agents concurrently. This latter example would result in admission to an emergency department and/or an inpatient hospitalization.

Of note, it is difficult to determine the underlying causes of adverse drug events, especially in the community setting. National data sets rely on emergency department personnel, who categorize ADEs as accidental, intentional, and unable to determine (Prybys et al., 2002). As a result, it is difficult to tease apart if an ADE is related to a patient accidentally or purposefully taking a discontinued or expired medication, doubledosing errors, or the purposeful misuse of a friend or family member's medications - as often happens with opioids and benzodiazepines (Ellis \& Mullan, 2009). Furthermore, there is no standard mechanism to capture ADEs in community-dwelling individuals who do not seek medical attention, which contributes to an underestimation of the incidences of ADEs in the overall population (Ellis \& Mullan, 2009).

ADE-related admissions to emergency departments and inpatient hospitalizations have risen steeply over the last 10 years (Ellis \& Mullan, 2009; Lucado, Paez, \& Elixhauser, 2011; Sorensen et al., 2004; Substance Abuse and Mental Health Services Administration, 2010b, 2011a). Older adults are more likely to be managing multiple comorbid conditions with multiple medications prescribed by multiple providers (Boparai $\&$ Korc-Grodzicki, 2011). Consequently, they are at risk for drug-drug interactions (Boparai \& Korc-Grodzicki, 2011; Sorensen et al., 2004; Werder \& Preskorn, 2003), which makes them seven times more likely to be admitted for treatment of sequelae related to an ADE (Lucado et al., 2011; Prybys et al., 2002; Werder \& Preskorn, 2003). Prybys et al. (2002) identified a precipitous increase in risk from 13 to $82 \%$ for an adverse drug event when comparing patients taking 2 versus $\geq 7$ medications (Prybys et al., 2002). Adding to the problem, patients are self-medicating with over-the-counter medications (Fulton \& Allen, 2005).

CACHES of unused medications in the home introduce the possibility of inadvertent mixing of current and discontinued medications (Prybys et al., 2002; Wasserfallen et al., 2003) as well as inappropriate use for self-medication (Barat et al., 2000; Ellis \& Mullan, 2009; Sorensen et al., 2004). This, in turn, can lead to medication errors including consumption of duplicate classes of medications, taking a previously 
discontinued medication, taking incompatible medications, and/or double dosing of the same medication (Sorensen et al., 2004; Wasserfallen et al., 2003). In the CACHES model, each of these scenarios carries an increased risk for the individual to experience an adverse drug event (Barat et al., 2000; Sorensen et al., 2004; Wasserfallen et al., 2003).

\section{Health Care System}

The individual exposed to CACHES is at risk for adverse outcomes including poisonings, prescription drug misuse/abuse, and adverse drug events. Oftentimes, the affected individual accesses the health care system seeking treatment for the sequelae associated with these adverse outcomes. In the CACHES model, the individual has a direct and negative impact on the HCS. Increased utilization of health care resources include admissions to the ED, hospital, or substance abuse treatment centers for treatment of: poisonings; adverse drug events, misuse of controlled substances; and substance abuse issues (Birnbaum et al., 2006; Gilson \& Kreis, 2009; Hohl et al., 2011; Mil, Schulz, \& Tromp, 2004; National Drug Intelligence Center, 2011b; Strassels, 2009; Substance Abuse and Mental Health Services Administration, 2010d; A. White et al., 2005). In addition, CACHES indirectly represent wasted health care resources. Nonadherence to prescribed medical regimens results in unused medications. In essence, these unused medications represent undertreated and untreated chronic health problems (Almarsdottir \& Asgeirsson, 2009; Coma et al., 2008; Garey et al., 2004; Langley et al., 2005).

Increased utilization of health care resources. The CACHES model identifies increased utilization of health care resources as an adverse outcome related to CACHES. Utilization includes patients accessing the Emergency Department, hospital, primary care provider office, and substance abuse treatment center.

In 2009, adverse drug events were responsible for approximately 4.6 million Emergency Department visits (Substance Abuse and Mental Health Services Administration, 2010b). These ADEs were either attributed to prescription drug misuse/abuse or an adverse reaction to taking a prescribed medication (Substance Abuse and Mental Health Services Administration, 2010b). Patients admitted for treatment of an adverse drug event stay in the hospital longer and require more outpatient care when compared to patients without an adverse event (Hohl et al., 2011). Estimated hospital expenditures related to treatment of adverse drug events range from $\$ 2.2$ to $\$ 5.6$ billion a year (Hohl et al., 2011) and place a financial burden on the health care system.

SAMHSA's Drug Abuse Warning Network (DAWN) tracks the number of Emergency Department visits related to the nonmedical use of prescription drugs (Substance Abuse and Mental Health Services Administration, 2010b, 2011b). Nonmedical use is defined by the Centers for Disease Control (CDC) as "taking a higherthan-recommended dose, taking a drug prescribed to another person, drug-facilitated assault, or documented misuse or abuse" (Center for Disease Control and Prevention, 
2010, p. 1). The DAWN report showed a $111 \%$ increase in ED visits related to nonmedical use from 2004 to 2008 (Substance Abuse and Mental Health Services Administration, 2010b). In addition to increased use of emergent health care facilities for the sequelae related to the nonmedical abuse of prescription drugs (Birnbaum et al., 2006; Gilson \& Kreis, 2009; Strassels, 2009), several studies note increased utilization of outpatient services. White et al. (2005) found opioid abusers averaged 18.7 clinic visits per year compared to 7 by non-opioid abusers .

Between 2004 and 2005, an estimated 71,224 children younger than 18 years of age were seen in EDs because of medication poisonings (Schillie et al., 2009). Of these cases, 156,613 (22\%) of ED visits resulted in hospitalization or transfer to another facility (Schillie et al., 2009). Poisonings led to an estimated \$248 million in medical and productivity costs (Centers for Disease Control and Prevention, 2011).

In 2010, nonmedical use of prescription opiates was the second most prevalent reported reason for admission to a treatment facility for persons age 12 and older (Substance Abuse and Mental Health Services Administration, 2010d). The NDIC estimates the total costs for substance abuse treatment (including detoxification, residential, and outpatient programs) in 2007 to be approximately $\$ 3$ billion (National Drug Intelligence Center, 2011b). Of note, many patients entering substance abuse treatment programs report abusing multiple substances. As a result, the costs calculated by the NDIC do not separate out the treatment costs for both illicit (heroin, cocaine, methamphetamine, marijuana) and prescription drug abuse (National Drug Intelligence Center, 2011b). However, it is likely that prescription drugs account for a substantial portion of the $\$ 3$ billion dollars of health care costs.

It is a challenging task to calculate the total health care costs associated with prescription drug misuse and abuse, adverse drug events, and poisonings (Strassels, 2009). However, the data imply utilization costs are considerable. These costs, along with loss of life, must be factored into the financial equation when looking at the economic burden to the health care system (Gilson \& Kreis, 2009; Strassels, 2009; A. White et al., 2005; Wysowski, 2007). The CACHES model identifies increased health care utilization as an adverse outcome related to unused medications in the home.

Unused medications as wasted health care dollars. CACHES of unused and expired medications also reflect direct and indirect waste of health care dollars (Cameron, 1996; Mackridge \& Marriott, 2007; Morgan, 2001; New England Healthcare Institute, 2009; Roebuck, Liberman, Gemmill-Toyama, \& Brennan, 2011). Direct costs include the costs represented by the unused medications themselves (Langley et al., 2005; Mackridge \& Marriott, 2007; Morgan, 2001; K. White, 2010). Multiple studies have attempted to calculate these costs through cataloging unused drug returns. For example, Cameron (1996) estimated the costs of unused medications, collected in Alberta providence over an 8-week period, equaled an estimated $\$ 710,000$ U.S. dollars. A fiveweek drug return campaign in Iceland collected unused medications with an estimated value of 198,000 Euros (Almarsdottir \& Asgeirsson, 2009). In Britain, a two-month 
count of unused medications returned to local pharmacies and General Practitioner surgeries in Eastern Birmingham totaled £33, 608 (Mackridge \& Marriott, 2007). A Houston pharmacy collected unused medications to the total of $\$ 26,000$ U.S. dollars over a six-month period (Garey et al., 2004). It is important to note these costs estimates are likely underestimates. None of these studies were designed to calculate the costs of additional unused and expired medications still left in the home (Almarsdottir \& Asgeirsson, 2009; Cameron, 1996; Garey et al., 2004; K. White, 2010).

CACHES of unused and expired medications also represent the indirect costs associated with nonadherence to prescribed pharmacological interventions for the management of acute and chronic conditions (Dunbar-Jacob \& Mortimer-Stephens, 2001; Hovstadius \& Petersson, 2011; New England Healthcare Institute, 2009; Roebuck et al., 2011; Ruhoy \& Daughton, 2008; Sorensen et al., 2005; Wasserfallen et al., 2003). Nonadherence is an umbrella term which can include a wide range of medication taking behaviors including taking none of the prescribed medication, taking less than the prescribed dosage, and taking more than the prescribed dosage. For the purposes of the CACHES model, the first two behaviors are considered to contribute to the accumulation of unused medications in the home setting.

\section{Criminal Justice System}

In the CACHES model, the criminal justice systems (CJS) are defined as those systems involved in the investigation, persecution, and imprisonment of individuals committing crimes as well as the costs associated with the victimization of the individual secondary to drug-related crime. Joranson and Gilson (2005) analyzed annual data from 2000 to 2003 from the Drug Enforcement Administration (DEA) "Report of Theft or Loss of Controlled Substances" and found 28 million dosage units of controlled substances were diverted during this 3-year period. Diversion occurred along different points of the supply chain including manufacturers, suppliers, pharmacies, health care practitioners' offices, and substance abuse treatment programs (Joranson \& Gilson, 2005). These diversion data do not include the diversion of controlled substances from the home setting, as oftentimes, these crimes are not reported to local police. The 2010 National Survey on Drug Use and Health found among people age 12 or older who reported using opioids non-medically in the past year, 70\% got the drug from a friend or relative for free (Office of National Drug Control Policy, 2008, 2011; Substance Abuse and Mental Health Services Administration, 2011c).

Nonmedical use of opioids places a financial burden on the criminal justice system (Birnbaum et al., 2006; Gilson \& Kreis, 2009; National Drug Intelligence Center, $2011 \mathrm{~b}$ ). Estimates regarding the total costs assumed by the criminal justice system range from $\$ 1.4$ billion on issues related to nonmedical use of opioids alone (Birnbaum et al., 2006 ) to $\$ 193$ billion for all illicit substances - which includes nonmedical use of prescription drugs (National Drug Intelligence Center, 2011a, 2011b). The National Drug Intelligence Center (NDIC) breaks down crime costs into three major categories: $\$ 1.46$ billion in victim costs, $\$ 56$ billion in criminal justice system costs, and $\$ 3.55$ 
billion in other crime costs (National Drug Intelligence Center, 2011b). The CACHES model focuses on the first two costs identifying victimization costs (drug theft, property damage/loss, and loss in productivity) and drug-related arrests/incarcerations as two significant adverse outcomes related to the presence of CACHES in the individual's home.

Victimization costs (drug theft, property damage/loss, loss in productivity). The costs of victimization can be calculated in a variety of ways. First, there is the direct loss of money as related to the costs of the stolen medications (National Drug Intelligence Center, 2011b). Second, a broader definition of costs includes those associated with property damage or loss and productivity costs (victim misses work) coinciding with the theft of medications (National Drug Intelligence Center, 2011b). In its 2010 report, the NDIC calculates the total costs at approximately $\$ 1.5$ billion (National Drug Intelligence Center, 2011b).

Drug-related arrests and incarceration. National numbers on drug-related arrests are collected via three surveys: the Survey of Inmates in Local Jails (SILJ), the Survey of Inmates in State Correctional Facilities, and the Survey of Inmates in Federal Correctional Facilities (National Drug Intelligence Center, 2011b). According to the 2006 SILJ report, 35,969 offenders admit to drug-related crimes in 2002, with an additional 201,662 in state and 23,333 in federal prisons (National Drug Intelligence Center, 2011b). Total costs, including the arrests, investigations, and incarceration of these individuals, are estimated at $\$ 56$ billion (National Drug Intelligence Center, 2011b). In 2011, there were 257 crimes related to narcotics (morphine and other narcotics) in Davidson County (Tennessee Bureau of Investigation, 2013). Costs related to these crimes are not available. However, the same issues of costs related to arrest, investigations, and incarceration would hold true at the local level as do at the state and federal.

\section{Ecosystem}

In the CACHES model, the ecosystem is defined as the local and/or regional ecosystem including microorganisms (bacteria), macro-organisms (flora, amphibians, reptiles, and mammals), and these organisms' natural habitats (water, plants, earth). Referring to the CACHES model (Figure 2-1), there is an interactive (double-headed arrow) relationship between the ecosystem and the individual. Improper disposal practices by individuals in the community introduce active pharmaceutical ingredients (APIs) directly into the ecosystem polluting the watersheds and streams that feed the drinking water supply. Currently, water-processing plants do not have the technology to remove these trace APIs from the drinking water (Snyder, Westerhoff, Yoon, \& Sedlak, 2003; Westerhoff et al., 2005) and, as a result, the individual and his/her larger community are exposed to these APIs. 
Options for individuals to dispose of unused or expired medications are limited in the U.S., thereby resulting in improper disposal practices such as throwing out in the trash and sewering (Abrons et al., 2010; Daughton \& Ruhoy, 2008; Environmental Protection Agency, 2010; Glassmeyer et al., 2009; Kotchen et al., 2009; Kuspis \& Krenzelok, 1996; Ruhoy \& Daughton, 2007; Seehusen \& Edwards, 2006). Over the last 20 years, water-sampling analyses have detected the presence of APIs in trace amounts in U.S. streams, watersheds, and drinking water (Barnes et al., 2008; Daughton \& Ruhoy, 2008; Environmental Protection Agency, 2010; Kidd et al., 2007; Snyder et al., 2003; Stackelberg et al., 2004; Westerhoff et al., 2005). Concerns over the potentially harmful effects of APIs on the ecosystem have been gaining momentum in the scientific and lay community (Abrons et al., 2010; Daughton, 2010b; Daughton \& Ruhoy, 2008; Furtula et al., 2010; Glassmeyer et al., 2009; Kidd et al., 2007; Orlando et al., 2004; Roig et al., 2009; Stackelberg et al., 2004; Westerhoff et al., 2005; M. Wu \& Janssen, 2011). To date, environmental studies of APIs in the environment have revealed exposure to these trace pharmaceuticals, in particular estrogenic hormones, result in the feminization of male fish of certain fish species (Bound \& Voulvoulis, 2005; Gross-Sorokin et al., 2006; Jobling et al., 1998; Kidd et al., 2007; Orlando et al., 2004). Microbe resistance secondary to bacteria's exposure to trace antibiotics in the water supply is another adverse outcome of APIs in the ecosystem (Furtula et al., 2010; Schwartz et al., 2006; Zhang et al., 2009). Finally, higher-level animals, in particular predators, have experienced adverse health outcomes secondary to the consumption of prey that have accumulated trace amounts of APIs (Oaks et al., 2006; Roig et al., 2009).

Environmentalists continue to examine the long-term effects of APIs on the health of both the ecosystem and humans (Daughton \& Ruhoy, 2009b; Furtula et al., 2010; Larsson, Pedro, \& Paxeus, 2007; Musson \& Townsend, 2009; M. Wu \& Janssen, 2011). These efforts are hindered by a lack of consensus on a) which routes of API introduction into the environment are the most problematic (Daughton \& Ruhoy, 2008; Larsson et al., 2007; Musson \& Townsend, 2009), b) how best to measure the levels of APIs in the ecosystem (Daughton \& Ruhoy, 2008; Musson \& Townsend, 2009; Wennmalm et al., 2010), c) what classes of APIs are most harmful to the micro and macro-environment (Daughton \& Ruhoy, 2008; Larsson et al., 2007), and d) how to determine what concentrations and durations of exposure (acute and chronic) to APIs are harmful to biological life forms (Daughton \& Ruhoy, 2008; Kidd et al., 2007; Larsson et al., 2007; Wennmalm et al., 2010). Regardless, there is sufficient evidence to suggest exposure to trace pharmaceuticals in the water supply results in adverse outcomes for lower levels of biologic life forms in the ecosystem. The CACHES model reflects this relationship. Improper disposal of medications introduce APIs into the ecosystem resulting in adverse outcomes. 


\section{CHAPTER 3. METHODOLOGY}

Chapter 3 includes a discussion of the research design, sample size, sampling techniques, the research site, inclusion/exclusion criteria, study variables and operational definitions, instrumentation, data collection procedures, and analyses performed.

\section{Research Design}

This study was a retrospective, secondary analysis of data extracted from existing death scene reports, medical records, autopsy and toxicology reports, and medication data originally collected over the course of death scene investigations by Forensic Medical, PLC in Nashville, Tennessee. Forensic Medical is a private company contracted by Davidson and Shelby County to provide professional forensic pathology, Medical Examiner, and medicolegal death investigative services for suspicious, traumatic, or unexpected deaths in Davidson and Shelby County. In addition, they provide autopsy on a fee-for-service basis to other Tennessee counties. This study examines the prevalence, size, and composition of CACHES found in decedents' homes during the course of death scene investigations. A descriptive analysis of the demographic data (gender, race, age, and comorbid conditions) was performed. Additionally, the geographic locations of CACHES were identified. Finally, the relationship between health care risk factors (number of prescribers, number of dispensaries) and CACHES was explored.

\section{Sample and Setting}

\section{Sample Size}

The Forensic Medical, PLC Investigators and Medical Examiners were involved in 2,546 death scene investigations in Middle Tennessee from January 1, 2011 through December 31, 2011. Of these cases, 1,146 deaths occurred outside of Davidson County and therefore were excluded from the sample. Of the remaining 1,400 Davidson County cases, 1,190 were excluded according to the study exclusion criteria (see below). The final study sample size included 210 cases of decedents with medications in the home and 80 decedents who died at home with no evidence of medications on the death scene.

\section{Sample Technique}

This study used a convenience sampling of data obtained via a retrospective review of existing Forensic Medical, PLC death scene charts. Each decedent's chart included the following documents: Investigator Report, Death Certificate, and Evidence Sheet. A subset of charts also included an Autopsy Report, Toxicology Report, outside electronic medical records, and a Medication List. 


\section{Site}

According to Tennessee Code 38-7-108,

"Any physician, undertaker, law enforcement officer, or other person having knowledge of the death of any person from violence or trauma of any type, suddenly when in apparent health, sudden unexpected death of infants and children, deaths of prisoners or persons in state custody, deaths on the job or related to employment, deaths believed to represent a threat to public health, deaths where neglect or abuse of extended care residents are suspected or confirmed, deaths where the identity of the person is unknown or unclear, deaths in any suspicious/unusual/unnatural manner, found dead, or where the body is to be cremated, shall immediately notify the county medical examiner or the district attorney general, the local police or the county sheriff, who in turn shall notify the county medical examiner. The notification shall be directed to the county medical examiner in the county in which the death occurred" (Tennessee Code Annotated, 2012).

Forensic Medical Management Services, PLC is a private company contracted to provide forensic examination of evidence collected in the case of violent, traumatic, suspicious, or sudden and unexpected deaths (as well in other specific circumstances listed in Tennessee Code 38-7-108) in Davidson and Shelby Counties. Forensic Medical's jurisdiction covers 68 out of the total 95 counties in Tennessee. As mandated by the State of Tennessee Code, Forensic Medical, PLC is accredited by the National Association of Medical Examiners (NAME). Forensic Medical's 10 Medicolegal Death Investigators (MLDIs) and 6 Medical Examiners Board Certified Forensic Pathologists (MEBCFPs) follow the standards, practices, and investigative procedures as dictated by NAME. The MLDIs are involved in on-scene collection of evidence, including the collection and cataloging of medications. The MEBCFPs perform the following services: in-house external examination, autopsy (for certain required or requested cases), toxicology screening, and examination of any on scene evidence accompanying the body. All Death Certificates are completed and signed by one of the six MEBCFPs.

Procedures for Forensic Medical's involvement in a death scene investigation begin with a notification from local law enforcement (Police or Sheriff's department). The Medicolegal Death Investigator consults with law enforcement and obtains a verbal report of the decedent's demographic information, location of death, and any other circumstantial evidence. If the on-scene law enforcement official is able to determine the name of the decedent's health care providers, the MLDI will attempt to contact the provider to obtain additional information regarding the decedent's health history. The MLDI waives jurisdiction if all three of the following conditions are met: 1) the provider indicates the decedent's death was not unexpected and likely due to natural causes; 2) the provider gives his/her verbal agreement to sign the Death Certificate; and 3) law enforcement reports no evidence of a homicide, suicide, or anything suspicious regarding the nature of the decedent's death. If these three conditions are not met, the MLDI accepts jurisdiction of the case. Once on scene, the MDLI performs a visual examination 
of the scene, takes pictures of the scene and body, collects evidence (including medications), and manually examines the body. All observations of the death scene are captured in the MLDI's written Investigator Report, as well as photographs. The body is then placed into a body bag, along with any evidence collected on scene, and transported to the Medical Examiner's Office for further examination by the MLDI and MEBCFP. The MEBCFP performs an external examination of the body, takes pictures, fingerprints and DNA samples, removes ballistics (if present) from the body, and collects blood and vitreous fluid samples for possible toxicology screening. Medications are identified, cataloged and then destroyed by the MLDI. Destruction of the medications is witnessed by a second MLDI. The MEBCFP summarizes all evidence and makes a final determination of the cause of death, manner of death, and contributing factors to the death as dictated by the NAME guidelines (Hanzlick, Hunsaker, \& Davis, 2002). A request for copies of the decedent's medical records is sent to likely health care facilities. The Investigator Report, photographs, copies of medical records, autopsy (if performed) and external exam report, toxicology screen results, medication list, and evidence log sheet are filed in paper charts maintained on site at Forensic Medical's offices. Data from these charts are also entered into DIDI - a proprietary database developed specifically for Forensic Medical, PLC.

Per legal requirements, MLDIs follow strict procedures in the on-scene search for and collection of medications as evidence. Medications found in the vicinity of or on the body are collected as evidence. In addition, the MDLIs search standard medication storage locations including bedside tables, bedroom dresser, medicine cabinet, kitchen counters and cabinets, and refrigerator. Medications must be designated as prescribed to the decedent; however, if the MDLI suspects the decedent's death was directly caused by the ingestion of a friend/family member's medications, those medications may also be collected. Over the counter medications are collected only if there is a high suspicion they contributed to the cause of death. Illicit substances found on scene are surrendered to law enforcement for identification, cataloging, and destruction.

\section{Inclusion Criteria}

The criteria for inclusion of subjects for this study were the following:

1. Decedents who died at home in Davidson County, Tennessee during the time period of January 1 through December 31, 2011.

2. Decedents whose cause and manner of death met the State of Tennessee's legal requirements mandating investigation by the Medical Examiner's (Forensic Medical, PLC) Office. 


\section{Exclusion Criteria}

The criteria for exclusion of subjects for this study were the following:

1. Decedents who were younger than 18 years of age at time of death.

2. Decedents who died outside of the home including hospital, prison, jail, longterm care facility, woods, bodies of water, hotel rooms (unless identified as primary place of residence), or other person's residence.

3. Decedents who had an in-home death involving Hospice Care.

4. Decedents requiring postmortem revision and re-issuance of Death Certificates by the Medical Examiner but did not have an on-scene investigation at the time of death.

\section{Variables and Operational Definitions}

This section identifies, defines, and operationalizes the major concepts and the concepts' associated characteristics studied in this pilot study. The study concepts and associated characteristics include the individual (gender, race, age, comorbid conditions, geographic location), the health care system (prescribers, dispensaries), and CACHES (prevalence, size, and composition). In addition, this section reviews the original data collection and documentation procedures followed by the Medicolegal Death Investigators and Medical Examiner Board Certified Forensic Pathologists.

\section{Individual}

The CACHES model defines the individual as a community-dwelling person. Specifically, the model delineates the individual as living in a residential (rented or owned) structure that does not meet any of the following definitions: long term care facility, jail, or prison. Decedents who died in their permanent place of residence were designated as a 0 in the study database. Procedurally, the MDLI of record consults with on-scene law enforcement and witnesses to make a determination the location of death was the decedent's permanent residence. The Investigator Reports captured these data for each decedent and final determination of the decedent's place of residence is captured in the Death Certificate. The researcher compared the MLDI's Investigator Report to the final Death Certificate's report of Location of Death and Residence to ensure confirmation the decedent died in his/her residence and the residence met the designation of residential structure. 


\section{Gender}

The CACHES model defines gender as the biological designation of either female or male. For the purposes of this study, gender is coded as female (0) or male (1). The MEBCFP makes a gender designation based on his/her external examination and/or autopsy of the decedent's body. For the purposes of this study, gender designation aligned with the decedent's gender as indicated in the Death Certificate. The researcher cross referenced the MLDI's Investigators Report and the MEBCFP's report of the decedent's gender in the Death Certificate.

\section{Race}

The CACHES model defines race according to the Death Certificate categories including Caucasian (0), African American (1), Hispanic (2), Asian (3), or Other (4). The MEBCFP and MDLI assign race category based on the decedent's state-issued Driver's License designation, family/friend report, and examination of the decedent's external facial and skin characteristics. The MEBCFP record the patient's race on the Death Certificate. The researcher used the Death Certificate designation of race for this secondary data analysis.

\section{Age}

The CACHES model defines age as chronological age (in years) at time of death. The MLDI determines the decedent's age at time of death by subtracting the determined date of death from the date of birth. Date of birth is obtained via the decedent's state issued Driver's License or other state issued identification. The MEBCFP enters the date of birth and age at death into the Death Certificate. The researcher obtained age at time of death from the decedent's Death Certificate. Birthdates were not collected by the researcher in order to protect the decedents' confidentiality.

\section{Comorbid Conditions}

The CACHES model defines comorbid conditions as chronic health diagnoses identified in the decedent's health history. The researcher captured the data as free text in the original study database and then later grouped the comorbid conditions data into the following categories: psychiatric (PSYCH), substance abuse (SUBST), cognitive disorder (COGN), and other (OTHER). For the first three diagnostic categories, the researcher designated the absence 0 or presence 1 of a psychiatric, substance abuse, or cognitive disorder diagnosis. All other diagnoses not captured under these three categories were classified as other and totaled as a sum number. Examples of psychiatric diagnoses included depression, anxiety, schizophrenia, bipolar disorder, schizoaffective disorder, and obsessive compulsive disorder. Substance abuse diagnoses included illicit drugs (cocaine, crack cocaine, heroin, marijuana, "K2", "Spice", and "Bath Salts") and licit 
substances (alcohol, prescription drugs). Examples of cognitive disorders/diseases included cerebrovascular accident, Alzheimer's disease, Parkinson's disease, frontotemporal dementia, traumatic brain injury, vascular dementia, and unspecified dementia. The MLDIs and MEBCFPs obtained the decedent's diagnostic information from a variety of sources. MLDI's on-scene interviews with family members, roommates, and/or neighbors were one source. If available, the MLDI used information from the decedent's prescription medications to contact the decedent's health care provider(s) for verbal confirmation of the decedent's diagnoses. The MLDI's Investigator Reports captured the data from these two main sources. An additional source of the decedent's comorbid conditions included diagnostic data obtained through the external examination and autopsy of the decedent's body. Finally, electronic medical records provided additional diagnostic data. The researcher used all of the above sources in the process of determining the decedent's comorbidities.

\section{Geographic Location}

The CACHES model defines geographic location as the geospatial location of the decedent's primary residence and place of death. The researcher operationalized this variable using the U.S. Postal Service's 5-numbered Zip code designation. The MDLIs obtain Zip code information via on-scene law enforcement report of the decedent's address/location of death. Both the Investigator Report and Death Certificate provide these data.

\section{Health Care System}

The CACHES model defines the health care system as the setting(s) in which the individual receives health care. Examples of health care settings include primary care offices, specialty clinics, Emergency Departments, hospitals, substance abuse treatment centers, and long term care facilities. Characteristics associated with the health care system include prescribers and dispensaries.

\section{Prescribers}

The CACHE model defines a prescriber as any health care provider (physician, nurse practitioner, physician's assistant, or dentist) with prescriptive authority. The CACHES model further identifies that as the total number of distinct prescribers increases, so does the individual's risk of CACHES. For the purposes of this study, each unique prescriber was identified by their last name using a free text field. The researcher then summed the total number of prescribers. The MLDIs obtain prescriber information directly from medication containers found at the death scene. They enter the prescriber's first and last name (if available) into DIDI, as part of the Medication List report, which is printed out and placed in the decedent's paper chart file. 


\section{Dispensaries}

The CACHES model defines dispensaries as any commercial pharmacy (national chain pharmacies, independent pharmacies, physician clinics) where prescription and OTC medications can be dispensed to the individual. In the CACHES data, the operationalized definition for a dispensary is the sum total of distinctly separate dispensaries used by the decedent. The MLDI's captured these original data directly from the medication containers found at the death scene. They enter the dispensary name and phone number into DIDI, as part of the Medication List report. The researcher entered the dispensaries data as both a free text entry (name of dispensary) and a calculated sum total of all dispensaries used by the decedent.

\section{CACHES}

The CACHES model defines CACHES as stockpiles of unused prescription and OTC medications found in the home setting. For the purposes of this study, unused medications were operationalized as any dosages $>7$ days beyond the prescribed use by date. This 7-day gap accommodated for potential left-over doses associated with recurring prescriptions (refills). The MLDI entered the following data (when available) into the Medication List: medication brand name, dosage, units, frequency, total doses dispensed, and total doses remaining. The researcher performed manual calculations to determine if the remaining doses were medications currently in use or unused. First, the researcher used the dosage, frequency, and number of doses dispensed to calculate the total number of days the prescription covered (10 days, 30 days, and 90 days). Next, the researcher used the date dispensed to determine how many pills should be remaining at the time of death, if the patient had been adherent to the prescribed regimen. Finally, the researcher compared the number of doses that should be remaining to the number of actual doses remaining. The researcher defined any doses $\leq 7$ days outside of the prescribed use-by date as currently in use and designated this in the study database as a value of 0 . Any doses $>7$ days outside of the use-by date were defined as unused and designated in the database with a 1 .

Additional calculations included the prevalence, size, and composition of CACHES. The prevalence of CACHES in the home was calculated by dividing the number of subjects with CACHES by the total sample size and then multiplying by 100 . The researcher defined the size of the CACHES according to the sum number of bottles or containers of unused medications found in the decedent's home. These data were available in the Medication List. Finally, the researcher analyzed the composition of the CACHES by assigning each medication a classification based on the system of activity (cardiovascular, gastrointestinal, central nervous system, etc.) as well as a category based on the disease/disorder for which the medication was used. The researcher used the Elsevier medication classification system to assign each medication entry a medication class and category. 


\section{Instrumentation}

The researcher developed the following three study-specific data extraction forms using Microsoft Excel®: Included_Demographics, Included_Medications, and Excluded_Demographics. These forms facilitated the extraction of data from the Forensic Medical charts and allowed easy uploading of the data into the SPSS ${ }^{\circledR} 21$ statistical software package.

\section{Data Collection Procedures}

After obtaining written permission from Dr. Amy McMaster Hawes (Chief Medical Officer and Chief Medical Examiner for Davidson County, Nashville Location), the researcher met with Forensic Medical, PLC personnel Fran Wheatley (Lead Administrator of Davidson County Contract), Lisa Robison (Director of Administrative and Clerical Services, Nashville Location) and Kathy VanBuren (Administrative Assistant, Nashville Location) to establish a schedule and review data collection and privacy protection procedures. In addition, the researcher provided a written copy of the study-specific privacy protection procedures. The researcher created a Master Study List containing the decedents' identifying case numbers (assigned by the Medical Examiner's office during the course of the death investigation) and initials. In addition, the researcher assigned each decedent a unique study number, which was included in the Master Study List. The Master Study List was the only study document containing both the identifying case numbers and the assigned study number. The Master Study List remained on site at Forensic Medical, PLC at all times over the duration of the study. It was kept in the chart room, which is a locked and secure room. The researcher followed this process as a precaution to ensure privacy of the decedent's personal health information. Upon completion of the pilot study, the Master Study List was destroyed on site at Forensic Medical, PLC.

Data collection occurred from September through December, 2012. Data collection techniques included a manual review and extraction of pertinent data from each of the decedent's paper charts. The researcher stored all study data in the three Excel ${ }^{\circledR}$ databases on an encrypted laptop. Decedents were identified by their assigned study number only in this database file to ensure the protection of the decedent data. The researcher collected individual Zip codes as part of the geographical mapping of the location the CACHES. These data were aggregated at the Zip code level to protect the individual decedents' identities. No individual decedent's data are reported in this dissertation or will be in any subsequent dissemination of the study findings.

\section{Data Analysis}

The researcher cleaned the data prior to analysis using the following values to designate missing data: gender (99), race (99), age (unknown), comorbid conditions (99), geographical location (Zip code $=99999)$, medication name brand $(99)$, dosage 
(unknown), frequency (unknown), date dispensed (unknown), number dispensed (unknown), number remaining at time of death (unknown), prescriber name (99), dispensary name (99), total number of prescribers (unknown), and total number of dispensaries (unknown). The researcher analyzed the data using SPSS $21 \circledR$ software.

SPSS $21 \circledR$ was used to perform simple descriptive analysis of the study sample demographics. In addition, SPSS $21 \AA$ was used for the analysis of specific aims one, two, three, four and five. The following section will list each specific aim and the analyses performed for each aim. An alpha level of 0.05 was used to determine statistical significance.

\section{Descriptive Statistics of the Study Sample}

Simple descriptive statistics were used to describe the study sample demographics (gender, race, age). The study sample was divided into two comparison groups:

decedents with medications (both current and unused) and decedents without medications in the home at the time of death. Simple univariate frequency statistics were performed on each of the demographic traits listed and the distribution reported as percentages. Age was categorized into ranges and then the distribution reported according to these ranges: less than 18 years of age, 18-35, 36-45, 46-64, and 65 and older. In addition, the central tendencies (mean, median, and interquartile range) of the two sample populations' ages were calculated. Finally, the total study sample demographics (gender, race, age) were compared to Davidson County population using data from the U.S. Census Bureau 2000 Census.

\section{Specific Aim One}

To describe the prevalence of CACHES found in decedents' homes in Davidson County, Tennessee from January 1, 2011 through December 31, 2011.

Prevalence rates are used to examine the occurrence of a particular disease or condition in a particular population. Prevalence is calculated using the total number of subjects with a condition and dividing that number by the total number of all subjects (with and without a condition) in the population. This number is then multiplied by 100 for a final percentage. For the purposes of this study, the subject was defined as decedents who lived in Davidson County, Tennessee and had a death investigation between January 1 - December 31, 2011. The condition was defined as having containers of unused medications (CACHES) in the home. The prevalence formula for this study was:

Number of decedents with CACHES $\quad$ x 100

Total number of decedents in sample 


\section{Specific Aim Two}

To examine the size and composition of CACHES found in decedents' homes in Davidson County, Tennessee from January 1, 2011 - December 31, 2011.

Simple univariate statistics were used to describe the size (total number of unused bottles or containers of medications in the decedent's home) and composition (types of medication classes) of CACHES. While the majority of medications collected were in their original containers (bottles, vials, metered-dose inhaler devices, tubes), some were found in unmarked plastic bags, bottles, weekly pill containers, or were un-contained (in the decedent's pocket, on the floor, on a table/counter). The researcher was unable to obtain the dispensed by date for medications not in their original pharmacy packaging and so these medications were not included in the CACHES calculations. The size of CACHES was determined based on the sum total of individual bottle/containers of unused ( $>7$ days past use-by date) medication in each decedent's home. The researcher reported these findings as frequency statistics.

For CACHES compositional calculations, the researcher classified each individual medication into its major system of action (cardiovascular, gastrointestinal, central nervous system, etc.) and disease/disorder category using the Elsevier classification system. The Elsevier classification system closely reflected categorizations made by previous researchers reporting medication returns to pharmacies (Coma et al., 2008; Garey et al., 2004; James et al., 2009; Langley et al., 2005; Mackridge \& Marriott, 2007) or unused medications found in the home (Ellis \& Mullan, 2009; Torrible \& Hogan, 1997; Wasserfallen et al., 2003). The researcher used frequency statistics to analyze these data.

\section{Specific Aim Three}

Among decedents with medications in the home, to compare individual risk factors (gender, race, age, comorbid conditions) between those with CACHES and those without CACHES in their Davidson County, Tennessee homes from January 1, 2011 December 31, 2011.

The study sample was divided into two groups: those with CACHES (unused medications) in the home and those without CACHES (all medications found were currently in use at time of death). Simple univariate descriptive statistics were used to describe the two sub-samples' demographics (gender, race, age). Frequency statistics were performed on each of the demographic traits listed and the distribution reported as percentages. The researcher performed a Pearson's Chi-squared analysis to determine if gender and race distribution differed between the two groups, CACHES versus no CACHES. In addition, the researcher used an independent t-test to compare the mean age for decedents with CACHES versus those without CACHES. 
The researcher categorized the total number of comorbid conditions according to the following ranges: $0-2,3-4,5-7$, and 8 or more comorbid conditions. Frequency statistics were performed on the comorbid totals for decedents with medications (currently in use and unused) in the home $(n=210)$, as well as for decedents with CACHES $(n=163)$ and without CACHES $(n=16)$. The central tendency of total comorbid conditions was calculated for both the CACHES and no CACHES group. The samples were skewed and therefore a Mann-Whitney analysis was performed to compare the medians of these two samples. Finally, the researcher converted the free text fields for each of CACHES and no CACHES groups' psychiatric, substance abuse, and cognitive decline diagnoses to a binary $(0=$ absent, $1=$ present $)$ value. A Pearson's Chisquared analysis was used to determine if CACHES were associated with a psychiatric, substance abuse, or cognitive disorder diagnosis.

\section{Specific Aim Four}

To describe the relationship between geographic location (Zip code) and the presence of CACHES in decedents' homes in Davidson County, Tennessee from January 1, 2011 - December 31, 2011.

Frequency statistics were performed on the number of CACHES per geographical location (Zip code). Due to a small sample size, statistical analysis of the relationship between geographical location and CACHES was not able to be performed.

\section{Specific Aim Five}

Among decedents with medications, to compare health care system risk factors (number of prescribers, number of dispensaries) between those with CACHES to those without CACHES.

Frequency statistics were performed on each of the health care system characteristics (number of prescribers, number of dispensaries) for decedents with CACHES and the distributions reported as percentages. A Mann-Whitney analysis was performed to compare the number of prescribers and dispensaries between the decedents' with CACHES and decedents' without CACHES.

\section{Protection of Human Subjects}

On August 30, 2011 the researcher contacted Dr. Amy McMaster Hawes, Chief Medical Examiner for Davidson County, requesting access to data contained in the Forensic Medical's death charts. Dr. McMaster Hawes granted entrée to the data on October 17, 2011, pending Institutional Review Board approval. The researcher requested permission to conduct the study from the University of Tennessee Health Sciences Center (UTHSC) Institutional Review Board (IRB) on June 18, 2012. Per the 
IRB review of the proposal, the study met criteria for Exempt status under 45CFR46.102 (f). Specifically, the human subjects were deceased at the time of the study and subjects' protected health information (PHI) would be kept confidential through the course of the study as well as in any subsequent published works stemming from this study. The IRB granted final approval for the study on July 13, 2012. The researcher sent an electronic copy of the approval letter to Dr. McMaster Hawes and Fran Wheatley prior to initiating data collection. During the course of the study, all efforts were made to protect the confidentiality of the decedents' data. 


\section{CHAPTER 4. RESULTS}

This chapter reports the results of a retrospective, secondary analysis of data collected by Forensic Medical Management Services, PLC during the course of death scene investigations in Davidson County, Tennessee from January 1, 2011 - December 31,2011. This chapter first presents a description of the study sample selection process (Figure 4-1). This is followed by a descriptive analysis of the demographic characteristics of the subjects who expired at home with medications $(n=210)$ versus without medications $(n=80)$. Next, the following five study aims are presented with the associated statistical analyses and discussion of results: 1) to describe the prevalence of CACHES found in decedents' homes in Davidson County; 2) to examine the size and composition of the CACHES; 3 ) among decedents with medications in the home, to compare individual risk factors (gender, race, age, comorbid conditions) between those with CACHES and those without CACHES; 4) to describe the relationship between geographic location (Zip code) and the presence of CACHES in decedents' homes; and 5) among decedents with medications, to compare health care risk factors (number of prescribers and number of dispensers) between those with CACHES and those without CACHES. Finally, a summarization of the study population and analysis results is provided.

\section{Final Study Sample}

The researcher selected the study sample based on the established inclusion and exclusion criteria (Figure 4-1). First, the researcher excluded decedents who had expired outside of Davidson County $(n=1146)$. Of the remaining decedents $(n=1400), 58$ were excluded due to less than 18 years of age and an additional 691 subjects were excluded due to their deaths happening in a hospital. Medical Examiner jurisdiction was waived for "home death" cases involving no evidence of trauma, drug overdose, homicide or suicide and manner of death was ruled "natural" by the decedent's primary care provider $(n=86)$. Ninety-nine non-residential deaths (decedent found in a hotel room, wooded area, river or lake, and in or near car) and eight deaths in which the decedent expired in a residence belonging to a friend, family member, or acquaintance were excluded. The researcher also excluded cases in which decedents expired under Hospice care $(n=122)$ or were institutionalized in a long term care facility, prison, or jail cell $(n=44)$. Finally, the Medical Examiner re-issued Death Certificates for two subjects due to a prior clerical error, but was not involved in investigation of these deaths. Of the remaining decedents $(n=290), 210$ expired in their homes with evidence of medications (currently in use and/or unused) in the home, while 80 subjects had no medications.

\section{Descriptive Statistics of Study Sample}

An analysis of the demographic characteristics of the decedents who expired at home with medications $(n=210)$ versus without medications $(n=80)$ was performed in 
Medical Examiner cases in Middle

Tennessee $(n=2546)$

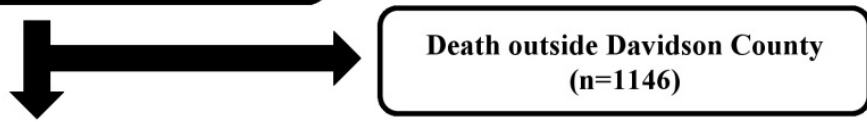

\section{Death in Davidson County $(\mathrm{n}=\mathbf{1 4 0 0})$}
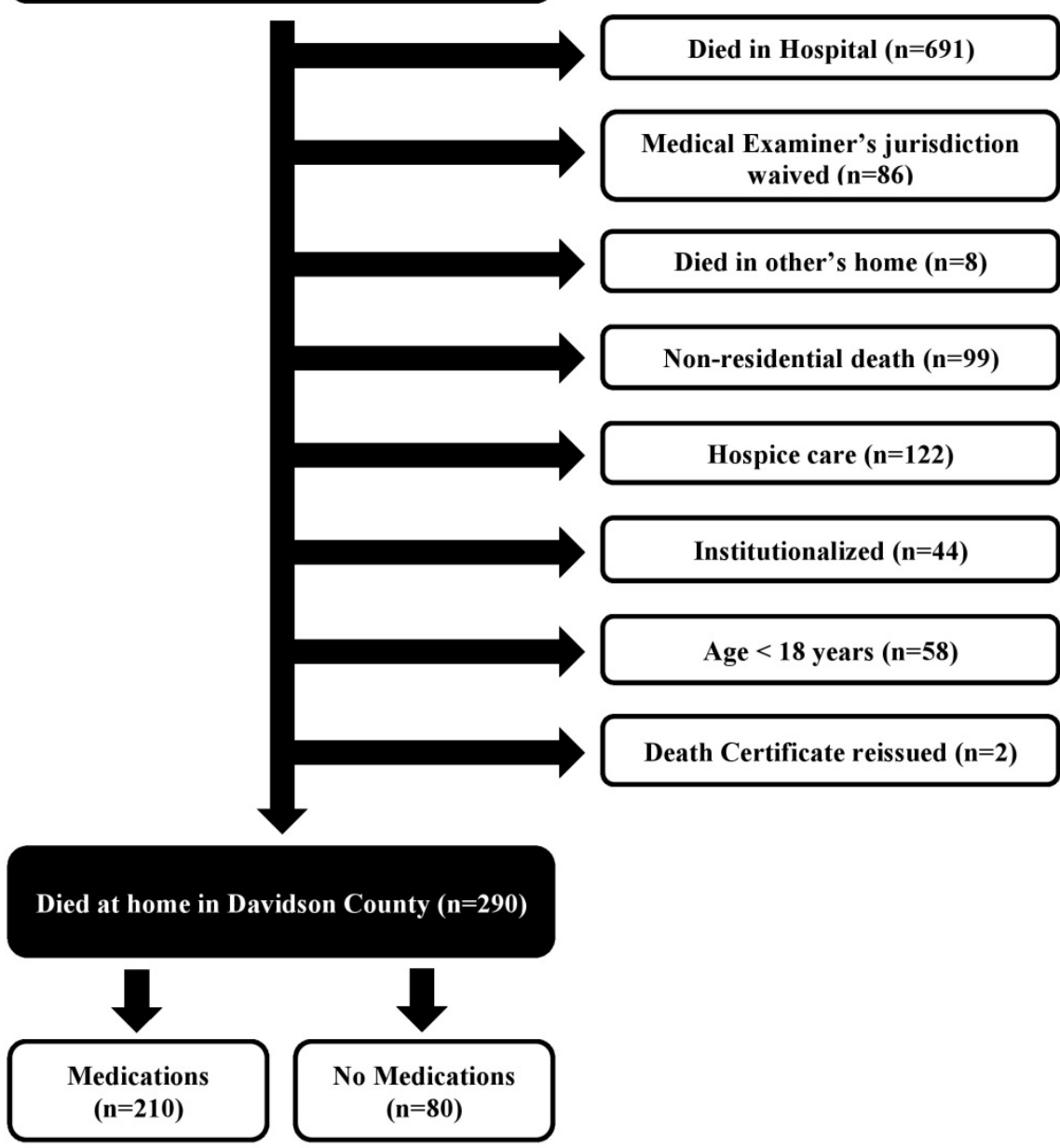

Figure 4-1. Process of Excluding Subjects for Dissertation Study 
two parts. First, the two groups were compared to determine differences in gender, race, and age (Table 4-1). Second, the decedents' $(n=290)$ gender, race, and age were compared to the population of Davidson County in 2011. An alpha level of 0.05 was adopted for this and all subsequent statistical tests.

\section{Decedents with versus without Medications}

Male decedents with medications in the home $(n=133,63 \%)$ outnumbered female decedents $(n=77,37 \%)$. The same gender difference was in evidence for those decedents without medications in the home with 53 (65\%) being men and 27 (34\%) being female. Similar proportions of men and women were found in both groups with almost two-thirds of the group being comprised of men. A Pearson's Chi-squared analysis was performed to determine if males and females were distributed differently across the group with medications in the home versus no medications in the home. The test failed to indicate a significant difference between the two groups, $X^{2}(1)=0.214, p=0.643$.

Caucasian/Non-Hispanics made up the majority of decedents for both the medications $(n=168,80 \%)$ and no medications $(n=59,74 \%)$ groups. The next largest racial group was African Americans $(n=41,19 \%$ vs. $n=20,25 \%)$. Other minorities represented included one Hispanic decedent (1\%) in the medications group and one Asian $(1 \%)$ in the no medications group. In light of the minimal number of Hispanic and Asian decedents, the decision was made to combine the African American, Hispanic and Asian decedents into one variable labeled non-Caucasian. A Pearson's Chi-squared analysis test failed to indicate a significant difference in racial distribution across the two groups (with medications and without), $X^{2}(1)=1.331, p=0.249$.

Finally, both the decedents with medications and the decedents without medications had a normal distribution for the variable of age. An independent two sample t-test $(288)=-0.351, p=0.726$ showed no statistical difference between the two groups.

\section{Sample Demographics versus Davidson County Demographics}

Table 4-2 compares demographic data of the study sample to the demographic data for all persons greater than 18 years of age living in Davidson County. A comparison of demographic characteristics of the sample shows an overrepresentation of males $(63 \%)$ to females (37\%) when compared to Davidson County (48\% and 52\%). The study sample racial distribution follows a similar trend to Davidson County:

Caucasians/Non-Hispanic (78\% vs. 67\%), African Americans (21\% vs. 26\%) and Other (1\% vs. $7 \%)$. Finally, the study sample has an underrepresentation of decedents ages 18 $44(23 \%)$ in comparison to the Davidson County population $(56 \%)$. This trend reverses for the 45-64 year old group when comparing the sample (57\%) versus Davidson County $(30 \%)$ and also those in the $65+$ age group (20\% vs. $14 \%)$. 
Table 4-1. Demographic Data for Subjects Who Died at Home with Medications in the Home versus Those without Medications in the Home $(N=290)$

\begin{tabular}{lcc}
\hline \multirow{2}{*}{ Subject Characteristics } & \multicolumn{2}{c}{ Sample } \\
\cline { 2 - 3 } & $\begin{array}{c}\text { Home Death with } \\
\text { Medications }(\boldsymbol{N}=\mathbf{2 1 0}) \\
\boldsymbol{n}(\mathbf{\%})\end{array}$ & $\begin{array}{c}\text { Home Death without } \\
\text { Medications }(\boldsymbol{N}=\mathbf{8 0})\end{array}$ \\
\hline Gender & $77(37 \%)$ & $27(34 \%)$ \\
Female & $133(63 \%)$ & $53(66 \%)$ \\
Male & & \\
Race/Ethnicity & $168(80 \%)$ & $59(74 \%)$ \\
Caucasian (Non-Hispanic) & $41(19 \%)$ & $20(25 \%)$ \\
African American & $1(1 \%)$ & $0(0 \%)$ \\
Hispanic & $0(0 \%)$ & $1(1 \%)$ \\
Asian & & $14(18 \%)$ \\
Age Group & $21(10 \%)$ & $5(6 \%)$ \\
18-35 & $30(14 \%)$ & $41(51 \%)$ \\
$36-45$ & $121(58 \%)$ & $20(25 \%)$ \\
$46-64$ & $38(18 \%)$ & $54.3(17.3)$ \\
65+ & & 55.0 \\
Mean Age (SD) & $53.6(13.7)$ & 20 \\
Median Age & 54.0 & \\
Interquartile Range & 17 & \\
\hline
\end{tabular}


Table 4-2. Demographic Data of Subjects versus Demographic Data for the Population of Davidson County

\begin{tabular}{|c|c|c|}
\hline \multirow[b]{2}{*}{ Subject Characteristic } & \multicolumn{2}{|c|}{ Sample } \\
\hline & $\begin{array}{c}\text { Home Deaths } \\
\left(\begin{array}{c}N=\mathbf{2 9 0}) \\
n(\%)\end{array}\right.\end{array}$ & $\begin{array}{c}\text { Davidson County }^{\mathrm{a}} \\
(N=443,444) \\
n(\%)\end{array}$ \\
\hline \multicolumn{3}{|l|}{ Gender } \\
\hline Female & $77(37 \%)$ & $252,089(52 \%)$ \\
\hline Male & $133(63 \%)$ & $231,137(48 \%)$ \\
\hline \multicolumn{3}{|l|}{ Race/Ethnicity } \\
\hline Caucasian (Non-Hispanic) & $227(78 \%)$ & $311,524(67 \%)$ \\
\hline African American & $61(21 \%)$ & $121,914(26 \%)$ \\
\hline Other & $2(1 \%)$ & $30,488(7 \%)$ \\
\hline \multicolumn{3}{|l|}{ Age Groups } \\
\hline $18-44$ & $66(23 \%)$ & $269,593(56 \%)$ \\
\hline $45-64$ & $166(57 \%)$ & $146,627(30 \%)$ \\
\hline $65+$ & $58(20 \%)$ & $67,006(14 \%)$ \\
\hline
\end{tabular}

${ }^{a} U . S$. Census, 2005-2009. 


\begin{abstract}
Aim One
Aim One: To describe the prevalence of CACHES found in decedents' homes in Davidson County from January 1, 2011 through December 31, 2011.

Of the 290 decedents, 210 had medications found in the home. For $31(15 \%)$ of these decedents with medication in the home, determination of CACHES was not possible because information on the medication's dispense date was missing. There were 163 decedents with one or more bottles of unused medications as defined for this study ( $>7$ days passed use by date). The prevalence of CACHES in the home was calculated by dividing the number of decedents with CACHES (163) by the total sample size (290) and then multiplying by 100 . This resulted in a calculated prevalence of $56 \%$.
\end{abstract}

\begin{abstract}
Aim Two
Aim Two: To examine the size and composition of CACHES found in decedents' homes in Davidson County from January 1, 2011 - December 31, 2011.

Table 4-3 provides the frequency distribution of the number of bottles of unused medications among the 163 decedents with CACHES. There were a total of 812 bottles of unused medications distributed among the 163 decedents. The mean number of bottles of unused medications for those decedents with CACHES in the home $(n=163)$ was $M=$ $5.0, S D \pm 4.5$. Approximately half $(53 \%)$ of the decedents had four or more bottles of unused medications. The maximum number of bottles found in a decedent's home was 23. The sum total of unused pills was 30,855.5. This translated into a mean of $M=38.9$, $S D= \pm 43.7$ unused pills per decedent. Of note, the researcher excluded medications in liquid, cream, or aerosolized form from these calculations, due to difficulty in accurately determining the remaining number of doses.

Table 4-4 provides the frequency distribution of the classes of medications found in CACHES in decedents' homes. Medications are classified according to their class (system of action) and category (specific disease/symptom treatment focus). Over $60 \%$ of the unused medications belonged to two major classes - those acting on the central nervous (CNS) system (34.7\%) and the cardiovascular (CV) system (26.5\%). Antihypertensives $(n=175,21.5 \%)$, antidepressants $(n=69,8.5 \%)$, anticonvulsants $(n=$ $50,6.2 \%)$, antibiotics $(n=51,6.3 \%)$, and antipsychotics $(n=41,5.0 \%)$ were the five most common classes of all unused medications. In addition, five commonly diverted classes (opioids, benzodiazepines, muscle relaxers, sedatives, and stimulants) comprised $11.8 \%(n=96)$ of all CACHES.
\end{abstract}


Table 4-3. Number of Bottles of Medications Found among Decedents with CACHES $(N=812)$

\begin{tabular}{cccc}
\hline $\begin{array}{c}\text { Bottles of Unused } \\
\text { Medications }\end{array}$ & Frequency & Percent & $\begin{array}{c}\text { Cumulative } \\
\text { Percent }\end{array}$ \\
\hline 1 & 40 & 24.5 & 24.5 \\
2 & 18 & 11.0 & 35.6 \\
3 & 18 & 11.0 & 46.6 \\
4 & 25 & 15.3 & 62.0 \\
5 & 7 & 4.3 & 66.3 \\
6 & 9 & 5.5 & 71.8 \\
7 & 9 & 5.5 & 77.3 \\
8 & 9 & 5.5 & 82.8 \\
9 & 8 & 4.9 & 87.7 \\
10 & 3 & 1.8 & 89.6 \\
11 & 1 & 0.6 & 90.2 \\
12 & 3 & 1.8 & 92.0 \\
13 & 4 & 2.5 & 94.5 \\
14 & 1 & 0.6 & 95.1 \\
15 & 0 & 0 & 95.1 \\
16 & 2 & 1.2 & 96.3 \\
17 & 1 & 0.6 & 96.9 \\
18 & 2 & 1.2 & 98.2 \\
19 & 1 & 0.6 & 98.8 \\
20 & 1 & 0.6 & 99.4 \\
21 & 0 & 0 & 99.4 \\
22 & 0 & 99.4 \\
23 & 0 & 0.6 & 100.0 \\
\hline
\end{tabular}


Table 4-4. Frequency of Classes of Unused Medications among Decedents with CACHES ( $N=812$ Medication Bottles)

\begin{tabular}{|c|c|c|c|c|}
\hline Class & Category & Frequency & Percent & $\begin{array}{c}\text { Cumulative } \\
\text { Percent }\end{array}$ \\
\hline $\begin{array}{l}\text { Central } \\
\text { Nervous } \\
\text { System }\end{array}$ & $\begin{array}{l}\text { Alzheimer's, anticonvulsant, } \\
\text { antidepressant, antihistamine, } \\
\text { antipsychotic, opiate, } \\
\text { Parkinson's, sedative, } \\
\text { benzodiazepine, sedative, } \\
\text { muscle relaxer, stimulant }\end{array}$ & 282 & 34.7 & 34.7 \\
\hline Cardiovascular & $\begin{array}{l}\text { Antihypertensive, antiplatelet, } \\
\text { cardiac inotropic, } \\
\text { hemorrheologic, antilipid, anti- } \\
\text { angina }\end{array}$ & 215 & 26.5 & 61.2 \\
\hline Dermatology & Analgesic, corticosteroid & 4 & 0.5 & 61.7 \\
\hline Endocrine & $\begin{array}{l}\text { Androgen, antiosteoporosis, } \\
\text { antithyroid, diabetes, estrogen, } \\
\text { thyroid, Vitamin D }\end{array}$ & 50 & 6.2 & 67.9 \\
\hline $\begin{array}{l}\text { Eyes, Ears, } \\
\text { Nose, Throat }\end{array}$ & $\begin{array}{l}\text { Antitussive, decongestant, } \\
\text { mucolytic, glaucoma }\end{array}$ & 11 & 1.3 & 69.2 \\
\hline Gastrointestinal & $\begin{array}{l}\text { Anticholinergic, antiemetic, } \\
\text { antiflatulent, antiulcer, } \\
\text { Chron's, H2 Blocker, laxative, } \\
\text { proton pump inhibitor, } \\
\text { prokinetic }\end{array}$ & 54 & 6.6 & 75.8 \\
\hline Genitourinary & $\begin{array}{l}\text { Anticholinergic, anti- } \\
\text { impotence, prostate, urinary } \\
\text { tract }\end{array}$ & 22 & 2.7 & 78.5 \\
\hline Hematology & Anticoagulant, hematinic & 8 & 1.0 & 79.5 \\
\hline $\begin{array}{l}\text { Infectious } \\
\text { Disease }\end{array}$ & $\begin{array}{l}\text { Antibiotic, antifungal, } \\
\text { antimalarial, antiretroviral, } \\
\text { antiviral }\end{array}$ & 69 & 8.5 & 88 \\
\hline Nutritional & Electrolyte, phosphate, vitamin & 30 & 3.7 & 91.7 \\
\hline Pulmonary & Bronchodilator & 3 & 0.4 & 92.1 \\
\hline Rheumatology & $\begin{array}{l}\text { Corticosteroid, DMARD, gout, } \\
\text { NSAID }\end{array}$ & 59 & 7.3 & 99.4 \\
\hline Cancer & Anti-androgen & 1 & 0.1 & 99.5 \\
\hline Other & $\begin{array}{l}\text { Antabuse, muscle rub, phenol } \\
\text { spray, unknown }\end{array}$ & 4 & 0.5 & 100 \\
\hline
\end{tabular}




\begin{abstract}
Aim Three
Aim Three: Among decedents with medications in the home, to compare individual risk factors (gender, race, age, comorbid conditions) of those with CACHES to those without CACHES.
\end{abstract}

\title{
Gender, Race, Age, and CACHES
}

Table 4-5 provides a summary of the individual risk factors (gender, race/ethnicity, age) of decedents with and decedents without CACHES in the home. A larger number of males than females were present in both the CACHES ( $n=100 \mathrm{vs.}$ $n=63)$ and no CACHES ( $n=12$ vs. $n=4)$ groups. A Pearson's Chi-squared analysis was performed to determine if males and females were distributed differently across CACHES versus no CACHES. The test failed to indicate a significant difference, $X^{2}(1)$ $=1.159, p=0.282$. Caucasians/Non-Hispanic were the predominant race represented in both the CACHES $(n=129,79 \%)$ and no CACHES $(n=12,75 \%)$ groups. NonCaucasian decedents made up the remaining sample population for both the CACHES $(n=34,21 \%)$ and no CACHES groups $(n=4,25 \%)$. There was no significant racial difference, $X^{2}(1)=0.149, p=0.699$ in the CACHES versus non CACHES groups. An independent t-test comparing the mean age for decedents with CACHES in the home $(M=55.5, S D \pm 13.4)$ versus decedents without CACHES in the home $(M=46.3, S D \pm$ 11.6) was statistically significant $(p=0.009, t$ value $=-2.64)$ with $95 \%$ CI $(-16.08,-2.33)$.

\section{Comorbid Conditions and CACHES}

Data on comorbid conditions were collected on all decedents with medications found in the home $(n=210)$. Comorbid conditions were coded into 4 major categories: psychiatric (anxiety, depression, bipolar, schizophrenia), substance abuse (illicit or "street" drugs, alcohol, prescription drugs), cognitive disorder (dementia, mild cognitive impairment, post cerebral vascular accident), and other (all other chronic diagnoses). A summary of the decedents' total comorbid conditions and breakdown into specific categories follows (Table 4-6).

Approximately one-quarter of the 210 decedents had 0-2 (26\%), 3-4 (26\%), 5-7 (24\%), and 8-14 (23\%) comorbid conditions. Of the 210 decedents with medications: 99 $(47 \%)$ had at least one psychiatric diagnosis; 90 (43\%) had a history of substance abuse, and; 27 (13\%) had documented evidence of a cognitive disorder diagnosis. The mean of the subjects' comorbid conditions was $M=5.0, S D \pm 3.2$. This sample was not normally distributed (Skewness $=0.69, S E=0.17)$.

Table 4-7 provides a summary of the decedents' total comorbid conditions and presence or absence of a psychiatric, substance abuse, or cognitive disorder diagnosis among decedents' with CACHES $(N=163)$ and those without CACHES $(N=16)$. The distribution of total comorbid conditions for the 179 subjects was not normal (Skewness 
Table 4-5. Demographic Data of Decedents Who Died at Home with CACHES $(N=163)$ versus Those without CACHES $(N=16)$

\begin{tabular}{lcc}
\hline \multirow{2}{*}{ Decedent Characteristic } & \multicolumn{2}{c}{ Sample $^{\mathbf{a}}$} \\
\cline { 2 - 3 } & $\begin{array}{c}\text { Home Death with } \\
\text { CACHES }(\boldsymbol{N}=\mathbf{1 6 3})\end{array}$ & $\begin{array}{c}\text { Home Death without } \\
\text { CACHES }(\boldsymbol{N}=\mathbf{1 6})\end{array}$ \\
\hline Gender & $\boldsymbol{n}(\mathbf{\%})$ & \\
Female & $63(39 \%)$ & $4(25 \%)$ \\
Male & $100(61 \%)$ & $12(75 \%)$ \\
Race/Ethnicity & & \\
Caucasian (Non-Hispanic) & $129(79 \%)$ & $12(75 \%)$ \\
Non-Caucasian (African & $34(21 \%)$ & $4(25 \%)$ \\
American, Hispanic, Asian) & & \\
& & $46.3 \pm 11.6$ \\
Age Group & $55.5 \pm 13.4$ & $2(13 \%)$ \\
18-35 & $12(7 \%)$ & $5(31 \%)$ \\
$36-45$ & $21(13 \%)$ & $8(50 \%)$ \\
$46-64$ & $97(60 \%)$ & $1(6 \%)$ \\
$65+$ & $33(20 \%)$ & \\
\hline
\end{tabular}

${ }^{a}$ Unable to determine CACHES categorization of medication data $(n=31)$, these decedents were not included in summary demographic statistics. 
Table 4-6. Total Comorbid Conditions and Presence or Absence of Psychiatric, Substance Abuse, and Cognitive Disorder Diagnoses for Decedents with Medications (Currently in Use and Unused) in the Home $(N=210)$

\begin{tabular}{lc}
\hline Decedent Characteristic & $\begin{array}{c}\text { Sample }(\boldsymbol{N}=\mathbf{2 1 0}) \\
\boldsymbol{n}(\mathbf{\%})\end{array}$ \\
\hline Sum of Comorbid Conditions & \\
$0-2$ & $55(26 \%)$ \\
$3-4$ & $55(26 \%)$ \\
$5-7$ & $51(24 \%)$ \\
$8-14$ & $49(23 \%)$ \\
Psychiatric & \\
No & $111(53 \%)$ \\
Yes & $99(47 \%)$ \\
Substance Abuse & \\
No & $120(57 \%)$ \\
Yes & $90(43 \%)$ \\
Cognitive Disorder & \\
No & $183(87 \%)$ \\
Yes & $27(13 \%)$ \\
\hline
\end{tabular}


Table 4-7. Total Comorbid Conditions and Presence or Absence of Psychiatric, Substance Abuse, and Cognitive Disorder Diagnoses for Decedents with CACHES $(N=163)$ versus Those without CACHES $(N=16)$ in the Home

\begin{tabular}{lcc}
\hline \multirow{2}{*}{ Decedent Characteristic } & \multicolumn{2}{c}{ Sample } \\
\cline { 2 - 3 } & $\begin{array}{c}\text { Home Death with } \\
\text { CACHES }(\boldsymbol{N}=\mathbf{1 6 3})\end{array}$ & $\begin{array}{c}\text { Home Death without } \\
\text { CACHES }(\boldsymbol{N}=\mathbf{1 6})\end{array}$ \\
\hline Sum of Comorbid Conditions & $36(22 \%)$ & $\mathbf{n}(\mathbf{\%})$ \\
$0-2$ & $40(25 \%)$ & $5(31 \%)$ \\
$3-4$ & $43(26 \%)$ & $5(31 \%)$ \\
$5-7$ & $44(27 \%)$ & $4(25 \%)$ \\
$8-14$ & & $2(13 \%)$ \\
Psychiatric & $74(45 \%)$ & $15(94 \%)$ \\
No & $89(55 \%)$ & $1(6 \%)$ \\
Yes & & $7(44 \%)$ \\
Substance Abuse & $97(60 \%)$ & $9(56 \%)$ \\
No & $66(40 \%)$ & \\
Yes & & $14(88 \%)$ \\
Cognitive Disorder & $140(86 \%)$ & $2(12 \%)$ \\
No & $23(14 \%)$ & \\
Yes & & \\
\hline
\end{tabular}

Note. Thirty-one decedents were excluded from this sample due to missing "dispense by" data hindering the researcher's ability to determine whether decedents were in the CACHES or No CACHES group. 
$=0.622, S E=0.182$ ). A Mann-Whitney analysis of the median total comorbid conditions in decedents with CACHES versus those without CACHES was not statistically significant ( $U=984, p=0.104)$. A Pearson's Chi-squared analysis was performed to determine if a psychiatric, substance abuse, or cognitive disorder diagnosis was associated with the presence of CACHES in the home. The test indicated a statistically significant association $\left(X^{2}(1)=13.6, p<0.05\right)$ of CACHES in the home for those decedents with a psychiatric diagnosis. However, there was no statistically significant association for decedents with a diagnosis of substance abuse $\left(X^{2}(1)=1.5, p=0.223\right)$ or cognitive deficit $\left(X^{2}(1)=0.03, p=0.859\right)$.

\begin{abstract}
Aim Four
Aim Four: To describe the relationship between geographic location (Zip code) and CACHES.

Table 4-8 provides the frequency distribution of CACHES in Davidson County. CACHES were found in 27 of 35 Davidson County Zip codes. Over half (50.3\%) of CACHES were distributed among 6 Zip codes: 37221 (4.9\%), 37013 (5.5\%), 37115 (7.9\%), 37206 (8.5\%), 37207 (9.1\%), and $37211(14 \%)$.
\end{abstract}

\begin{abstract}
Aim Five
Aim Five: Among decedents with medications, to compare health care system risk factors (number of prescribers, number of dispensaries) between those with CACHES to those without CACHES.

Tables 4-9 and 4-10 display the frequency distribution of the number of prescribers used by decedents with (Table 4-9) and without (Table 4-10) CACHES in the home.

Table 4-11 provides a comparison of the mean, median, and standard deviation of the number of prescribers used by decedents with and without CACHES in the home. According to the analysis (Table 4-11), the CACHES group had a skewed distribution of prescribers (Skewness $=1.1, S E=0.2$ ), as did the no CACHES group (Skewness $=1.7$, $S E=0.6$ ) group. A Mann-Whitney analysis of the two group medians showed a statistically significant difference $(U=433.5, p<0.05)$ between the two groups. The CACHES group used a significantly higher number of prescribers than the decedents without CACHES.
\end{abstract}

Tables 4-12 and 4-13 display the frequency distribution of the number of dispensaries used by decedents with (Table 4-12) and without (Table 4-13) CACHES in the home. 
Table 4-8. Frequency Table of Number of CACHES per Zip Code $(N=163)$

\begin{tabular}{cccc}
\hline Zip Code & Frequency & Percent & Cumulative Percent \\
\hline 37080 & 1 & .6 & .6 \\
37116 & 1 & .6 & 1.2 \\
37212 & 1 & .6 & 1.8 \\
37220 & 1 & .6 & 2.5 \\
37027 & 2 & 1.2 & 3.7 \\
37215 & 2 & 1.2 & 4.9 \\
37219 & 2 & 1.2 & 6.1 \\
37189 & 3 & 1.8 & 8.0 \\
37204 & 3 & 1.8 & 9.8 \\
37216 & 3 & 1.8 & 11.7 \\
37072 & 4 & 2.5 & 14.1 \\
37138 & 4 & 2.5 & 16.6 \\
37205 & 4 & 2.5 & 19.0 \\
37217 & 4 & 2.5 & 21.5 \\
37218 & 4 & 2.5 & 23.9 \\
37076 & 7 & 4.3 & 28.2 \\
37203 & 7 & 4.3 & 32.5 \\
37208 & 7 & 4.3 & 36.8 \\
37209 & 7 & 4.3 & 41.1 \\
37210 & 7 & 4.3 & 45.4 \\
37214 & 7 & 4.3 & 49.7 \\
37221 & 8 & 4.9 & 54.6 \\
37013 & 9 & 5.5 & 60.1 \\
37115 & 13 & 7.9 & 68.1 \\
37206 & 14 & 8.5 & 76.7 \\
37207 & 15 & 9.1 & 85.9 \\
37211 & 23 & 14.0 & \\
\hline
\end{tabular}


Table 4-9. Frequency Distribution of the Number of Prescribers Used by Decedents with CACHES in the Home $(N=161)$

\begin{tabular}{cccc}
\hline $\begin{array}{c}\text { Number of } \\
\text { Prescribers }\end{array}$ & Frequency & Percent & $\begin{array}{c}\text { Cumulative } \\
\text { Percent }\end{array}$ \\
\hline 1 & 41 & 25.5 & 25.5 \\
2 & 43 & 26.7 & 52.2 \\
3 & 30 & 18.6 & 70.8 \\
4 & 20 & 12.4 & 83.2 \\
5 & 11 & 6.8 & 90.1 \\
6 & 8 & 5.0 & 95.0 \\
7 & 4 & 2.5 & 97.5 \\
8 & 3 & 1.9 & 99.4 \\
9 & 1 & 0.6 & 100.0 \\
\hline
\end{tabular}

Note. Prescriber information unavailable for 2 of the original 163 decedents with CACHES in the home.

Table 4-10. Frequency Distribution of the Number of Prescribers Used by Decedents without CACHES in the Home $(N=15)$

\begin{tabular}{cccc}
\hline $\begin{array}{c}\text { Number of } \\
\text { Prescribers }\end{array}$ & Frequency & Percent & $\begin{array}{c}\text { Cumulative } \\
\text { Percent }\end{array}$ \\
\hline 1 & 12 & 80.0 & 80.0 \\
2 & 3 & 20.0 & 100.0 \\
\hline
\end{tabular}

Note. Prescriber information unavailable for 1 of the original 16 decedents without CACHES in the home.

Table 4-11. Descriptive Statistics of the Number of Prescribers Used by Decedents with CACHES and without CACHES $(N=176)$

\begin{tabular}{lcccccccc}
\hline Groups & Decedents & Mean & Median & SD & $\begin{array}{c}\text { Min, Skewness } \\
\text { Max }\end{array}$ & $\begin{array}{c}\text { Std. } \\
\text { Error }\end{array}$ & $\begin{array}{c}\text { Shapiro- } \\
\text { Wilk }\end{array}$ \\
\hline $\begin{array}{l}\text { CACHES } \\
\text { Without }\end{array}$ & 161 & 2.9 & 2.0 & \pm 1.8 & 1,9 & 1.1 & 0.2 & 0.0 \\
CACHES & 15 & 1.2 & 1.0 & \pm 0.4 & 1,2 & 1.7 & 0.6 & 0.0 \\
\hline
\end{tabular}

Note. Prescriber data unavailable for $(n=3)$ decedents. 
Table 4-12. Frequency Distribution of the Number of Dispensaries Used by Decedents with CACHES in the Home $(N=162)$

\begin{tabular}{cccc}
\hline $\begin{array}{c}\text { Number of } \\
\text { Dispensaries }\end{array}$ & Frequency & Percent & $\begin{array}{c}\text { Cumulative } \\
\text { Percent }\end{array}$ \\
\hline 1 & 81 & 50.0 & 50.0 \\
2 & 43 & 26.5 & 76.5 \\
3 & 25 & 15.4 & 92.0 \\
4 & 6 & 3.7 & 95.7 \\
5 & 6 & 3.7 & 99.4 \\
6 & 1 & 0.6 & 100.0 \\
\hline
\end{tabular}

Note. Dispensary information missing for 1 of the original 163 decedents with CACHES in the home.

Table 4-13. Frequency Distribution of the Number of Dispensaries Used by Decedents without CACHES in the Home $(N=15)$

\begin{tabular}{cccc}
\hline $\begin{array}{c}\text { Number of } \\
\text { Dispensaries }\end{array}$ & Frequency & Percent & $\begin{array}{c}\text { Cumulative } \\
\text { Percent }\end{array}$ \\
\hline 1 & 12 & 80.0 & 80.0 \\
2 & 3 & 20.0 & 100.0 \\
\hline
\end{tabular}

Note. Dispensary information missing for 1 of the original 16 decedents without CACHES in the home. 
Table 4-14 displays the mean, median, and standard deviation of the number of dispensaries used by decedents with CACHES and without CACHES in the home.

An analysis of the distribution of the two groups (CACHES and without CACHES) based on the number of dispensers also showed a non-normal, skewed distribution (Table 4-14). A Mann-Whitney analysis of the two group medians showed a statistically significant difference $(U=793.5, p=0.015)$ with the CACHES group using a higher number of dispensers than the decedents without CACHES in the home.

In summary, analysis of the Medical Examiner data showed no statistical differences in gender, race, or age when comparing decedents with medications (used and unused) in the home and those decedents with no medications in the home. The ME study sample is majority male, Caucasian/Non-Hispanic, and older than the general Davidson County population. CACHES are a prevalent issue with more than half of the study sample having four or more bottles of unused medications in the home with a mean of $5.0(S D \pm 4.5)$ bottles and $38.9(S D \pm 43.7)$ unused pills per decedent. On average, $60 \%$ of these unused medications come from two major classes of medications - those affecting the central nervous system and the cardiovascular system. There are several significant differences between the decedents with CACHES and those without CACHES in the home. The CACHES group is significantly older, has a higher likelihood of having a psychiatric diagnosis, sees more prescribers and uses more dispensaries than the decedents without CACHES in the home. The analyses did not support a statistical difference between the two groups with regards to gender, race/ethnicity, or total number of comorbid conditions. There were insufficient data to perform an analyses on the relationship between geographical location (Zip code) and CACHES.

Table 4-14. Descriptive Statistics of the Number of Dispensaries Used by Decedents with CACHES and without CACHES $(N=177)$

\begin{tabular}{lcccccccc}
\hline Groups & Decedents & Mean & Median & SD & $\begin{array}{c}\text { Min, Skewness } \\
\text { Max }\end{array}$ & $\begin{array}{c}\text { Std. } \\
\text { Error }\end{array}$ & $\begin{array}{c}\text { Shapiro- } \\
\text { Wilk }\end{array}$ \\
\hline $\begin{array}{l}\text { CACHES } \\
\text { Without }\end{array}$ & 162 & 1.9 & 1.5 & \pm 1.1 & 1,6 & 1.4 & 0.2 & 0.0 \\
CACHES & 15 & 1.2 & 1.0 & \pm 0.4 & 1,2 & 1.7 & 0.6 & 0.0 \\
\hline
\end{tabular}

Note. Dispensary data unavailable for $(n=2)$ decedents. 


\section{CHAPTER 5. DISCUSSION}

The CACHES pilot study was a retrospective, secondary analysis of data collected by Forensic Medical's Medicolegal Death Investigators and Medical Examiners Board Certified Pathologists during the investigation of 210 home deaths occurring in Davidson County, Tennessee between January 1, 2011 through December 31, 2011. This chapter provides an in depth discussion of the study results in the context of the CACHES conceptual framework and the supporting literature. First, will be a discussion about differences between the study sample and Davidson County demographics (gender, race, age) and potential reasons for these differences. Second, this chapter will compare and contrast the prevalence rate, size and composition of CACHES to those found in previous studies. Furthermore, the chapter will address the relationship between individual risk factors (gender, race, age, comorbid conditions, geographical location) and stockpiling of unused medications in the home. The researcher also will discuss the relationship between health care risk factors (multiple prescribers, multiple dispensaries) and CACHES. Finally, this chapter will discuss the limitations of this pilot study, implications of the study findings for practice, policy, and future research.

\section{CACHES Sample versus Davidson County Population}

The study population displayed several demographic differences when compared to the general population of Davidson County. The CACHES study population was majority male, Caucasian/Non-Hispanic, and over half of the sample was in the age range of 44-64 years of age. This section addresses the factors influencing the gender, race, and age distribution of the CACHES sample.

\section{Gender}

There is an overrepresentation of male decedents in the CACHES study sample (63\%) in contrast to Davidson County (48\%) (Tennessee Department of Health, 2011). As mentioned previously, the Medical Examiner accepts jurisdiction in cases of violent (homicide), traumatic (suicide, accident), and/or unexpected deaths. A review of law enforcement statistics for Davidson County identify males as being at higher risk for a violent or traumatic death in comparison to their female counterparts. The 2011 Metropolitan Nashville Police Department (MNPD) homicide data report indicated 303 males died as a result of homicide versus 95 females (Metro Nashville Police Department, 2011). This trend is also seen in the most recent data available (2007) from the Tennessee Department of Health's analysis of age-adjusted homicide rate for males (21.1) versus females (4.2). Rogers et al. (2013) analysis of Davidson County 2010 data for suicides also show males outnumbering females in age-adjusted suicide rates (19.1 versus 3.4). In Davidson County, men are at higher risk to die from a violent (homicide) or traumatic (suicide) death than their female counterparts. These data provide an 
explanation for the disparity of gender distribution seen in the Medical Examiner data when compared to the gender distribution of the population of Davidson County.

\section{Race}

The distribution of race in the study population also varied when compared to Davidson County statistics (2011): Caucasians/Non-Hispanic (78\% vs. 67\%), African Americans (21\% vs. 26\%), and Other (1\% vs. 7\%). African Americans, Hispanics, and Asians are underrepresented in the CACHES sample. Nashville's Metro Department of Health's analysis of "Age-adjusted Mortality Rated for 10 Overall Leading Causes of Death Ranked by Frequency for Racial/Ethnic and Sex Groups, Davidson County, TN 2010" provide a potential explanation for this mismatch. In 2010, African Americans had a higher mortality rate than Caucasian/Non-Hispanics and Hispanics in 5 out of the 10 leading causes of death (Rogers et al., 2013). These five categories include: heart disease, cancer, stroke, diabetes, and Alzheimer's Disease. Furthermore, the Department of Health's age-adjusted mortality rates (2013) show that Hispanics died from complications related to Nephritis/Nephrotic Syndrome/Nephrosis at a rate 4 times (40.3) as often as Caucasians (9.5) and almost 2 times as often as African Americans (25.4). All six of these categories fall under the definition of death due to natural causes. Procedural rules dictate Forensic Medical's MLDIs make contact with the decedent's PCP (if this information is made available) to obtain a medical history prior to accepting jurisdiction of a new death investigation. If the PCP indicates the decedent likely died from natural causes, agrees to sign the Certificate of Death, and on-scene law enforcement rule out signs of trauma, homicide and/or a suspicious death, then ME jurisdiction is waived. Law enforcement and the ME release the decedent's body to be transferred directly to the funeral home without further on scene investigations. Per the Metro Department of Health's statistics (2013), African Americans and Hispanics are more likely to die of natural causes when compared to their Caucasian/Non-Hispanic counterparts. This then contributes to the underrepresentation of African American and Hispanic subjects in the ME data when compared to the general Davidson County population.

This race disparity is further heightened by an overrepresentation of Caucasians/Non-Hispanics in the CACHES data. Again turning to the Metro Health Department "Causes of Death" data, in Davidson County Caucasians/Non-Hispanics have a higher age-adjusted mortality rate secondary to accidents (59.5) and suicides (14.4) than their African American (49.4 and 3.9) and Hispanic (24.7 and 1.8) counterparts (Rogers et al., 2013). According to the TN legal code and NAME guidelines, deaths related to accidents and suicide automatically are accepted under the ME's jurisdiction. In conclusion, the overrepresentation of Caucasian/Non-Hispanics and underrepresentation of African Americans, Hispanics and Asians in the CACHES sample reflects the patterns seen in the Davidson County statistics on race and likely cause (disease vs. trauma) and nature of (natural vs. accident/violent) death. 
The age of the CACHES sample population skewed older when compared to the larger Davidson County population. Decedents in the 44-64 years old category represented over half $(57 \%)$ of the CACHES study sample, followed by $(20 \%)$ in the $65+$ age category. In addition, the study sample has an underrepresentation of subjects ages $18-44(23 \%)$ in comparison to the Davidson County population (56\%). These findings are not surprising when considering the positive relationship between increasing age and increased mortality rates and the source of the CACHES data set. The Tennessee Deaths 2011 report clearly demonstrates this relationship people with a rate of 189.9 deaths/100,000 for people ages $25-44$ versus 9,629 deaths/100,000 for people ages $65-74$ (Office of Health Statistics, 2011).

It is important to note in the CACHES sample the largest percentage of decedents were those in the 44-64 year old category. Revisiting the list of leading causes of death in TN, the underrepresentation of decedents 65 and older likely is explained by two factors. First, subjects 65 years and older are more likely to die from natural causes than their younger counterparts, as is reflected in the Davidson County 2007-2009 death data (Tennessee Department of Health, 2011). In these cases, the ME would waive jurisdiction, which would lead to an under sampling of decedents ages $65+$ years of age. In addition, when comparing death related to assault (homicide) or intentional self-harm (suicide), the TN Department of Health statistics (2011)provide a clear picture of increased risk of death secondary to assault (homicide) and self-inflicted harm (suicide) when comparing younger adults (35-64) to older adults (65+). Suspected homicides and suicides are automatically accepted under the jurisdiction of the ME's office, thus weighting the ME sample towards subjects in the 44-64 year age range.

In summary, due to the legal jurisdiction requirements of $\mathrm{ME}$ involvement in the investigation of traumatic, violent, and suspicious deaths, the ME data sample is skewed towards those populations at risk for homicide, suicide, and/or accidental deaths. This is reflected by the overrepresentation of 44-64 year old, Caucasian/Non-Hispanic males in the CACHES data set. As such, the results of the CACHES pilot study have limited generalizability when applied to the larger Davidson County population.

\section{Medications in the Home}

The CACHES study examines the prevalence, size, and composition of unused medications found in the homes of decedents by the MLDIs during the course of death scene investigations. Out of the final study sample $(n=290), 72 \%(n=210)$ of the decedents had at least one or more containers of currently-in-use and/or unused medications in the home at the time of their death. While not a direct comparison, the Institute of Medicine's "Quality Chasm" series reported $80 \%$ of the sampled US population using at least one prescription or OTC medication in the past week (Institute of Medicine of the National Academies, 2007). In contrast, the U.S. Department of Health and Human Services examination of trends from 2005-2008 in health statistics 
reported $47.2 \%$ of non-institutionalized (community-dwelling) individual's being on at least one prescription medication in the last 30 days (National Center for Health Statistics, 2011). The CACHES results fall between these two national trends and highlight the fact that the majority of decedents had at least one medication in the home at the time of their death. A further parsing of the CACHES data set reveals a sum number of 1770 medications (currently-in-use and unused) found during the course of death scene investigations. This averages to 6.1 medications per decedent. This study finding is not unexpected when placed in the context of Tennessee's 17.6 prescriptions per capita rate (Kaiser Family Foundation, 2011b).

Of those decedents' with medications in the home, $56 \%$ of the decedents had a CACHE of least one or more containers of unused medications ( $>7$ days past "use by" date). There are a handful of existing studies involving the direct survey of medications found in the community-dwelling adult's home. However, a comparison of the CACHES study findings to these existing studies is complicated by the following differences: variations in study population age and geographical location, differing definitions of what qualifies as "unused" medications, and origination of the data. This next section compares the CACHES results to the existing studies, discusses these differences, and provides a final explanation as to the significance of the CACHES findings. In addition, the limitations of the CACHES medication data are discussed and the impact of these limitations on the final calculations of prevalence rate, size and composition.

\section{Comparing Prevalence}

Differences in study population. Five of the nine comparison studies restricted sampling to an older adult population ( $\geq 65$ years of age) with the majority having a mean age 70 years of age or older (Barat et al., 2000; Der, Rubenstein, \& Choy, 1997; Morgan, 2001; Torrible \& Hogan, 1997; Wasserfallen et al., 2003). The prevalence of unused medications for each of these studies were: 17.7\% (Barat et al., 2000), 35\% (Der et al., 1997), 35.7\% (Wasserfallen et al., 2003), 51.5\% (Morgan, 2001), and 76\% (Torrible \& Hogan, 1997). In contrast, the CACHES study population included subjects 18 years of

age and older with a mean age of $53.8(S D \pm 14.7$ years. The four remaining comparison studies had similar study population age ranges (18 and older) with a trending of $>50 \%$ of their population being 50+ years old (Bolle et al., 2008; Seehusen \& Edwards, 2006; Shin et al., 2009; Sorensen et al., 2005). The reported prevalence of unused medications for these studies were: 18.5\% (Shin et al., 2009), 21\% (Bolle et al., 2008), 21.1\% (Sorensen et al., 2005), and 56.4\% (Seehusen \& Edwards, 2006). When comparing these studies, the inclusion of younger subjects (who would be less likely to need or buy prescription medications) in the CACHES study likely accounts for the slightly lower prevalence rate. However, the difference in study subjects' ages does not, by itself, provide sufficient explanation for the variation of prevalence rates. For example, Seehusen and Edwards report (2006) the second highest prevalence rate $(56.4 \%)$ of all studies, but had an equal distribution of subjects ages $18-49(48.2 \%)$ and $50+(51.8 \%)$. Additional factors, such as 
geographic location and source of the data contribute to the differences in prevalence rates. These differences will be addressed next.

Differences in geographical location. Six out of the nine comparison studies on unused medication prevalence were done in countries outside of the U.S. (Barat et al., 2000; Bolle et al., 2008; Shin et al., 2009; Sorensen et al., 2005; Torrible \& Hogan, 1997; Wasserfallen et al., 2003). This is potentially significant when considering the U.S. population, on average, consumes more prescription medications than any of the other countries (Australia, Belgium, Canada, Denmark, South Korea, and Switzerland) represented in these comparison studies (Peterson \& Burton, 2007). More prescriptions per person increase the likelihood of unused medications in the home and ultimately would increase the prevalence rate. Two out of the three highest prevalence rates come from U.S. studies (Morgan, 2001; Seehusen \& Edwards, 2006) with the CACHES prevalence rate coming a close third. One U.S. study (Der et al., 1997) had an outlier lower prevalence rate of $35 \%$. However, these investigators used one of the most restrictive definitions of unused medications limiting their data collection to those medications $>1$ year past the dispensed date.

In 2011, Tennessee had the third highest number of prescriptions per capita in the U.S. (Kaiser Family Foundation, 2011b). This begs the question as to why the CACHES prevalence rate was not equal to or higher than the two other US studies, which took place in New Hampshire (Morgan, 2001) and Washington State (Seehusen \& Edwards, 2006). This difference is likely explained by the nature of the ME data set. As mentioned previously, the ME waives jurisdiction in cases of decedents determined to have died of natural causes ("expected deaths"). Had these decedents been included in the data set, it is likely they would have increased the prevalence rate, as they would have been taking medications to manage their comorbid conditions.

Defining "unused". The comparison of prevalence rates is further complicated due to there being little consensus between studies regarding what constitutes an unused medication. Across the studies, definitions of unused medications included: "expired" medications as per the expiration date on the bottle label or $>1$ year past dispense date (Bolle et al., 2008; Der et al., 1997; Seehusen \& Edwards, 2006; Sorensen et al., 2005); medications that were "discontinued" or no longer in use in the past month, but not expired (Barat et al., 2000; Torrible \& Hogan, 1997; Wasserfallen et al., 2003); "wasted" medications prescribed within last year, but the participant indicated he/she had no intention to use the medication and expired medications (Morgan, 2001), and; "surplus" medications - which were not clearly defined by the researchers (Shin et al., 2009). The CACHES study definition of unused medications most closely aligns with those used by Morgan, including both expired and unused medications (discontinued by provider or the decedent). 
Differences in data sources. All nine of the comparison studies conducted faceto-face interviews, surveys, and/or made direct observations of the medications in the home setting with clarification of medication status (currently in use, not in use, expired) confirmed by the subject. In contrast, the CACHES study involved a secondary analysis of medication data collected during death scene investigations. Out of the 1770 medication entries in the ME dataset, 373 (21.1\%) lacked a "dispensed by" date. Per discussions with Fran Wheatley (Lead Administrator), this is not uncommon as medications often are found on scene stored in weekly pill boxes and unmarked containers or loose in the vicinity of and/or on the decedent's body. These missing data made it impossible to calculate a "used by" date for these 373 medication entries, which hindered the determination of whether or not the medications were in current use or unused at the time of death. As a result, these medications were excluded from the final CACHES prevalence rate. Therefore, the CACHES study $56 \%$ prevalence rate is likely an underestimation of the overall prevalence of unused medications. This then places the CACHES prevalence rate in line with the studies prevalence rates seen in other U.S. studies.

\section{Comparing Size}

To facilitate a comparison of the size of the CACHES with prior studies, the discussion will define "size" both in terms of the number of bottles of unused medications and also the number of unused pills. In the CACHES study, the mean number of unused bottles of medications in the home was $5.0(S D \pm 4.5)$. Fifty-three percent of decedents had four or more bottles of unused medications in the home. Ten percent had 10 or more bottles of unused medications stored in the home with one subject having a maximum of 23 bottles.

Direct comparison. Three studies (Der et al., 1997; Torrible \& Hogan, 1997; Wasserfallen et al., 2003) reported the number of bottles of unused medications per subject. Torrible and Hogan(1997) found subjects had, on average, 2 bottles of unused medications stored in the home. However, Torrible and Hogan limited their data collection to prescription medications only, whereas the CACHES study includes both prescription and OTC medications. Der et al.(1997) reported a similar finding to Torrible and Hogan, with each subject averaging 1.9 bottles of expired medications in the home . These researchers defined unused medications as those medications $>1$ year past expiration date, thereby excluding any unused medications in the home that had been discontinued within the past 12 months. As a result, a substantial number of bottles of unused medications could have been excluded from the final count. In comparison, the CACHES study included unused medications that fell within the 12 month window. Therefore, it is not unexpected the CACHES average bottle count per subject was higher than Der et al.'s findings. Wasserfallen et al. (2003) reported an average of 3.7 bottles of discontinued medications per subject . Similar to the CACHES study, Wasserfallen et al.(2003) included both prescription and OTC medications in this data set. However, the researchers excluded $354(17.3 \%)$ bottles of medications from the calculations due to the 
subject's being unable to vocalize the indication for use, frequency of use, and/or any information regarding the medication (Wasserfallen et al., 2003). Therefore, it is possible the average number of bottles of unused medications per subject was, in fact, higher for Wasserfallen et al.

Indirect comparison. Four of the nine studies do not provide direct comparisons to the CACHES estimation of size. At issue is the type of data collected (Barat et al., 2000; Bolle et al., 2008) and how it was reported (Seehusen \& Edwards, 2006; Sorensen et al., 2005). Barat et al. (2000) and Bolle et al. (2008) included both the subject's and the subject's spouse's medications in the count of unused medications in the home. Barat et al. (2000) reported 1.3 bottles per household and Bolle et al. (2008) an average of 6.5 bottles per subject. For the Medical Examiner data, legal procedures dictate the MLDIs limit on-scene medication collection to those medications found in the decedent's name only. In specific cases if the MLDIs have a high suspicion the decedent's death was secondary to the consumption of another household member's medication, then this person's medications may be collected as evidence. However, this 2011 data set included only one such case out of the 210. Seehusen and Edwards(2006) reported the number of unused medication bottles as ranges rather than an overall average number of bottles per subject. Forty-eight percent of their subjects had 1-5 bottles of unused medications in the home followed by $6.4 \%$ having $6-10$ bottles, $1.3 \%$ having $11-25$, and $0.7 \%>25$ (Seehusen \& Edwards, 2006). Sorensen et al. (2005) do not directly report the number of unused bottles or pills in their study findings. Instead, they report on average the subjects were taking 9.9 medications, but had a total of 14.7 medications in the home. The researchers do not explicitly state if the 4.8 difference includes PRN, expired, and/or discontinued medications. The divergent nature of the data sets (Barat et al., 2000; Bolle et al., 2008) and reporting of the results (Seehusen \& Edwards, 2006; Sorensen et al., 2005) preclude making a direct comparison to the CACHES study findings.

Finally, Morgan's study (2001) reported the total number of wasted pills ( $n=$ 2078) with an average of 31.5 wasted pills per participant. Morgan (2001) also excluded 32 subjects who had no wasted pills. Of the 163 decedents with CACHES, there were a total of $n=794$ separate medication entries with a sum of $n=30,855.5$ unused pills. This translated into a mean of $38.9(S D \pm 43.7)$ pills per decedent. Of note, the researcher excluded medications in liquid, cream, or aerosolized form from these calculations, due to difficulty in accurately determining the remaining number of doses. As such, this means the average number of unused pills (doses) per decedent was likely higher than 38.9 .

In conclusion, in the CACHES study the size of the unused medication stockpiles was larger than those found in prior studies. This difference is even more striking when taking into consideration $21 \%$ of the CACHES medication information was excluded from the calculation due to missing "dispensed by" dates. As with the high prevalence of CACHES in the homes, it is likely a combination of factors contributing to the larger size of the CACHES, including: geographical location (Tennessee has one of the highest prescription/capita rates in the country), sample age (older adults use more medications), 
the use of a broader definition of unused medications ( $>7$ days past use-by-date), and the inclusion of both prescription and OTC medications in the sample.

\section{Composition}

The CACHES study assigned each unused medication a category based on both the system of action (cardiovascular, central nervous system, infectious disease, etc...) as well as the disease-specific medication categories (hypertension, hyperlipidemia, antidepressants, etc...). Sixty-one percent of the unused medications belonged to two major classes - those acting on the central nervous (CNS) system (34.7\%) and the cardiovascular (CV) system (26.5\%). These findings are similar to those in other studies of unused medications in the home (Barat et al., 2000; Linjakumpu et al., 2002; Torrible \& Hogan, 1997; Wasserfallen et al., 2003) or returned to pharmacies for disposal (Bolle et al., 2008; Braund, Gn, et al., 2009; Cameron, 1996; Coma et al., 2008; Garey et al., 2004; James et al., 2009; Langley et al., 2005). Five of the most commonly diverted classes of medications (Manchikanti \& Singh, 2008) including, opioids, benzodiazepines, muscle relaxers, sedatives, and stimulants, comprised $11.8 \%$ of all unused medications found in the homes of decedents. Finally, unused infectious disease (ID) medications (antibiotics, antivirals, and antimalarial) were $8.7 \%$ of all unused medications.

$\mathrm{CV}$ and CNS medications are two of the most frequently prescribed classes of prescription and OTC medications in both the US (Bartholow, 2012; Raofi \& Schappert, 2006) and outside the U.S. (Barat et al., 2000; Braund, Gn, et al., 2009; Linjakumpu et al., 2002). Therefore, it is not surprising the CACHES study found these two categories of medications comprised the largest portion of unused medications in decedents' homes. Of interest is the low number of unused controlled substances, when compared to the CV and non-controlled CNS medications. There are three factors influencing this finding. First, $15.0 \%$ of the recorded controlled substances had no dispensed by date and/or were missing dose frequency information. Therefore, the researcher could not make a determination of whether the remaining medications were currently in use or unused and therefore they were not included in the CACHES calculations. Second, of the 166 controlled substances calculated as having no unused doses (i.e. not defined as CACHES), $38.6 \%$ of these were due to over compliance (subject took more than the prescribed dosage). Third, per discussions with Lead Administrator F. Wheatley (personal communication, March 28, 2013) it is not an uncommon occurrence for family members, friends, roommates, or other witnesses at the death scene to divert the decedent's controlled substances prior to law enforcement or the MLDIs arrival on scene. This issue of diverted controlled substances from the death scene was captured in several of the reviewed cases - either in the Investigator Notes or in the Police Report. These oral and written reports support the CACHES conceptual framework, which draws a direct relationship between unused controlled substances in the home and the diversion of these medications by friends and family members. 


\section{Individual Risk Factors}

The CACHES model proposes specific characteristics of the individual (gender, race, age, and comorbid conditions) place him/her at risk for having CACHES in the home. The model predicts female gender, Caucasian/Non-Hispanic race, advanced age ( $\geq 65$ years of age), and having multiple comorbid conditions as placing the individual at highest risk for stockpiling unused medications in the home. This pilot study attempts to explore the relationship of these risk factors and CACHES through an examination of the ME data. This next section discusses the study findings and whether or not the findings support the CACHES model.

Gender. The CACHES model proposes female gender places the individual at increased risk for the accumulation of unused and expired medications in the home. This assertion was based on previous studies demonstrating women are more likely than men to access medical care including prescription medications (Kaiser Family Foundation, 2010c, 2011a). Analysis of the Medical Examiner data showed no significant relationship between gender and the presences of CACHES. There are several potential explanations for this finding. As previously discussed, the study sample was skewed with men representing $63 \%$ of the population. In comparison, the 2010 Census of Davidson County found men to make up $48 \%$ of the total population (Division of Health Statstics, 2010).

One additional complicating factor is the influence of gender on adherence. Adherence studies have found women to be more likely to follow a prescribed medication regimen than their male counterparts (Fine et al., 2009). These findings might suggest female gender could be both a protective and a risk factor for CACHES. Finally, this pilot study had a small sample size, which contributes to the difficulty of determining the relationship between CACHES and gender.

Race. Analysis of the CACHES data showed no significant relationship between race and risk for CACHES. The researcher proposes these findings are likely due to two complicating factors. First, as noted earlier, the Medical Examiner data set heavily skewed towards Caucasian/Non-Hispanic verses African Americans and Hispanics due to the nature of death (traumatic/violent vs. natural causes). Second, African Americans and Hispanics are less likely to have access to and utilize health care - including prescription medications (Adams et al., 2013; Gellad et al., 2007; McClelland et al., 2013). Third multiple studies report African American and Hispanic patients are less adherent to prescribed medication regimens (Benner et al., 2002; Bosworth et al., 2008; Rolnick, Pawloski, Hedblom, Asche, \& Bruzek, 2013; Siegel et al., 2007); however, additional research suggests this is a factor of socioeconomic status rather than race alone (Adams et al., 2013; Gellad et al., 2007; Goldman et al., 2007; McClelland et al., 2013; Rolnick et al., 2013; Turner et al., 2009). The ME data do not provide information on the decedent's socioeconomic status. As a result, the researcher was not able to further explore the relationship between CACHES, race, adherence, and socioeconomic status. 
Age. The CACHES model posits advanced age ( $\geq 65$ years of age) places the individual at higher risk for unused medications in the home. Analysis of the study data showed a significant relationship between older age and having CACHES in the home. Of interest, the mean age for decedents' with CACHES was 55.5 ( $S D \pm 13.4)$ years old. While the standard deviation places the ME study sample within the CACHES proposed \pm 65 years old margin, the CACHES group mean age is approximately 10 years younger than predicted. As previously discussed, the age group 45-64 was the largest segment $(57 \%)$ of the CACHES study population with the $\geq 65$ year old being the next largest group $(20 \%)$. This discrepancy was likely due to an under sampling of decedent's $\geq 65$ in the ME data. This under sampling was the result of the following factors: 1) subjects $\geq$ 65 years of age are at lower risk for death secondary to violence (suicide, homicide) than their counterparts in the 45-64 age range; and, 2) decedents $\geq 65$ years of age are at an increased likelihood to have died secondary to natural causes and therefore $\mathrm{ME}$ jurisdiction was waived.

Comorbid conditions. The CACHES model identifies having comorbid conditions as increasing the individual's risk for accumulating unused medications in the home. An analysis of the ME data did not support this relationship. Again, the explanation of this finding likely lies within the nature of the ME data. Decedents with a higher number of comorbid conditions would be at higher risk for a death secondary to natural causes. This, in turn, would have eliminated the need for ME involvement in the investigation of the decedent's death - leading to an under sampling of these decedents.

The ME data did reveal a significant relationship between having a diagnosed psychiatric disorder and the presence of unused medications in the home. Previous research suggests patients with psychiatric disorders are less adherent to prescribed medication regimens than those without a psychiatric disorder (Hansen, Maciejewski, Yu-Isenberg, \& Farley, 2012; Lacro, Dunn, Dolder, Leckband, \& Jeste, 2002; Rolnick et al., 2013). This behavior of nonadherence would increase the risk of the accumulation of unused medications in the home.

This pilot study explores the relationship between gender, race, age, and comorbid conditions and the presence of CACHES in the home. The study findings support advanced age placing the individual at risk for the accumulation of unused medications in the home. Furthermore, having a psychiatric condition also appears to increase this risk. More research needs to be done to tease out the effect of gender, race, and comorbid conditions on the individual's risk for CACHES. In addition, the researcher recommends further investigations into the influence of these demographic factors on medication adherence and subsequent stockpiling of unused medications.

\section{Geographical Location}

The CACHES study explored the relationship between geographical location (defined as Zip code for the purposes of this study) and the accumulation of unused 
medications in the home. Previous studies examined the relationship between urban/rural dwelling adults and the use of prescription medications (Carrie et al., 2006; Grymonpre $\&$ Hawranik, 2008). These studies found location of residence did not have an effect on prescription drug purchase and use (Carrie et al., 2006; Grymonpre \& Hawranik, 2008). However, studies propose adherence to prescribed medication regimens is more likely in patients who are both highly educated and earn a higher income (Rolnick et al., 2013). With nonadherence comes increased risk of unused medications in the home. The CACHES study explores this relationship.

In this pilot study CACHES of unused medications were found in 27 Davidson County Zip codes with half of CACHES distributed across just 6 Zip codes, including: 37221 (4.9\%), 37013 (5.5\%), 37115 (7.9\%), 37206 (8.5\%), 37207 (9.1\%), and 37211 (14\%). According to the U.S. Census data (2011), 37211 had the highest percentage of males $(50.7 \%)$ and second highest percentage of Caucasian/Non-Hispanics $(67.9 \%)$ out of the 6 Zip codes. Revisiting the earlier discussion, these two factors (Caucasian/NonHispanic race and male gender) likely result in a higher rate of violent and/or traumatic deaths in this Zip code tract. This in turn would increase the number of death investigation cases in this Zip code tract that fell under the jurisdiction of the Medical Examiner. However it is important to note, due to the limited sample size, the CACHES data are insufficient to draw conclusions as to the relationship between geographical location and the stockpiling of unused medications. Additional studies will be needed to clarify both the strength and direction of this relationship.

\section{Health Care Risk Factors}

In the CACHES model, the health care system plays a dual role - both as a contributor to risk and also as the victim of adverse events (increased health care utilization and wasted health care dollars) associated with the misuse and abuse of controlled substances, poisonings, and adverse drug events. In the U.S., health care delivery is decentralized with health care consumers using multiple prescribers (primary care providers, specialists, dentists) and multiple dispensaries (pharmacies). The ME data provide an opportunity to explore the relationship between the number of prescribers and dispensaries (health care system risk factors) with the formation of CACHES of unused medications in the home.

Number of prescribers. The ME pilot study data show a statistically significant relationship between the decedent's use of multiple prescribers and unused medications in the home. The existing literature supports this finding. There are a number of prior studies identifying multiple prescribers as a risk factor for polypharmacy and subsequent nonadherence as well as adverse drug events (Barat et al., 2000; Boparai \& KorcGrodzicki, 2011; Fulton \& Allen, 2005; Hajjar et al., 2007; Junius-Walker et al., 2006; Prybys et al., 2002; Sorensen et al., 2005). Both nonadherence and adverse drug events contribute to the presence of unused medications in the home. 
Number of dispensaries. There are fewer studies examining the link between the number of dispensaries used as a risk for unused medications (Boparai \& KorcGrodzicki, 2011; Torrible \& Hogan, 1997; Werder \& Preskorn, 2003). However, the existing studies identify the use of multiple dispensaries as increasing the risk of the individual purchasing duplicate prescriptions as well as contraindicated medication regimens (Boparai \& Korc-Grodzicki, 2011; Torrible \& Hogan, 1997; Werder \& Preskorn, 2003). Other studies have identified the use of multiple dispensaries as a significant risk factor for the overprescribing, misuse and/or abuse of prescription opioids (Parente et al., 2004; Sullivan et al., 2010).

In conclusion, the pilot study data support the CACHES model, which proposes a relationship between health care risk factors (use of multiple prescribers and dispensaries) and the accumulation of unused medications in the individual's home.

\section{Limitations}

This pilot study was designed to describe the prevalence, size (number of bottles and pills), and types of unused medications stockpiled in the home. The study used data originally collected by MLDIs in the course of death scene investigations in Davidson County, TN from January 1 - December 31, 2013. This next section will discuss the limitations of this pilot study including 1) generalizability; 2) descriptive data; and 3) procedural limits on the original data collection.

The generalizability of the study findings is limited due to the nature of the original data set. As noted earlier, a comparison of the demographics of the ME data set to Davidson County population reveals the sampled ME data to be skewed towards Caucasian/Non-Hispanic males in the 44-64 year old age range. The ME accepts jurisdiction in the case of violent, traumatic, and/or unexpected deaths in Davidson County. The Department of Health Mortality statistics reveal that Caucasian/NonHispanic men are at higher risk for suicide and traumatic (accidental) deaths than their female and non-Caucasian counterparts. Furthermore, death rates secondary to natural causes are higher for African American men and women than Caucasian/Non-Hispanics across five leading cause of death categories. Finally, older adults ( $\geq 65$ years of age) are less likely to die from traumatic (homicide) deaths and more likely to die from natural causes (thus negating the need for the ME involvement) than their younger counterparts.

The descriptive nature of this study did not allow for the determination of a causal relationship among the individual, geographical, and health care risk factors and CACHES. Additional research is needed to clarify the nature of the relationships among the risk factors and the development of CACHES. As noted earlier, there are several individual risk factors identified in the CACHES conceptual model that may serve as a protective mechanism rather than as a risk factor. For example, while women are more likely to access and use prescription medications (thus possibly increasing the risk of unused medications in the home) previous research has shown them to be more adherent to prescribed medication regimens (thus decreasing the risk of unused medications). 
Further research would help illuminate the possibility of co-linearity between certain risk factors. For example, there is a question regarding the interplay between race, geographical location and socioeconomic status. Prior studies examining adherence and race found if the researchers controlled for socioeconomic status, they uncovered the socioeconomic status to have a significant effect on adherence rather than race. The CACHES conceptual model proposes there are multiple risk factors associated with the accumulation of unused medications in the home. Determining the direction, power, and interplay between these risk factors will require a larger, more high-powered study or group of studies.

Finally, the study prevalence rate likely underestimates the number of Davidson County households with unused medications in the home due to five limitations of the original data set including 1) legal restrictions on the MLDIs procedural search for and collection of medications during the death scene investigation; 2) legal restrictions set by the State and NAME guidelines requiring the MLDIs to determine ownership of the medications prior to collecting the medications; 3 ) potential diversion of the decedent's medications by family members, roommates, friends, and/or others prior to law enforcement and the MDLI's search of the scene; 4) missing dispensed dates negating a determination of whether the medication was currently in use versus unused; and, 5) an undercounting of older decedents due to the nature of their deaths (expected/natural).

The MDLIs follow NAME and state guidelines restricting their search for medications to certain designated areas, including: a) common storage locations (bedside table, bathroom medicine cabinet, kitchen counters); b) those found in plain view of the decedent; and/or, c) those found on the decedent's person. In the community setting, individuals oftentimes store medication in multiple locations within the home. As a result, standard MLDI search procedures might not uncover all of the decedent's medications thereby contributing to an under sampling of the stockpile of unused medications in the home.

Furthermore, MDLIs typically limit the collection and cataloging of medications to those clearly indicated as being dispensed to the decedent. Identification of the end user can be difficult when prescription medications are found in unmarked containers. Furthermore, OTC medications typically do not have "dispensed to" information attached to the container. The researcher was able to make a determination of "dispensed to" information for a portion of the CACHES OTC medication entries due to a subset of the decedents' obtaining OTC medications through the Veteran's Administration. It is standard practice at the Veteran's Administration to attach "dispensed to" information to both prescription and OTC medications. However, overall the total number of unused OTCs in decedent's homes was under sampled due to these medications being found in unmarked containers and/or a lack of "dispensed to" information.

MLDIs' Investigator Reports address law enforcement concerns about medications being removed from the decedent's premises by family, roommates, or friends prior to law enforcement arrival on the scene. This behavior most often occurs with controlled substances (opioids, benzodiazepines, stimulants, and barbituates). This 
diversion also could contribute to an under sampling of the decedent's medications found at the death scene.

Finally, out of the 1770 medication entries in the ME dataset, 21.1\% lacked a "dispensed by" date. This disallowed for the determination of whether the medications were in current use or unused at the time of death. Therefore, the CACHES study $56 \%$ prevalence rate is likely an underestimation of the overall prevalence of unused medications.

\section{Practice and Policy Implications}

This research has practice and policy implications for the health care system (prescribers and dispensaries) as well as the individual health care consumer. The CACHES framework highlights the need for a multi-interventional approach to reducing unused medications in the home. The next section will discuss practice implications including the need to 1) change prescribing behaviors; 2) perform medication reconciliation at all points of patient contact in the health care continuum; 3) assess for adherence and barriers to adherence; and 4) educate patients on the importance of safe storage of currently-in-use medications and prompt disposal of unused medications to reduce the risk of diversion, accidental poisonings, and adverse drug events. In addition, this section will address the policy implications of the CACHES study findings.

\section{Practice}

In the U.S. health care system, patients with comorbid conditions are likely being seen by more than one health care provider (Anderson \& Horvath, 2004; Boparai \& Korc-Grodzicki, 2011; Himmel et al., 1996; Lehnert et al., 2011; Mansur, Weiss, \& Beloosesky, 2008; Prybys et al., 2002; Starfield et al., 2005). This decentralized delivery of health care has the potential to contribute to polypharmacy or, at worst, duplicate prescriptions for the same medication or same medication class (Green et al., 2007; Linjakumpu et al., 2002; Mansur, Weiss, Hoffman, et al., 2008; New England Healthcare Institute, 2009; Prybys et al., 2002; Werder \& Preskorn, 2003). Polypharmacy contributes to poor adherence (Dunbar-Jacob \& Mortimer-Stephens, 2001; Mansur, Weiss, Hoffman, et al., 2008; New England Healthcare Institute, 2009; Prybys et al., 2002; Sorensen et al., 2005; Witticke et al., 2013) and adverse drug events (Boparai \& Korc-Grodzicki, 2011; Prybys et al., 2002; Sorensen et al., 2004; Werder \& Preskorn, 2003). Nonadherence results in poorly controlled comorbid conditions. In response, a patient's health care provider often makes changes to the patient's medication regimen prior to his/her having used the entire 30 days of medication. Adverse drug events have similar consequences. The offending medication is discontinued and the patient placed on a different medication for the management of his/her chronic condition. Both of these issues contribute to the accumulation of unused medications in the home. Pharmacy returns data reflect these trends with common themes for returned unused medications being: provider changed prescription due to ineffectiveness, patient discontinued 
prescription due to side effects, and/or provider changed prescription due to adverse drug event (Bolle et al., 2008; Braund, Gn, et al., 2009; Cameron, 1996; Coma et al., 2008; Garey et al., 2004; James et al., 2009; Langley et al., 2005).

The CACHES study results highlight the relationship between a decentralized health care system - defined as the individual having multiple prescribers - and the accumulation of unused medications in the home. Three prescriber behaviors aimed at reducing this risk for unused medications include: writing short scripts ((Herring et al., 2008; Steiner et al., 1993), medication reconciliation, and collaborating with patients to increase adherence.

Short scripts. Writing short scripts for a new medication allows for the patient to have a trial period. During this trial period, the patient and provider can determine the safety of the medication. For example, does the patient experience any side effects that impact negatively on his/her quality of life? Or is this medication going to cause an adverse drug event such as an allergic reaction or, at worst, anaphylaxis? In each of these scenarios, there is a high chance the medication will be discontinued either by the patient or the prescriber. The majority of side effects and adverse drug events occur within the first few days to weeks of a patient's exposure to a medication. As the pharmacy takeback studies show, the remaining pills often are stockpiled in the home.

Writing short scripts also allows for the provider to determine the efficacy of the medications and assess for patient adherence. Best practices dictate the "start low and go slow" process of initiating a new medication. Oftentimes, patients require a titration to effect on medications. Therefore, it behooves the provider to give short scripts (14 days to 30 days) of the medication knowing there is a chance he/she will need to write another prescription for a higher dose, or different medication in the same class, in the near future.

Medication reconciliation. Prior research suggests regular medication reviews reduce polypharmacy and nonadherence (Sorensen et al., 2004). This in turn reduces adverse drug events, hospitalizations, and even mortality (Mil et al., 2004; Sorensen et al., 2004; Wasserfallen et al., 2003; Werder \& Preskorn, 2003). Reviewing the patient's current medications at each visit allows for the provider to determine if the patient is adherent to his/her medication regimen. In addition, medication reconciliation allows the provider to determine what changes have been made by other providers involved in the patient's care. The CACHES model proposes coordination of care, in particular pharmacological interventions, could reduce the accumulation of unused medications in the patient's home, as well as reduce the risk of adverse drug events.

Adherence. Improving adherence to prescribed medication regimens reduces the risk of stockpiles of unused medications in the home (Ruhoy \& Daughton, 2008; Wasserfallen et al., 2003). Estimates of nonadherence range from 50-60\% (Choudhry et 
al., 2009; Dunbar-Jacob \& Mortimer-Stephens, 2001; Wasserfallen et al., 2003; Wilke et al., 2012), which results in a significant number of unused medications. Over half of the CACHES study population had unused medications in the home. These data emphasize the need for providers and patients to collaborate and improve patients' medication adherence rates. In addition to reducing the risk of adverse outcomes associated with unused medications in the home, increased adherence saves money by reducing wastage of health care dollars spent on medications and also reducing health care spending secondary to improved health outcomes.

\section{Policy Implications}

Currently there is a national discussion about how to provide the individual health care consumer access to a safe and reliable disposal site for his/her unused medications (Office of National Drug Control Policy, 2011). One suggestion being considered is having pharmacies serve as disposal sites (Herring et al., 2008; Wasserfallen et al., 2003). This is the current practice in many non-U.S. countries (Great Britain, New Zealand, Spain, Germany, Kuwait, Iceland). In the U.S., controlled substances, and the laws surrounding the disposal of these substances, complicates the disposal process. The 2010 Safe and Secure Drug Disposal Act sets the stage for this to change, but final regulatory guidelines have not yet been published by the DEA as to how this law will look in practice. The DEA has put out several calls to the public requesting feedback on the 2010 Safe and Secure Drug Disposal Act with the latest being in December, 2012 (Drug Enforcement Administration, 2012). In the interim, the DEA has created a biannual "Drug Take Back" initiative coordinating with local law enforcement agencies to provide individual health care consumers the chance to bring their unused medications (including controlled substances) to specified locations for disposal. However, these events are only a temporary measure and are not meant to be a sustained program for drug disposal.

There are several issues with the proposed plan of having pharmacies be responsible for drug disposal. First, there is the issue of the safety of the pharmacy staff. Second, there is the question of how returned medications will be monitored (to reduce possibility of black market diversion). Third, who will pay for this disposal program? Should the costs be taken on by the pharmacies, the individual health care consumer, or the local, state, or federal government? Some countries have proposed legislation requiring the pharmaceutical industry to assume the costs of disposal (Herring et al., 2008). Ultimately, final policy decisions surrounding the disposal of unused medications will require a coordinated effort from the DEA, FDA, National Board of Pharmacies, state Pharmacy Boards, the Pharmaceutical Industry, health care providers, and the individual health care consumer.

\section{Implications for Future Research}

The CACHES model proposes the accumulation of unused medications in the home setting are the result of a complex series of risk factors including a decentralized 
health care system, restrictive state and regulatory guidelines, and individual characteristics of the health care consumer. This pilot study explores the relationship between CACHES and the individual's gender, race, age, number of comorbid conditions, geographical location, as well as the number of prescribers and dispensaries used by the individual. The results of this study suggest advanced age, having a psychiatric comorbid condition, and the use of multiple prescribers and dispensaries increases risk for the individual having CACHES in the home. However, additional research is needed to further investigate the effects of gender, race, comorbid conditions, and geographical location on CACHES.

In addition, future studies are needed to explore the right-hand side of the CACHES model - adverse outcomes associated with unused medications in the home. In particular, researchers should seek to clarify the relationship between CACHES and adverse outcomes for the individual (poisonings, diversion for misuse/abuse, adverse drug events, etc..), health care system (increased utilization of health care resources, wasted health care dollars), criminal justice system (victimization costs associated with drug crimes, incarceration costs related to prescription drug diversion/misuse/abuse), and ecosystem (APIs as pollutants).

As the CACHES model proposes, the accumulation of unused medications in the home is a complex issue requiring the evaluation of the effectiveness of multiple interventions on reducing risk (upstream) as well as adverse outcomes (downstream). Suggested risk reduction interventions include 1) changing health care system practices (short scripts, medication reconciliation, assessing for adherence); 2) removing federal and state regulatory barriers (providing easy and safe access to drug disposal options); and 3) identifying high risk individuals (screening for polypharmacy, nonadherence, and poor health literacy, reducing risky behaviors such as improper storage, prescription stockpiling and sharing).

Older adults ( $\geq 65$ years of age) are a particular population of interest in future research on CACHES. Older adults are at higher risk for having multiple comorbid conditions requiring pharmacological management. In today's health care system, this individual is managed by multiple providers in a variety of health care settings, which places them at higher risk for polypharmacy and ultimately contributes to nonadherence. As a result older adults are at risk for unused medications in the home. Scientists and health care providers at the National Institutes of Health, the Gerontological Society of America, and other major Physician groups identify transitions of care (the point at which a patient is discharged from the hospital to skilled nursing facility, hospital to home, or skilled nursing facility to home) as contributing to the issue of polypharmacy, nonadherence, adverse drug events, and readmissions to acute care settings (Snow et al., 2009). Additional research is needed to identify how medication reconciliation, including the disposal of stockpiled unused medications, could reduce adverse outcomes including hospital readmissions and increased morbidity and mortality.

Downstream interventions in need of evaluation include the development and implementation of environmentally friendly drug disposal mechanisms, as well as safe 
and effective processes for the removal of APIs from the water supply. Increasingly, communities are offering Drop Boxes at local police and fire department stations for community members to drop of their unused medications. What is missing is an understanding of whether or not access to these types of disposal options has a significant impact on the accumulation of medications in the home. Furthermore, there is the question as to what medications are being disposed of at these types of venues and what medications the individual might continue to store at home. Previous studies have reported health care consumers hoarding unused antibiotics and pain medications with the intention of using them, as needed, at a later date (Bolle et al., 2008; Kotchen et al., 2009). A comparison of the types and frequencies of stockpiled medications in the home versus those brought to Drop Boxes would provide a better understanding of disposal patterns. This information could then inform further interventions aimed improving disposal and reducing medications in the home.

\section{Summary}

The accumulation of unused medications by health care consumers results in

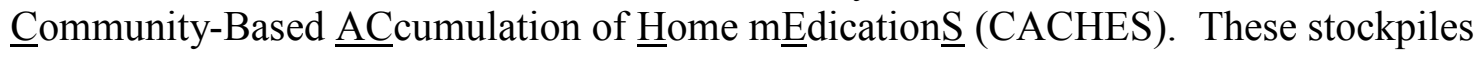
of unused medications place the individual, health care and justice systems, and ecosystem at risk for adverse outcomes. Adverse outcomes for the individual include: the diversion of controlled substances by friends and family members, pediatric poisonings, and adverse drug events. Health care costs associated with the treatment of adverse drug events, poisonings, and prescription drug abuse/misuse present an increasing financial burden for the health care system. For the criminal justice system, adverse outcomes include the costs related to theft of prescription drugs and the incarceration of persons who committed crimes related to prescription drug abuse. Finally, improper disposal of unused medications results in the pollution of local water supplies. The CACHES model proposes health care systems risk factors (multiple prescribers, multiple providers, and prescribing practices), federal and state regulatory risk factors (The Controlled Substance Act 1970 and pharmacy rules), and individual risk factors (gender, race, age, comorbid conditions, polypharmacy, nonadherence, drug costs, drug hoarding, drug sharing, perceptions of medication safety, and geographic location) affect the individual's risk for having CACHES in the home setting.

This pilot study explores the relationship between individual risk factors (gender, race, age, comorbid conditions), geographical location, and health care risk factors (number of prescribers and number of dispensaries) and CACHES. The researcher performed a secondary analysis of data extracted from charts created by the Medical Examiners and Medicolegal Death Scene Investigators of Forensic Medical, PLC in Nashville, Tennessee. The study sample included 290 Davidson County residents whose deaths fell under the jurisdiction of the Medical Examiner's office from January 1 through December 31, 2011. The study explored the prevalence, size, and composition of CACHES found in decedents' homes. In addition, a descriptive analysis was performed comparing the demographic data (gender, race, age, and comorbid conditions) of decedents with and decedents without CACHES in the home. Additionally, the 
geographic locations of CACHES were mapped. Finally, the relationship between health care risk factors (number of prescribers, number of dispensaries) and the presence or absence of CACHES was explored.

There was no statistical difference in the gender, race, or age of decedents with medications (used and unused) and decedents without medications in the home. In contrast to the Davidson County general population, the CACHES study sample was majority male, Caucasian/Non-Hispanic, and older. The prevalence rate of CACHES was $56 \%$. More than half of decedents with CACHES had a mean of $38.9(S D \pm 43.7)$ unused pills and $\geq 4$ bottles of unused medications. Sixty percent of the unused medications came from two major classes - those affecting the central nervous system and the cardiovascular system. The decedents with CACHES were significantly older, had a higher likelihood of having a psychiatric diagnosis, and used more prescribers and dispensaries than those without CACHES in the home. The two groups did not statistically differ with regards to gender, race, or comorbid conditions.

The generalizability of the study findings is limited due to the nature of the original data set. The ME accepted jurisdiction for violent, traumatic, and/or unexpected deaths. As a result, the ME data skewed towards Caucasian/Non-Hispanic males in the 44-64 year old age range. Furthermore, statistical determination of a causal relationship among the individual, geographical, and health care risk factors and CACHES could not be performed. The calculated prevalence rate is a likely underestimation secondary to the legal restrictions regarding the search and seizure of medications from in-home death scene investigations. Furthermore, older adult decedents were under represented in the study sample due to their increased risk of having a death ruled as natural and/or expected. This under sampling of older adult decedents likely decreased the study prevalence rate. In addition, there was an under representation of controlled substances in the study sample due to diversion of these medications by family and friends prior to law enforcement arrival on scene. Finally, approximately $20 \%$ of the medication data were missing "dispensed by" dates, thereby necessitating the exclusion of these data from the final analyses.

The CACHES conceptual model identifies individual, health care system, and federal and state regulatory risk factors associated with the accumulation of unused medications in the home. Additional research is needed to determine the relationship between gender, race, comorbid conditions and CACHES. Furthermore, future research must focus on establishing a causal relationship between CACHES and adverse outcomes for the individual, health and criminal justice systems, and ecosystem. Proposed interventions for the reduction of CACHES include: changes to prescribing practices, assessing individuals for risk of CACHES, improving transitions of care across different health care settings, and expanding the individual health care consumer's access to easy and safe medication disposal options. 


\section{LIST OF REFERENCES}

Abahussain, E. A., Ball, D. E., \& Matowe, W. C. (2006). Practice and opionion towards disposal of unused medication in Kuwait. Medical Principals and Practice 15, 352-357. doi: 10.1159/000094268

Abrons, J., Vadala, T., Miller, S., \& Cerulli, J. (2010). Encouraging safe medication disposal through student pharmacist intervention. Journal of the American Pharmacists Association, 50(2), 169-173.

Adams, A., Uratsu, C., Dyer, W., Magid, D., O'Connor, P., Beck, A., . . S Schmittdiel, J. (2013). Health system factors and antihypertensive adherence in a racially and ethnically diverse cohort of new users. Journal of the American Medical Association Internal Medicine, 173(1), 54-61. doi:

10.1001/2013.jamainternmed.955

Almarsdottir, A. B., \& Asgeirsson, A. G. (2009). Unused drugs in Iceland: Value of and reason for disposal. Pharmacoepidemiology and Drug Safety, 18. doi: $10.1002 / \mathrm{pds}$

American Association of Poison Control Centers. (n.d.). Poison Prevention Tips for Adults. Retrieved August 30, 2011, 2011

Anderson, G., \& Horvath, J. (2004). The growing burden of chronic disease in America. Public Health Reports, 119, 263-270.

Baena, M. I., Faus, M. J., Fajardo, P. C., Luque, F. M., Sierra, F., Martinez-Olmos, J., . . . Zarzuelo, A. (2006). Medicine-related problems resulting in emergency department visits. European Journal of Clinical Pharmacology, 62, 387-393. doi: $10.1007 / \mathrm{s} 00228-006-0116-0$

Barat, I., Andreasen, F., \& Damsgaard, E.M.S. (2000). The consumption of drugs by 75year-old individuals living in their own homes. Pharmacoepidemiology and Prescription, 56, 501-509.

Barnes, K., Kolpin, D., Furlong, E., Zaugg, S., Meyer, M., \& Barber, L. (2008). A national reconnaissance of pharmaceuticals and other organic wastewater contaminants in the United States - I) Groundwater. Science of the Total Environment, 402, 192-200.

Bartholow, M. (2012). 2011 top 200 generic and brand drugs. Pharmacy Times. 
Benner, J. S., Glynn, R. J., Mogun, H., Neumann, P. J., Weinstein, M. C., \& Avorn, J. (2002). Long-term persistence in use of statin therapy in elderly patients. Journal of the American Medical Association, 288(4), 455-461. doi:

10.1001/jama.288.4.455

Bhamb, B., Brown, D., Hariharan, J., Anderson, J., Balousek, S., \& Fleming, M. F. (2006). Survey of select practice behaviors by primary care physicians on the use of opioids for chronic pain. Current Medical Research and Opinion, 22(9), 18591865.

Birnbaum, H. G., White, A. G., Reynolds, J. L., Greenberg, P. E., Zhang, M., Vallow, S., ... Katz, N. P. (2006). Estimated costs of prescription opioid analgesic abuse in the United States in 2001. Clinical Journal of Pain, 22(8), 667-676.

Blazer, D., \& Wu, L. (2009). Nonprescription use of pain relievers by middle-aged and elderly community-living adults: National survey on drug use and health. Journal of the American Geriatric Society, 57, 1252-1257. doi: 10.1111/j.1532-

5415.2009.02306.x

Bolle, L. De, Mehuys, E., Adriaens, E., Remon, J., Bortel, L. Van, \& Christiaens, T. (2008). Home medication cabinets and self-medication: A source of potential health threats? The Annals of Pharmacotherapy, 42, 572-579.

Boparai, M. K., \& Korc-Grodzicki, B. (2011). Prescribing for older adults. Mount Sinai Journal of Medicine, 78(4), 613-626. doi: 10.1002/msj.20278

Bosworth, H. B., Powers, B., Grubber, J. M., Thorpe, C. T., Olsen, M. K., Orr, M., \& Oddone, E. Z. (2008). Racial differences in blood pressure control: Potential explanatory factors. Journal of General Internal Medicine, 23(5), 692-698. doi: $10.1007 / \mathrm{s} 11606-008-0547-7$

Bound, J. P., \& Voulvoulis, N. (2005). Household disposal of pharmaceuticals as a pathway for aquatic contamination in the United Kingdom. Environmental Health Perspectives, 113(12), 1705-1710.

Braund, R., Gn, G., \& Matthews, R. (2009). Investigating unused medications in New Zealand. Pharmacy World Science, 31, 664-669.

Braund, R., Peake, B. M., \& Shieffelbein, L. (2009). Disposal practices for unused medications in New Zealand. Environment International, 35, 952-955.

Breuer, B., Cruciani, R., \& Portenoy, R. K. (2010). Pain management by primary care physicians, pain physicians, chiropractors, and acupuncturists: A national survey. Southern Medical Journal, 103(8), 738-747. doi:

10.1097/SMJ.0b013e3181e74ede 
Bronstein, A. C., Spyker, D. A., Cantilena, L. R., Green, J. L., Rumack, B. H., \& Dart, R. C. (2011). 2010 annual report of the American Association of Poison Control Centers' National Poison Data System (NPDS): 28th annual report. Clinical Toxicology, 49, 910-941. doi: 10.3109/15563650.2011.635149

Bronstein, A. C., Spyker, D. A., Cantilena, L. R., Green, J. L., Rumack, B. H., \& Griffin, S. L. (2010). 2009 Annual report of the American Association of Poison Control Centers' national poison data system (NPDS): 27 th annual report. Clinical Toxicology, 48, 979-1178.

Brownstein, J., Green, T., Cassidy, T., \& Butler, S. (2010). Geographic information systems and pharmacoepidemiology: Using spacial cluster detection to monitor local patterns of prescription opioid use. Pharmacoepidemiology and Drug Safety, 19, 627-637. doi: 10.1002/pds.1939

Cameron, S. (1996). Study by Alberta pharmacists indicates drug wastage a "mammoth" problem. Canadian Medical Association Journal, 155(11), 1596-1598.

Cantrill, S. V., Brown, M. D., Carlisle, R. J., Delaney, K. A., Hays, D. P., Nelson, L. S., . . Whitson, R. R. (2012). Clinical policy: Critical issues in the prescribing of opioids for adult patients in the Emergency Department. Annals of Emergency Medicine, 60(4), 499-525. doi: 10.1016/j.annemergmed.2012.06.013

Carrie, A. G., Grynmonpre, R. E., \& Blandford, A. A. (2006). Impact of residence on prevalence and intensity of prescription drug use among older adults. The Annals of Pharmacotherapy, 40, 1932-1938.

Census Bureau. (2011). ZIP Code Tabulation Area (ZCTA): Frequently asked questions. Washington D.C.: US Census Bureau Retrieved from http://www.census.gov/geo/ZCTA/zctafaq.html.

Center for Disease Control and Prevention. (2010). Emergency department visits involving nonmedical use of selected prescription drugs: United States, 20042008 Morbidity and Mortality Weekly Reports (Vol. 23, pp. 705-709). Atlanta: Center for Disease Control and Prevention.

Center for Substance Abuse Research. (2012). Current Substance Abuse Legislation. CESAR: Center for substance abuse research. Retrieved February 7, 2012, from http://www.cesar.umd.edu/cesar/library/statutes.asp

Centers for Disease Control and Prevention. (2011). Data \& Statistics (WISQARS): Cost of injury reports. Atlanta: Centers for Disease Control and Prevention.

Choudhry, N., Shrank, W. H., Levin, R. L., Lee, J. L., Jan, S. A., Brookhart, M. A., \& Solomon, D. H. (2009). Measuring concurrent adherence to multiple related medications. American Journal of Managed Care, 15(7), 457-464. 
Cicero, T., Dart, R., Inciardi, J., Woody, G., Schnoll, S., \& Munoz, A. (2007). The development of a comprehensive risk-management program for prescription opioid analgesics: Researched Abuse, Diversion, and Addiction-Related Surveillance (RADARS). Pain Medicine, 8(2), 157-170. doi: 10.1111/j.15264637.2006.00259.x

Cicero, T., Surratt, H., Inciardi, J., \& Munoz, A. (2007). Relationship between therapeutic use and abuse of opioid analgesics in rural, suburban, and urban locations in the United States. Pharmacoepidemiology and Drug Safety, 16, 827840. doi: $10.1002 /$ pds. 1452

Colliver, J. D., Compton, W. M., Gfroerer, J. C., \& Condon, T. (2006). Projecting drug use among aging baby boomers in 2020. Annals of Epidemiology, 16, 257-265.

Coma, A., Modamio, P., Lastra, C. F., Bouvy, M. L., \& Marino, E. L. (2008). Returned medicines in community pharmacies of Barcelona, Spain. Pharmacy World Science, 30, 272-277. doi: 10.1007/s11096-007-9177-0

Comprehensive Drug Abuse Prevention and Control Act of 1970, § 801-971 (1970).

Daniel, K., Honein, M., \& Moore, C. (2003). Sharing prescription medication among teenage girls: Potential danger to unplanned/undiagnosed pregancies. Pediatrics, 111(5), 1167-1170.

Daughton, C. G., \& Ruhoy, I. S. (2009a). Environmental footprint of pharmaceuticals: The significance of factors beyond direct excretion to sewers. Environmental Toxicology and Chemistry, 28(12), 2495-2521.

Daughton, C. G., \& Ruhoy, I. S. (2009b). Pharmaceuticals and sustainability: Concerns and opportunities regarding human health and the environment $A$ Healthy Future - Pharmaceuticals in a Sustainable Society (1 ed., Vol. 1, pp. 14-39). Stockholm: Apoteket AB, MistraPharma, and Stockholm County Council.

Daughton, C. G., \& Ruhoy, I. S. (2013). Lower-dose prescribing: Minimizing "side effects" of pharmaceuticals on society and the environment. Science of the Total Environment, 443, 324-337. doi: 10.1016/j.scitotenv.2012.10.092

Daughton, Christian G. (2003). Cradle-to-cradle stewardship of drugs for minimizing their environmental disposition while promoting human health. II. Drug disposal, waste reduction, and future directions. Environmental Health Perspectives, $111(5), 775-785$.

Daughton, Christian G. (2010a). Drugs and the environment: Stewardship and sustainability (pp. 196). Las Vegas: United States Environmental Protection Agency. 
Daughton, Christian G. (Ed.). (2010b). Pharmaceutical ingredients in drinking water: Overview of occurrence and significance of human exposure (1st ed.). Washington D.C.: American Chemical Society.

Daughton, Christian G., \& Ruhoy, Ilene Sue. (2008). The afterlife of drugs and the role of PharmEcovigilance. Drug Safety, 31(12), 1069-1082.

Der, E. Hsia, Rubenstein, L., \& Choy, G. (1997). The benefits of in-home pharmacy evaluation for older persons. Journal of the American Geriatrics Society, 45(2), 211-214.

Division of Health Statstics. (2010). Tennessee U.S. Census Population Data 2010 (P. a. A. Office of Policy, Division of Health Statistics, Trans.) (pp. 1-98). Nashville, TN: Tennessee Department of Health.

Drug Enforcement Administration. (2012). Disposal of controlled substances. Federal Register. Retrieved 05/08/2013, 2013, from http://www.deadiversion.usdoj.gov/fed_regs/rules/2012/fr1221_8.htm

Dunbar-Jacob, J., \& Mortimer-Stephens, M. K. (2001). Treatment adherence in chronic diseases. Journal of Clinical Epidemiology, 54, S57-S60.

Dymowski, J. J., \& Uehara, D. T. (1987). Common household poisonings. Pediatric Emergency Care, 3(4), 261-265.

Edwards, G. P. L. (1982). The family medicine cabinet. Journal of the Royal College of General Practitioners, 681-683.

Ekedahl, A. B. E. (2006). Reasons why medicines are returned to Swedish pharmacies unused. Pharmacy World Science, 28, 352-358.

Ellis, J., \& Mullan, J. (2009). Prescription medication borrowing and sharing: Risk factors and management. Australian Family Physician, 38(10), 816-819.

Environmental Protection Agency. (2010). Persistance of contaminants from wastewater discharges during drinking water treatment: Identification of compounds and degredation/disinfection byproducts, evaluation of removal, and potential exposure. Washington D.C.: Environmental Protection Agency.

Fine, R. N., Becker, Y., Geest, S. De, Eisen, H., Ettenger, R., Evans, R., . . Dobbels, F. (2009). Nonadherence consensus conference summary report. American Journal of Transplantation, 9, 35-41. doi: 10.1111/j.1600-6143.2008.02495.x.

Food and Drug Administration. (2011a). Blueprint for prescriber continuing education program. Silver Springs: Food and Drug Administration. 
Food and Drug Administration. (2011b). Draft blueprint for prescriber education for long-acting/extended-release opioid class-wide risk evaluation and mitigation strategy: availability; request for comments. Silver Springs: Food and Drug Administration.

Fulton, M. M., \& Allen, E. R. (2005). Polypharmacy in the elderly: A literature review. Journal of the American Academy of Nurse Practitioners, 17(4), 123-132.

Furtula, V., Farrell, E., Diarrassouba, F., Rempel, H., Pritchard, J., \& Diarra, M. (2010). Veterinary pharmaceuticals and antibiotic resistance of Escherichia coli isolates in poultry litter from commercial farms and controlled feeding trials. Poultry Sciences, 89, 180-188. doi: 10.3382/ps.2009-00198

Garey, K., Johle, M. L., Behrman, K., \& Meuhauser, M. M. (2004). Economic consequences of unused medications in Houston, Texas. The Annals of Pharmacotherapy, 38(July/August), 1165-1168.

Garnier, L., Arria, A., Caldeira, K., Vincent, K., O'Grady, K., \& Wish, E. (2010). Sharing and selling of prescription medications in a college student sample. Journal of Clinical Psychiatry, 71(3), 262-269. doi: 10.4088/JCP.09m05189ecr.

Gellad, W. F., Haas, J. S., \& Safran, D. G. (2007). Race/ethnicity and nonadherence to prescription medications among seniors: Results of a national study. Journal of General Internal Medicine, 22(11), 1572-1578. doi: 10.1007/s11606-007-0385-z

Gilson, A. M., \& Kreis, P. (2009). The burden of the nonmedical use of prescription opioid analgesics. Pain Medicine, 10(S2), S89-S100. doi: 10.1111/j.15264637.2009.00668.x

Glassmeyer, S. T., Hinchey, E. K., Boehme, S. E., Daughton, C. G., Ruhoy, I. S., Conerly, O., ... Thompson, V. G. (2009). Disposal practices for unwanted residential medication in the United States. Environment International, 35, 566572.

Goldman, D. P., Joyce, G. F., \& Zheng, Y. (2007). Prescription drug cost sharing: Associations with medication and medical utilization and spending and health. Journal of the American Medical Association, 298(1), 61-69.

Goldsworthy, R. C., Schwartz, N. C., \& Mayhorn, C. B. (2008). Beyond abuse and exposure: Framing the impact of prescription-medication sharing. American Journal of Public Health, 98(6), 1115-1121.

Grady, D., Berkowitz, S., \& Katz, M. (2011). Less is more: Opioids for chronic pain. Archives of Internal Medicine, E1-E2. doi: 10.1001/archinternmed.2011.213 
Gray-Winnett, M. D., Davis, C. S., Yokley, S. G., \& Franks, A. S. (2010). From dispensing to disposal: The role of student pharmacists in medication disposal and the implementation of a take-back program. Journal of the American Pharmacy Association, 50, 613-618.

Green, J. L., Hawley, J. N., \& Rask, K. J. (2007). Is the number of prescribing physicians an independent risk factor for adverse drug events in an elderly outpatient population? The American Journal of Geriatric Pharmacotherapy, 5(1), 31-39.

Gross-Sorokin, M. Y., Roast, S. D., \& Brighty, G. C. (2006). Assessment of feminization of male fish in English rivers by the Environment Agency of England and Wales. Environmental Health Perspectives, 114(S-1), 147-151. doi: 10.1289/ehp.8068

Grymonpre, R. E., \& Hawranik, P. G. (2008). Rural residence and prescription medication use by community-dwelling older adults: A review of the literature. The Journal of Rural Health, 24(2), 203-209. doi: 10.1111/j.17480361.2008.00159.x

Grynmonpre, R. E., Didur, C. D., Montgomery, P. R., \& Sitar, D. S. (1998). Pill count, self-report, and pharmacy claims data to measure medication adherence in the elderly. Annals of Pharmacotherapeutics, 32, 749-754.

Gu, Q., Dillon, C., \& Burt, V. (2010). Prescription drug use continues to increase: U.S. prescription drug data for 2007-2008 NCHS Data Brief, no. 42 (pp. 1-8). Hyattsville: National Center for Health Statistics.

Haider, S. I., Johnell, K., Weitoft, G. R., Thorslund, M., \& Fastbom, J. (2008). The influence of educational level on polypharmacy and inappropriate drug use: A register-based study of more than 600,000 older people. JOurnal of the American Geriatrics Society, 57(1), 62-69. doi: 10.1111/j.1532-5415.2008.02040.x

Hajjar, E. R., Cafiero, A. C., \& Hanlon, J. T. (2007). Polypharmacy in elderly patients. The American Journal of Geriatric Pharmacotherapy, 5(4), 345-351. doi: 10.1016/j.amjopharm.2007.12.002

Hall, A. J., Logan, J. E., Toblin, R. L., Kaplan, J. A., Kraner, J. C., Bixler, D., . . Paulozzi, L. J. (2008). Patterns of abuse among unintentional pharmaceutical overdose fatalities. Journal of the American Medical Association, 300(22), 26132620.

Han, B., Gfroerer, J., \& Colliver, J. (2009). An examination of trends in illicit drug use among adults aged 50 to 59 in the United States OAS Data Review (pp. 1-10). Rockville: Office of Applied Studies. 
Hansen, R. A., Maciejewski, M., Yu-Isenberg, K., \& Farley, J. F. (2012). Adherence to antipsychotics and cardiometabolic medications: Association with health care utilization and costs. Psychatric Services, 63(9), 920-928. doi: 10.1176/appi.ps.201100328

Hanzlick, R., Hunsaker, J., \& Davis, G. (2002). A guide for manner of death classification. In N. B. o. Directors (Ed.), (First ed., pp. 1-29): National Association of Medical Examiners.

Herring, M. E., Shah, S. K., Shah, S., \& Gupta, A. K. (2008). Current regulations and modest proposals regarding disposal of unused opioids and other controlled substances. Journal of the American Ostopathic Association, 108(7), 338-343.

Himmel, W., Tabache, M., \& Kochen, M. M. (1996). What happens to long-term medication when general practice patients are referred to hospital? European Journal of Clinical Pharmacology, 50, 253-257.

Hofer-Ducklemann, C. (2012). Gender and polypharmacotherapy in the elderly: A clinical challenge. In V. Regitz-Zagrosek (Ed.), Sex and Gender Differences in Pharmacology (1 ed., Vol. 214, pp. 169-182). Berlin Heidelberg: Springer-Verlag. doi: 10.1007/978-3-642-30726-3_9

Hohl, C. M., Nosyk, B., Kuramoto, L., Zed, P. J., Brubacher, J. R., Abu-Laban, R. B., . . . Sobolev, B. (2011). Outcomes of emergency department patients presenting with adverse drug events. Annals of Emergency Medicine, XX(X), 1-14.

Hovstadius, B., \& Petersson, G. (2011). Non-adherence to drug therapy and drug acquisition costs in a national population - A patient-based register study. $B M C$ Health Services Research, 11(326), 1-11.

Institute of Medicine of the National Academies. (2007). Preventing medication errors: Committee on identifying and preventing medication errors Quality Chasm Series, J. Wolcott, J. Bootman \& L. Cronenwett (Eds.), (pp. 480).

James, T. H., Helms, M. L., \& Braund, R. (2009). Analysis of medications returned to community pharmacies. The Annals of Pharmacotherapy, 43, 1631-1635.

Jobling, S., Nolan, M., Tyler, C. R., Brighty, G. C., \& Sumpter, J. P. (1998). Widespread sexual disruption in wild fish. Environmental Science \& Technology, 32(17), 2498-2506. doi: 10.1021/es9710870

Johnston, L., O'Malley, P. M., Bachman, J. G., \& Schulenberg, J. E. (2011). Monitoring the Future national results on adolescent drug use: Overview of key findings, 2010. Ann Arbor: University of Michigan. 
Jones, C. (2011, May 13th, 2011). [Discussion regarding the "Safe and Reliable Drug Disposal Act" of 2010].

Joranson, D. E., \& Gilson, A. M. (2005). Drug crime is a source of abused pain medications in the United States. Journal of Pain and Symptom Management, 30(4), 299-201.

Junius-Walker, U., Theile, G., \& Hummers-Pradier, E. (2006). Prevalence and predictors of polypharmacy among older primary care patients in Germany. Family Practice, 24(1), 14-19.

Kaiser Family Foundation. (2010a). Prescription drug trends Fact Sheet (pp. 1-10). Washington D.C.: Henry J. Kaiser Family Foundation.

Kaiser Family Foundation. (2010b). Tennessee: Retail prescription drugs filled at pharmacies (annual per capita by age), 2010 Individual State Profiles: The Henry J. Kaiser Family Foundation.

Kaiser Family Foundation. (2010c). Tennessee: Retail prescription drugs filled at pharmacies (annual per capita by gender), 2010: The Henry J. Kaiser Family Foundation

Kaiser Family Foundation. (2010d). United States: Retail prescription drugs filled at pharmacies (annual per capita by gender), 2010: The Henry J. Kaiser Family Foundation.

Kaiser Family Foundation. (2011a). Tennessee: Retail prescription drugs filled at pharmacies (annual per capita by gender), 2011: The Henry J. Kaiser Family Foundation.

Kaiser Family Foundation. (2011b). Tennessee: Retail prescription drugs filled at pharmacies (annual per capita), 2011: The Henry J. Kaiser Family Foundation.

Kaiser Family Foundation. (2011c). Tennessee: Uninsured rates for the nonelderly by race/ethnicity, states (2010-2011), U.S. (2011): Kaiser Family Foundation.

Kallaos, J., Wheeler, K., Wong, C., \& Zahller, M. (2007, May 2007). Pharmaceuticals in wastewater streams: Disposal practices and policy options in Santa Barbara. [Master's Project]. Santa Barbara.

Kidd, K. A., Blanchfield, P. J., Mills, K. H., Palace, V. P., Evans, R. E., Lazorchak, J. M., \& Flick, R. W. (2007). Collapse of a fish population after exposure to a synthetic estrogen. Proceedings of the National Academy of Sciences of the United States, 104(21), 8897-8901. doi: 10.1073/pnas.0609568104 
Kotchen, M., Kallaos, J., Wheeler, K., Wong, C., \& Zahller, M. (2009). Pharmaceuticals in wastewater: Behavior, preferences, and willingness to pay for a disposal program. Journal of Environmental Management, 90, 1476-1482.

Kuspis, D. A., \& Krenzelok, E. P. (1996). What happens to expired medications? A survey of community medication disposal. Veternarian and Human Toxicology, $38(1), 48-49$.

Lacro, J. P., Dunn, L. B., Dolder, C. R., Leckband, S. G., \& Jeste, D. V. (2002). Prevalence of and risk factors for medication nonadherence in patients with schizophrenia: A comprehensive review of recent literature. Journal of Clinical Psychiatry, 63(10), 892-909.

Landi, F., Onder, G., Cesari, M., Barillaro, C., Lattanzio, F., Carbonin, P., \& Berabei, R. (2004). Comorbidity and social factors predicted hospitalization in frail elderly patients. Journal of Clinical Epidemiology, 57, 832-836.

Langley, C., Marriott, J., Mackridge, A., \& Daniszewski, R. (2005). An analysis of returned medicines in primary care. Pharmacy World Science, 27, 296-299.

Larsson, D. G. Joakim, Pedro, C. de, \& Paxeus, N. (2007). Effluent from drug manufactures contains extremely high levels of pharmaceuticals. Journal of Hazardous Materials, 148, 751-755. doi: 10.1016/j.jhazmat.2007.07.008

Lehnert, T., Heider, D., Leicht, H., Heinrich, S., Corrieri, S., Luppa, M., . . Konig, H. H. (2011). Review: Health care utilization and costs of elderly persons with multiple chronic conditions. Medical Care Research and Review, 68, 387-420. doi: $10.1177 / 1077558711399580$

Linjakumpu, T., Hartikainen, S., Klaukka, T., Veijola, J., Kivela, S., \& Isoaho, R. (2002). Use of medications and polypharmacy are increasing among the elderly. Journal of Clinical Epidemiology, 55, 809-817.

Lucado, J., Paez, K., \& Elixhauser, A. (2011). Medication-related adverse outcomes in U.S. hospitals and emergency departments, 2008. . In H. S. Brief (Ed.), (pp. 1-17). Rockville: Agency for Healthcare Research and Quality.

Mackridge, A., \& Marriott, J. (2007). Returned medicines: Waste or a wasted opportunity? Journal of Public Health, 29(3), 258-262. doi: 10.1093/pubmed/fdm037

Manchikanti, L., \& Singh, A. (2008). Therapeutic Opioids: A ten-year perspective on the complexities and complications of the escalating use, abuse, and nonmedical use of opioids. Pain Physician, 11, S63-S88. 
Manchikanti, L., Standiford, H., Fellows, B., Janata, J. W., Pampati, V., Grider, J. S., \& Boswell, M. V. (2012). Opioid epidemic in the United States. Pain Physician, 15, ES9-ES38.

Mansur, N., Weiss, A., \& Beloosesky, Y. (2008). Relationship of in-hospital medication modifications of elderly patients to postdischarge medications, adherence, and mortality. The Annals of Pharmacotherapy, 42, 783-789. doi: 10.1345/aph.1L070

Mansur, N., Weiss, A., Hoffman, A., Gruenewald, T., \& Beloosesky, Y. (2008). Continuity and adherence to long-term drug treatment by geriatric patients after hospital discharge. Drugs Aging, 25(10), 861-870.

Martin, B. C., Wiley-Exley, E. K., Richards, S., Domino, M. E., Carey, T. S., \& Sleath, B. L. (2009). Contrasting measures of adherence with simple drug use, medication switching, and therapeutic duplication. The Annals of Pharmacotherapy, 43, 36-44. doi: 10.1345/aph.1K671

McCabe, S. E. (2005). Correlates of nonmedical use of prescription benzodiazepine anxiolytics: Results from a national survey of U.S. college students. Drug and Alcohol Dependance, 79, 53-62. doi: 10.1016/j.drugalcdep.2004.12.006

McCabe, S. E., Boyd, C. J., \& Teter, C. J. (2005). Illicit use of opioid analgesics by high school seniors. Journal of Substance Abuse Treatment, 28, 225-230. doi: 10.1016/j.jsat.2004.12.009

McCabe, S. E., Boyd, C. J., \& Teter, C. J. (2006). Medical use, illicit use, and diversion of abusable prescription drugs. Journal of the American College of Health, 54(5), 269-278.

McCabe, S. E., Cranford, J. A., Boyd, C. J., \& Teter, C. J. (2007). Motives, diversion and routes of administration associated with nonmedical use of prescription opioids. Addictive Behaviors, 32, 562-575. doi: 10.1016/j.addbeh.2006.05.022

McClelland, R. L., Jorgensen, N. W., Post, W. S., Szklo, M., \& Kronmal, R. A. (2013). Methods for estimation of disparities in medication use in an observational cohort study: results from the Multi-Ethnic Study of Atherosclerosis. Pharmacoepidemiology and Drug Safety(Feb 4). doi: 10.1002/pds.3406

McCullagh, M. C., Schim, S., \& Ortner, P. (2012). Drug disposal among hospice home care nurses: A pilot study of current practice and attitudes. Journal of Pain and Symptom Management, 42(2), 287-292.

McFee, R., \& Caraccio, T. (2006). "Hang up your pocketbook" - An easy intervention for the Granny Syndrome: Grandparents as a risk factor in unintentional pediatric exposures to pharmaceuticals. Journal of the American Ostopathic Association, 106(7), 405-411. 
Metro Nashville Police Department. (2011). Victims by offense, age, gender and race.

Meyer, S., Eddleston, M., Bailey, B., Desel, H., Gottschling, S., \& Gortner, L. (2007). Unintentional household poisoning in children. Clinical Pediatrics, 219, 254-270.

Mil, J. W. Foppe van, Schulz, M., \& Tromp, T. F. J. (2004). Pharmaceutical care, European developments in concepts, implementation, teaching, and research: A review. Pharmacy World Science, 26, 303-311.

Morgan, T. M. (2001). The economic impact of wasted prescription medication in an outpatient population of older adults. The Journal of Family Practice, 50(9), 779781.

Musson, S. E., \& Townsend, T. G. (2009). Pharmaceutical compound content of municipal solid waste. Journal of Hazardous Materials, 162, 730-735. doi: 10.1016/j.jhazmat.2008.05.089

National Center for Health Statistics. (2011). Health, United States, 2011: With special feature on socioeconomic status and health (C. f. D. C. a. Prevention, Trans.) (pp. 1 - 583). Hyattsville, MD: U.S. Department of Health and Human Services.

National Drug Intelligence Center. (2011a). The economic impact of illicit drug use on American society (pp. 1-109). Washington D.C.: U. S. Department of Justice.

National Drug Intelligence Center. (2011b). The economic impact of illicit drug use on American society. Washington D.C.: United States Department of Justice.

New England Healthcare Institute. (2009). Thinking outside the pillbox: A system-wide approach to improving patient medication adherence for chronic disease $N E H I$ Research Brief (pp. 1-21).

Nola, K. (2011, August 22nd, 2011). [Discussion regarding Safe and Reliable Drug Act and Pharmacies resistance].

Oaks, J. L., Gilbert, M., Virani, M., Watson, R. T., Meteyer, C. U., Rideout, B. A., .. . Khan, A. A. (2006). Diclofenac residues as the cause of vulture population decline in Pakistan. Nature, 427(12 February), 630-633.

Office of Health Statistics. (2011). Tennessee Deaths 2011 Tennessee Deaths (pp. 1-6). Nashville, TN: Tennessee Department of Health.

Office of National Drug Control Policy. (2008). Prescription for danger: A report on the troubling trend of prescription and over-the-counter drug abuse among the nation's teens (pp. 1-11). Washington D.C.: Executive Office of the President. 
Office of National Drug Control Policy. (2011). Epidemic: Responding to America's prescription drug abuse crisis. Washington D.C.: Office of National Drug Control Policy.

Orlando, E. F., Kolok, A. S., Binzcik, G. A., Gates, J. L., Horton, M. K., Lambright, C. S., . . Guillette, L. J. (2004). Endocrine-disrupting effects of cattle feedlot effluent on an aquatic sentinel species, the Fathead Minnow. Environmental Health Perspectives, 112(3), 353-358. doi: 10.1289/ehp.6591

Ortner, P., \& McCullagh, M. (2010). Hospice nurses and drug disposal: The convergence between nursing practice and the environment. Journal of Hospice and Palliative Nursing, 12(1), 15-26.

Owens, G. (2008). Gender differences in health care expenditures, resource utilization, and quality of care. Supplement to Journal of Managed Care Pharmacy, 14(3), S2-S6.

Parente, S. T., Kim, S. S., Finch, M. D., Schloff, L. A., Rector, T. S., Seifeldin, R., \& Haddox, J. D. (2004). Identifying controlled substance patterns of utilization requiring evaluation using administrative data claims. Drug Safety, 10(11), 783790.

Paulozzi, L., Baldwin, G., Franklin, G., Kerlikowske, R., Jones, C., \& Ghiya, N. (2012). Prescription drug overdoses - a U.S. epidemic (N. C. f. I. P. a. Control, Trans.) Morbidity and Mortality Weekly Report (MMWR). Atlanta, GA: Center for Disease Control and Prevention.

Paulozzi, L., \& Xi, Y. (2008). Recent changes in drug poisoning mortality in the United States by urban-rural status and by drug type. Pharmacoepidemiology and Drug Safety, 17(10), 997-1005.

Petersen, E., Rasmussen, S., Daniel, K., Yazdy, M., \& Honein, M. (2008). Prescription medication borrowing and sharing among women of reproductive age. Journal of Women's Health, 17(7), 1073-1080. doi: 10.1089/jwh.2007.0769

Peterson, C., \& Burton, R. (2007). U.S. health care spending: Comparison with other OECD countries (D. S. P. Division, Trans.) CRS Report for Congress (pp. 1-65). Washington, D.C.: Library of Congress.

Prybys, K. M., Melville, K. A., Hanna, J. R., Gee, A., \& Chyka, P. A. (2002). Polypharmacy in the elderly: clinical challenges in emergency practice. Parti I: Overview, etiology, and drug interactions. Emergency Medicine Reports, 23(11), 145-152. 
Qato, D. M., Alexander, G. C., Conti, R. M., Johnson, M., Schumm, P., \& Lindau, S. T. (2008). Use of prescription and over-the-counter medications and dietary supplements among older adults in the United States. The Journal of the American Medical Association, 305(16), 1625-1722.

Raofi, S., \& Schappert, S. (2006). Medication therapy in ambulatory medical care: United States, 2003-2004. (163). Hyattsville: Centers for Disease Control and Prevention.

Roebuck, M. C., Liberman, J. N., Gemmill-Toyama, M., \& Brennan, T. A. (2011). Medication adherence leads to lower health care use and costs despite increased drug spending. Health Affairs, 30(1), 91-99. doi: 10.1377/hlthaff.2009.1087

Rogers, B., Thomas-Trudo, S., \& McKelvey, B. (2013). Davidson County mortality report, Data for 2010 (pp. 1 - 19). Nashville, TN: Metropolitan Nashville Public Health Department.

Roig, B., Greenwood, R., \& Barcelo, D. (2009). An international conference on "Pharmaceuticals in the Environment" in a frame of EU Knappe project. Environment International, 35, 763-765. doi: 10.1016/j.envint.2009.01.012

Rolnick, S. J., Pawloski, P. A., Hedblom, B. D., Asche, S. E., \& Bruzek, R. J. (2013). Patient characteristics associated with medication adherence. $C M \& R$ Rapid Release. doi: 10.3121/cmr.2013.1113

Ruhoy, I. S., \& Daughton, C. G. (2007). Types and quantities of leftover drugs entering the environment via disposal to sewage - Revealed by coroner records. Science of the Total Environment, 388, 137-148.

Ruhoy, I. S., \& Daughton, C. G. (2008). Beyond the medicine cabinet: An analysis of where and why medications accumulate. Environment International, 34, 11571169.

Salinas, G., Susalka, D., Burton, B., Roepke, N., Evanyo, K., Biondi, D., \& Nicholson, S. (2012). Risk assessment and counseling behaviors of healthcare professionals managing patients with chronic pain: A national multifaceted assessment of physicians, pharmacists, and their patients. Journal of Opioid Management, 8(5), 273-284. doi: 10.5055/jom.2012.0127

Schillie, S. F., Shehab, N., Thomas, K. E., \& Budnitz, D. S. (2009). Medication overdoses leading to emergency department visits among children. American Journal of Preventative Medicine, 37(3), 181-187. doi:

10.1016/j.amepre.2009.05.018 
Schwartz, T., Kohnen, W., Jansen, B., \& Obst, U. (2006). Detection of antibiotic-resistant bacteria and their resistance genes in wastewater, surface water, and drinking water biofilms. FEMS Microbiology Ecology, 43(3), 325-335. doi: 10.1111/j.1574-6941.2003.tb01073.x

Seehusen, D. A., \& Edwards, J. (2006). Patient practices and beliefs concerning disposal of medications. Journal of the American Board of Family Medicine, 19, 542-547.

Senft, D. J. (2010). Increased scrutiny of medication disposal - Time to focus on your medication waste management practices. Geriatric Nursing, 31(2), 126-127.

Shin, S., Kim, E., \& Lee, H. (2009). The contributing factors to surplus medicine by long-term users of medical aid in Korea. Journal of Preventive Medicine and Public Health, 42(6), 403-407.

Siegel, D., Lopez, J., \& Meier, J. (2007). Antihypertensive medication adherence in the Department of Veterans Affairs. The American Journal of Medicine, 120, 26-32. doi: 10.1016/j.amjmed.2006.06.028

Snow, V., Beck, D., Budnitz, T., Miller, D. C., Potter, J., Wears, R. L., .. . Williams, M. V. (2009). Transitions of care consensus policy statement American College of Physicians, Society of General Internal Medicine, Society of Hospital Medicine, American Geriatrics Society, American College of Emergency Physicians, Society of Academic Emergency Medicine. Journal of General Internal Medicine, 24(8), 971-976. doi: 10.1007/s11606-009-0969-x

Snyder, S. A., Westerhoff, P., Yoon, Y., \& Sedlak, D. L. (2003). Pharmaceuticals, personal care products, and endocrine disruptors in water: Implications for the water industry. Environmental Engineering Science, 20(5), 449-469.

Sorensen, L., Stokes, J., Purdie, D., Woodward, M., Elliott, R., \& Roberts, M. (2004). Medication reviews in the community: results of a randomized, controlled effectiveness trial. British Journal of Clinical Pharmacology, 58(6), 648-664.

Sorensen, L., Stokes, J., Purdie, D., Woodward, M., \& Roberts, M. (2005). Medication management at home: Medication-related risk factors associated with poor health outcomes. Age and Ageing, 34, 626-632. doi: 10.1093/ageing/afi202

Sorensen, L., Stokes, J., Purdie, D., Woodward, M., \& Roberts, M. (2006). Medication management at home: medication risk factor prevalence and inter-relationships. Journal of Clinical Pharmacy and Therapeutics, 31(5), 485-491.

Stackelberg, P. E., Furlong, E. T., Meyer, M. T., Zaugg, S. D., Henderson, A. K., \& Reissman, D. B. (2004). Persistence of pharmaceutical compounds and other organic wastewater contaminants in a conventional drinking-water-treatment plant. Science of the Total Environment, 329, 99-113. 
Starfield, B., Lemke, K., Herbert, R., Pavlovich, W., \& Anderson, G. (2005). Comorbidity and the use of primary care and specialist care in the elderly. Annals of Family Medicine, 3, 215-222.

Statement of the National Association of Chain Drug Stores on Drug Waste and Disposal, U.S. Senate, 111th Sess. 1-9 (2010).

Steiner, J., Robbins, L., Roth, S., \& Hammond, W. (1993). The effect of prescription size on acquisition of maintenance medications. Journal of General Internal Medicine, 8 (June), 306 - 310.

Strassels, S. A. (2009). Economic burden of prescription opioid misuse and abuse. Journal of Managed Care Pharmacy, 15(7), 556-562.

Substance Abuse and Mental Health Services Administration. (2005). The NSDUH report: Substance or dependence in metropolitan and non-metropolitan areas: 2004 update (O. o. A. Studies, Trans.). Rockville: Substance Abuse and Mental Health Services Administration.

Substance Abuse and Mental Health Services Administration. (2007). The DASIS report: Adults aged 65 or older in substance abuse treatment: 2005. Rockville: Substance Abuse and Mental Health Services Administration.

Substance Abuse and Mental Health Services Administration. (2010a). The DAWN report: Emergency department visits involving accidental ingestion of drugs by children aged 5 or younger. Rockville.

Substance Abuse and Mental Health Services Administration. (2010b). The DAWN report: Highlights of the 2009 Drug Abuse Warning Network (DAWN) findings on drug-related Emergency Department visits. Rockville.

Substance Abuse and Mental Health Services Administration. (2010c). Results from the 2009 National Survey on Drug Use and Health: Summary of National Findings NSDUH Series (Vol. 1). Rockville: Substance Abuse and Mental Health Services Administration.

Substance Abuse and Mental Health Services Administration. (2010d). The TEDS Report: Characteristics of substance abuse treatment admissions reporting primary abuse of prescription pain relievers: 1998 and 2008. Rockville.

Substance Abuse and Mental Health Services Administration. (2011a). The DAWN report: Emergency Department visits involving adverse reactions to medications among older adults. Rockville. 
Substance Abuse and Mental Health Services Administration. (2011b). The DAWN Report: Emergency Department visits involving patients seeking detoxification or substance abuse treatment services. Rockville.

Substance Abuse and Mental Health Services Administration. (2011c). Results from the 2010 National Survey on Drug Use and Health: Summary of national findings NSDUH Series H-41 (pp. 144). Rockville: Substance Abuse and Mental Health Services Administration.

Substance Abuse and Mental Health Services Administration. (2012). A comparison of rural and urban substance abuse treatment admissions The TEDS Report. Rockville: Center for Behavioral Health Statistics and Quality.

Sullivan, M., Edlund, M., Fan, M., DeVries, A., Braden, J., \& Martin, B. (2010). Risks for possible and probable opioid misuse among recipients of chronic opioid therapy in commercial and medicaid insurance plans: The TROUP study. Pain $150,332-339$.

Tacci, J., Webster, B., Hashemi, L., \& Christiani, D. (1999). Clinical practices in the management of new-onset, uncomplicated, low back pain: Workers' compensation disability claims. Journal of Occupational \& Environmental Medicine, 41(5), 397-404.

Tennessee Bureau of Investigation. (2013). Drug offenses by drug type. Nashville, TN: Tennessee Bureau of Investigations.

Death under suspicious, unusual or unnatural circumstances $§ 7-108$ (2012).

Tennessee Department of Health. (2007). Leading causes of death: Age-adjusted mortality rates per 100,000 population by race and gender, Davidson County, 2007 (pp. 1). Nashville, TN: Tennessee Department of Health.

Tennessee Department of Health. (2011). Metropolitan counties (P. A. Office of Policy, Surveillance, Epidemiology and Evaluation, Trans.) Chronic disease health profile - region and counties: Tennessee (pp. 1 - 113). Nashville, TN: Tennessee Department of Health.

Thomas, C., Conrad, P., Casler, R., \& Goodman, E. (2006). Trends in the use of psychotropic medications among adolescents, 1994 to 2001. Psychiatric Services, 57(1), 63-69.

Thomas, C., Wallack, S., Lee, S., \& Ritter, G. A. (2002). Impact of health plan design and management on retirees' prescription drug use and spending. Health Affairs, W408-W419. doi: 10.1377/hlthaff.w2.408 
Torrible, S. J., \& Hogan, D. B. (1997). Medication use and rural seniors: Who really knows what they are taking? Canadian Family Physician, 43, 893-898.

Turner, B. J., Hollenbeak, C., Weiner, M. G., Have, T. T., \& Roberts, C. (2009). Barriers to adherence and hypertension control in a racially diverse representative sample of elderly primary care patients. Pharmacoepidemiology and Drug Safety, 18(8), 672-681. doi: 10.1002/pds.1766

U.S. Drug Enforcement Administration. (2012). National forensic laboratory information system: Year 2011 annual report (O. o. D. Control, Trans.) National Forensic Laboratory Information System Annual Report (pp. 1-36). Springfield, VA: U.S. Drug Enforcement Administration.

Veehof, L. J. G., Stewart, R. E., Haaijer-Ruskamp, F. M., \& Jong, B. Meyboom-de. (2000). The development of polypharmacy. A longitudinal study. Family Practice, 17(3), 261-267. doi: 10.1093/fampra/17.3.261

Volkow, N., McLellan, T., \& Cotto, J. (2011). Characteristics of opioid prescriptions in 2009. The Journal of the American Medical Association, 305(13), 1299-1300.

Warner, M., Chen, L. H., Makuc, D., Anderson, R. N., \& Minino, A. M. (2011). Drug poisoning deaths in the United States, 1980-2008. (81). Hyattsville: National Center for Health Statistics.

Warner, M., Chen, L. H., \& Makuc, D. M. (2009). Increase in fatal poisonings involving opioid analgesics in the United States, 1999-2006 NCHS data brief, no 22 (pp. 18). Hyattsville: National Center for Health Statistics.

Wasserfallen, J., Bourgeois, R., Bula, C., Yersin, B., \& Buclin, T. (2003). Composition and cost of drugs stored at home by elderly patients. The Annals of Pharmacotherapy, 37, 731-737.

Wazaify, M., Shields, E., Hughes, C. M., \& McElnay, J. C. (2005). Societal perspectives on over-the-counter (OTC) medicines. Family Practice, 22, 170-176.

Wennmalm, A., Gunnarsson, B., \& Eckermann, I. (2010). Pharmaceuticals - Permanent pollutants in environment. Basic facts and proposed measures to protect the public health and the environment. Paper presented at the International Society of Doctors for the Environment Stockholm.

Werder, S. F., \& Preskorn, S. H. (2003). Managing polypharmacy: Walking the fine line between help and harm. Current Psychiatry, 2(2), 24-36.

Westerhoff, P., Yoon, Y., Snyder, S., \& Wert, E. (2005). Fate of endocrine-disruptor, pharmaceutical, and personal care product chemicals during simulated drinking water treatment processes. Environmental Science \& Technology, 39, 6649-6663. 
White, A., Birnbaum, H., Mareva, M., Daher, M., Vallow, S., Schein, J., \& Katz, N. (2005). Direct costs of opioid abuse in an insured population in the United States. Journal of Managed Care Pharmacy, 11(6), 469-479.

White, B., Blease, K., \& Bishop, K. (2006). Stimulant medication use, misuse, and abuse in an undergraduate and graduate student sample. Journal of American College Health, 54(5), 261-268.

White, K. (2010). UK interventions to control medicines wastage: A critical review. INternational Journal of Pharmacy Practice, 18(3), 131-140. doi:

10.1211/ijpp/18.03.0002

Wilke, T., Groth, A., Mueller, S., Reese, D., Linder, R., Ahrens, S., \& Verheyen, F. (2012). How to use pharmacy claims data to measure patient nonadherence? The example of oral diabetics in therapy of type 2 diabetes mellitus. European Journal of Health Economics. doi: 10.1007/s10198-012-0410-y

Wisniewski, A. M., Purdy, C. H., \& Blondell, R. D. (2008). The epidemiologic association between opioid prescribing, non-medical use, and emergency department visits. Journal of Addictive Diseases, 27(1), 1-11. doi: 10.1300/J069v27n01_01

Witticke, D., Seidling, H., Lohmann, K., Send, A., \& Haefeli, W. (2013). Opportunities to reduce medication regimen complexity: A retrospective analysis of patients discharged from a university hospital in Germany. Drug Safety, 36(1), 31-41. doi: $10.1007 / \mathrm{s} 40264-012-0007-5$

Wolfert, M., Gilson, A., Dahl, J., \& Cleary, J. (2010). Opioid analgesics for pain control: Wisconsin physicians' knowledge, beliefs, attitudes, and prescribing practices. Pain Medicine, 11, 425-434.

Wu, L., \& Blazer, D. (2011). Illicit and nonmedical drug use among older adults: A review. Journal of Aging and Health, 23(3), 481-504. doi: $10.1177 / 0898264310386224$

Wu, M., \& Janssen, S. (2011). Dosed without prescription: A framework for preventing pharmaceutical contamination of our nation's drinking water. Environmental Science \& Technology, 45(2), 366 - 367.

Wysowski, D. (2007). Surveillance of prescription drug-related mortality using death certificate data. Drug Safety, 30(6), 533-540. 
Young, A., Havens, J., \& Leukefeld, C. (2012). A comparison of rural and urban nonmedical prescription opioid users' lifetime and recent drug use. The American Journal of Drug and Alcohol Abuse, 38(3), 220-227. doi: $10.3109 / 00952990.2011 .643971$

Zhang, X., Zhang, T., \& Fang, H. (2009). Antibiotic resistance genes in water environment. Applied Microbiology and Biotechnology, 82, 397-414. doi: $10.1007 / \mathrm{s} 00253-008-1829-\mathrm{z}$ 


\section{VITA}

Carrie Elizabeth Plummer was born in Nashville, Tennessee in 1971. She received a Bachelor of Arts Degree with a special major in Psychological Biology from Swarthmore College in Swarthmore, Pennsylvania in 1993. As a requirement for this major, Carrie completed a senior thesis studying the effects of general anesthesia on memory in rats with surgically-induced preclinical Alzheimer's disease. She received a Master of Science in Nursing from Vanderbilt School of Nursing in Nashville, Tennessee in 2005. Carrie worked as a Board Certified Adult Nurse Practitioner on the Vanderbilt Senior Care Service at Vanderbilt Medical Center from 2005 through 2008. In the fall of 2008, Carrie transitioned to a full-time faculty position at Vanderbilt School of Nursing.

As a doctoral student, Carrie was chosen to be a John A. Hartford Foundation Building Academic Geriatric Nursing Capacity Predoctoral Scholar for the 2011 -2013 funding cohort. In addition, she served as a doctoral intern in the Office of National Drug Control Policy which falls under the jurisdiction of the Executive Office of the President of the United States. From 2012-2013, Carrie served as the Senior Health Sciences Representative for the Emerging Scholars and Professionals Organization of the Gerontological Society of America. She presented posters at the Association for Gerontology in Higher Education, the Southern Nursing Research Society, and the Hartford Leadership Conference at the Gerontological Society of America national conference. She has co-authored a manuscript that was published in Geriatric Nursing in 2013 and has been a member of Sigma Theta Tau since 2005.

Carrie Plummer received a Doctor of Philosophy in nursing degree from the University of Tennessee Health Science Center in August 2013. Her dissertation research focused on the individual and health care risk factors associated with the accumulation of unused medications in the home. Currently, she is an instructor of nursing at Vanderbilt School of Nursing in the Adult and Geriatric Primary Care Nurse Practitioner Program. 